\title{
Diversidad de las subfamilias Grewioideae y Tilioideae (Malvaceae) en Guerrero, México
}

\section{Diversity of subfamilies Grewioideae y Tilioideae (Malvaceae) in the state of Guerrero, Mexico}

1 Comisión Nacional para el Conocimiento y Uso de la Biodiversidad (CONABIO), Liga-Periférico Sur No. 4903, Parques del Pedregal, 14010 Cd. Mx., México.

2 Universidad Nacional Autónoma de México, Facultad de Ciencias, Laboratorio de Plantas Vasculares, $04510 \mathrm{Cd}$. Mx., México.

3 Autor para la correspondencia: martha.gual@conabio.gob.mx.

\section{Citar como: \\ Gual-Díaz, M. y N. Diego-Pérez. 2018. Di- versidad de las subfamilias Grewioideae y Tilioideae (Malvaceae) en Guerrero, México. Acta Botanica Mexicana 122 33-96. DOI: http://dx.doi.org/10.21829/ abml22.2018.1161}

Recibido: 5 de octubre de 2016. Revisado: 22 de noviembre de 2016. Aceptado: 19 de septiembre de 2017. Primero en línea: 24 de noviembre de 2017 Publicado: 1 de enero de 2018

DOI:

http://dx.doi.org/10.21829/abml22.2018.1161

\author{
Martha Gual-Díaz,3 (10 , Nelly Diego-Pérez²
}

\section{Resumen:}

Antecedentes y Objetivos: En México las subfamilias Brownlowioideae, Grewioideae y Tilioideae (Malvaceae) están representadas por 11 géneros, 75 especies y una variedad; de estos taxones, 44 especies y la variedad son endémicas de su territorio. La distribución total abarca 28 estados, destaca la mayor diversidad de especies en las zonas tropicales de dos estados del centro-sureste del país (los tres primero lugares corresponden a Oaxaca, Chiapas y Guerrero). El objetivo de este trabajo fue caracterizar a las especies presentes en el estado de Guerrero, aportando información detallada acerca de la diversidad, distribución y endemismo, conocimiento que nos lleva a comprender mejor a un grupo de plantas poco estudiadas en el país. Métodos: Se analizó la información contenida en estudios regionales de florística, taxonomía y vegetación, de los especímenes colectados en la entidad, depositados en herbarios y disponibles en internet, y se colectó material en campo. Con lo anterior, se elaboró el listado final; se realizaron las descripciones correspondientes a los géneros y especies, y se prepararon las claves para la determinación de éstos.

Resultados clave: Los géneros con mayor número de especies son Triumfetta (19) y Corchorus (5). Se proporcionan claves dicotómicas para la identificación de los géneros y las especies registrados en el estado, su descripción, sinonimia, cita de su publicación, datos ecológicos e información de los especímenes de respaldo, así como de sus usos. Se incluyen mapas de distribución geográfica en el estado y una ilustración por cada género.

Conclusiones: Se presenta la revisión florística-taxonómica de siete géneros y 32 especies de las subfamilias Grewioideae y Tilioideae (Malvaceae) registradas en Guerrero.

Palabras clave: distribución, endemismo, florística, taxonomía, Tiliaceae, vegetación.

\section{ABSTRACT:}

Background and Aims: In Mexico, the subfamilies Tilioideae, Brownlowioideae and Grewioideae (Malvaceae) are represented by 11 genera, 75 species and one variety; 44 of these species and the variety are endemic to its territory. Their total distribution covers 28 states, highlighting the largest species diversity in the tropical areas of two states of the center-south-east of the country (the three first places correspond to Oaxaca, Chiapas and Guerrero). The objective of this work was to characterize the species present in the state of Guerrero, providing detailed information about the diversity, distribution and endemism. This knowledge leads to a better understanding of a group of little studied vascular plants in the country.

Methods: We analyzed the information contained in regional studies published about floristics, taxonomy and vegetation, as well as that of the specimens collected in the entity, deposited in herbaria and available on the internet; for its completeness material was collected in the field. Based on all this, the final list was developed with the descriptions corresponding to the genera and species, and keys were prepared for the identification of these.

Key results: The genera with the highest number of species are Triumfetta (19) and Corchorus (5). Dichotomous keys are provided for the identification of the genera and species recorded in the state, their description, synonymy, publication reference, ecological data and information of vouchers specimens, as well as their uses. Maps of geographical distribution in the state, as well as an illustration for each genus are included.

Conclusions: We present a floristic-taxonomical review of seven genera and 32 species of the subfamilies Tilioideae and Grewioideae (Malvaceae) registered in Guerrero.

Key words: distribution, endemism, floristics, taxonomy, Tiliaceae, vegetation. 


\section{INTRODUCCIÓN}

En la circunscripción del sistema filogenético de clasificación APG II y APG IV (Angiosperm Phylogeny Group) (APG, 2003; 2016), los integrantes de la familia Tiliaceae (sensu Cronquist, 1981) han sido confinados dentro de Malvaceae (Alverson et al., 1999; Cheek, 2007), en las subfamilias Brownlowioideae, Grewioideae y Tilioideae. Brownlowioideae incluye los géneros Berrya Roxb., Carpodiptera Griseb. y Christiana DC. (sin representantes en Guerrero); Grewioideae agrupa Apeiba Aubl., Corchorus L., Luehea Willd. y Triumfetta L., y Tilioideae circunscribe Tilia L. y Mortoniodendron Standl. \& Steyerm. (este último no registrado de Guerrero).

Las tres subfamilias incluyen aproximadamente 50 géneros y 700 especies, su distribución es principalmente pantropical y ocasionalmente templada (Standley y Steyermark, 1946; Robyns, 1964; Brizicky, 1965; Cronquist, 1981; Heywood, 1993; Villaseñor, 2004). La categoría genérica con mayor número de taxones es Grewia L., presente en África, Asia y Australia, con aproximadamente 150 integrantes (Heywood, 1993). En los trópicos de América el más diverso es Triumfetta con 43 categorías específicas, mientras que el único con hábito herbáceo, Corchorus, se distribuye también en Asia y Australia (Heywood, 1993). Con distribución estrictamente templada están Tilia, presente en América y Europa, así como Sparrmannia L. f., distribuido en Cabo de Buena Esperanza, África (Heywood, 1993).

En México las subfamilias Brownlowioideae, Grewioideae y Tilioideae están integradas por 11 géneros, 75 especies y una variedad; 43 especies y la variedad son endémicos de su territorio. Básicamente los géneros con gran diversidad y taxones de distribución restringida son Heliocarpus L. y Triumfetta. En cuanto a la distribución general, las tres subfamilias abarcan prácticamente todos los estados de la Republica Mexicana, destaca la mayor diversidad específica en las zonas tropicales de los estados del centro-sureste (principalmente Guerrero, Oaxaca, Chiapas, Veracruz). En Aguascalientes, Baja California, Baja California Sur, Ciudad de México, Durango, Guanajuato, Nuevo León, San Luis Potosí, Tlaxcala y
Tamaulipas, se detectó un profundo desconocimiento de los integrantes de las subfamilias por la falta de registros (documentado o colecta) aún cuando son entidades en los que la familia no tiene mayor diversidad.

En la Norma Oficial Mexicana NOM-059-SEMARNAT-2010 (SEMARNAT, 2010) están incluidas Tilia americana var. mexicana (Schltdl.) Hardin y Mortoniodendron guatemalense Standl. \& Steyerm.; ambas en peligro de extinción. Ninguna de las especies mexicanas están consideradas en la lista de CITES (Convención sobre el Comercio Internacional de Especies Amenazadas de Fauna y Flora Silvestres) (CITES, 2013), ni en la Lista Roja de especies amenazadas (IUCN, 2010); aunque en la Lista Roja de especies mexicanas de árboles del bosque mesófilo de montaña (González-Espinosa et al., 2011), se evaluaron cuatro especies del género Heliocarpus y una de Trichospermum Blume en la categoría de preocupación menor: H. americanus L., H. appendiculatus Turcz., H. donnellsmithii Rose, H. mexicanus (Turcz.) Sprague y T. mexicanum (DC.) Baill. Adicionalmente, incluyeron a Mortoniodendron ruizii Miranda en peligro crítico y a Tilia americana var. mexicana, en la categoría de vulnerable.

Existen pocos estudios respecto a los diferentes niveles de conocimiento de Brownlowioideae, Grewioideae y Tilioideae en México (los trabajos más completos son los de los géneros Heliocarpus y Triumfetta (Lay, 1949; 1950). Esta investigación aporta de manera regional información detallada acerca de la diversidad, distribución y endemismo de las 32 especies registradas en Guerrero de las subfamilias Grewioideae y Tilioideae, un conocimiento que lleva a definir áreas claras de prioridad para conservación o bien vacíos de información.

\section{Materiales y Métodos}

\section{Zona de estudio}

El área de estudio corresponde al estado de Guerrero, el cual se sitúa al suroeste de la República Mexicana, entre los paralelos $16^{\circ} 18^{\prime}$ y $18^{\circ} 48^{\prime}$ de latitud $\mathrm{N}$ y $98^{\circ} 03^{\prime}$ y $102^{\circ} 12^{\prime}$ de longitud $\mathrm{O}$. Su extensión territorial ocupa más 
o menos $64,282 \mathrm{~km}^{2}$ (3.2\% del país); limita al $\mathrm{N}$ con los estados de México y Morelos, al NE con Puebla, al NO con Michoacán, al E con Oaxaca y al S con el Océano Pacífico.

$\mathrm{Su}$ litoral abarca aproximadamente $500 \mathrm{~km}$; geopolíticamente está dividido en 81 municipios y seis regiones fisiográficas (Norte, Tierra Caliente, Montaña, Centro, Costa Grande, Costa Chica) (INEGI, 2016). Cuenta con cinco elevaciones superiores a los 3000 m s.n.m.: los cerros Teotepec (3507 m), Tlacotetepec (3198 m), Tejamanil (3180 m), Yahualtepetl (3081 m) y San Pedro (3036 $\mathrm{m}$ ). Todas forman parte de la Sierra Madre del Sur (GualDíaz, 1998).

Las unidades edafológicas principales son los regosoles, litosoles y cambisoles, siendo de gran importancia los dos primeros ya que cubren aproximadamente $80 \%$ del área estatal (SPP, 1981). Climáticamente sobre la región de la costa predomina el Aw (cálido subhúmedo); al ascender hacia la Sierra Madre del Sur está presente el $\mathrm{A}(\mathrm{C}) \mathrm{W}$ (semicálido), mientras que en su parte más elevada se encuentra el tipo $\mathrm{Cw}$ (templado subhúmedo) (García, 1988). Hacia la porción de la Cuenca del Balsas, se caracterizan dos tipos climáticos BS y BS1 (semisecos). Prevalece el régimen de lluvias en verano. La Vertiente del Pacífico presenta las mayores precipitaciones de todo el estado pues recibe directamente la influencia de brisas marinas y ciclones; por ejemplo, la estación Acapulco registra $1338.9 \mathrm{~mm}$ promedio anual. En la Depresión del Balsas la precipitación es menor debido a que las montañas actúan como barreras contra la penetración de vientos húmedos. Existen tres zonas donde la precipitación anual es menor a $800 \mathrm{~mm}$; entre ellas, la estación Aratichanguío registra $669.1 \mathrm{~mm}$ promedio anual (Meza y López, 1997; INEGI, 2016).

En cuanto a la vegetación, se han registrado 12 tipos de acuerdo con Rzedowski (1978); bosques tropicales (caducifolio y subcaducifolio), matorral, bosque de galería, pastizal, palmar, vegetación acuática y subacuática, vegetación halófila, bosque de coníferas, bosque de Quercus, bosque mixto y bosque mesófilo de montaña.

\section{Literatura, herbarios y trabajo de campo} Como parte del proyecto Flora de Guerrero (Facultad de Ciencias, UNAM), se inició el estudio sobre las subfamilias Brownlowioideae, Grewioideae y Tilioideae (Malvaceae) en el estado, analizando la información contenida en revisiones del grupo y de sus géneros (Watson, 1887, 1923; Rose, 1897, 1905; Hochreutiner, 1914; Lay, 1949, 1950; Kostermans, 1962; Hardin, 1990; Dorr, 1992; Fryxell, 1998; Gual-Díaz et al., 2001; Gual-Díaz y Moreno, 2009; Dorr, 2011), en estudios florísticos y de vegetación regionales publicados en México y países colindantes (Standley, 1923; Standley y Steyermark, 1946; Robyns, 1964; Brizicky, 1965; Pennington y Sarukhán, 1968; Jansen-Jacobs y Meijer, 1995; Gual-Díaz, 1998, 2011; Peralta et al., 2000; Diego et al., 2001; Fonseca et al., 2001; Fryxell, 2001; Meijer, 2001; Villaseñor, 2004; Gual-Díaz et al., 2008; Pérez-Calix, 2009; Colmenero et al., 2010; Ramos, 2015; Villaseñor, 2016), así como la de los especímenes depositados en los herbarios CIIDIR, ENCB, FCME, IEB, MEXU y UAGC, colectados en la entidad, y recursos disponibles en internet como el herbario MO (TROPICOS, 2017) y Global Plants (JSTOR, 2017), de donde se obtuvo la lista preliminar de las especies registradas de Guerrero.

Para asegurar la completitud de las especies que prosperan en Guerrero, se colectó material en campo. Con la información anterior, se realizaron claves y descripciones correspondientes a los géneros y especies, así como los mapas de su distribución conocida. Solamente en el caso de Triumfetta se elaboraron dos claves, una donde se tomaron en cuenta todas las estructuras de la planta y otra en donde se enfatizaron las características del fruto, pues el material colectado de este grupo no siempre tiene flor y fruto al mismo tiempo.

La sinonimia de las especies básicamente incluye basónimos y nombres asignados a plantas mexicanas en la literatura consultada. Los usos y nombres comunes, así como los tipos de vegetación y límites altitudinales de distribución, corresponden con la información disponible en los especímenes consultados en los herbarios anteriormente mencionados, con algunas adiciones de 
Biblioteca Digital de la Medicina Tradicional Mexicana (BDMTM, 2009).

Para asignar categorías de riesgo, se tomaron en cuenta el número de colectas registradas en el estado, por taxon, y la información de abundancia contenida en sus etiquetas, así como la información de endemismo, excepto en el caso de Apeiba tibourbou Aubl., cuyos datos se tomaron de la literatura y de ejemplares colectados en Oaxaca. Por lo tanto, esas evaluaciones deben considerarse provisionales y servir de base para futuras mejoras y la posible inclusión de los taxones en la NOM-059-SEMARNAT-2010, CITES o IUCN en categoría de riesgo significativo.

En especial para Apeiba tibourbou, reportada en Guerrero por Pennington \& Sarukhán (1968; 2012), cuya descripción se basa en la literatura y en ejemplares colectados en el estado de Oaxaca, y que no fue posible localizarla en campo o a través de especímenes en los herbarios consultados, no existe mapa de distribución conocida en la entidad.

Se proporciona la ilustración de una especie de cada género, siete en total. Se destacan la flor y el fruto característicos de cada caso sin omitir los caracteres diagnósticos.

\section{Resultados}

La mayor diversidad para las tres subfamilias (Brownlowioideae, Grewioideae y Tilioideae) de Malvaceae, en México, se presenta en el estado de Oaxaca con 42 especies, 20 de las cuales son endémicas del país y dos exclusivas para el estado (Triumfetta calzadae Fryxell y T. martinezalfaroi Gual \& F. Chiang) (Gual-Díaz, 2011). El segundo estado más diverso es Chiapas con 37 especies, de las cuales 11 son endémicas del país y cuatro, exclusivas al estado (Mortoniodendron ocotense Ishiki \& T. Wendt, M. ruizi, M. sulcatum Lundell y Triumfetta attenuata Lay). El tercer lugar corresponde a Guerrero, en él se documentaron una variedad y 32 especies, 13 de las cuales tienen una amplia distribución en América (desde Estados Unidos de América, México, Centroamérica, Antillas hasta Sudamérica) y una más es introducida de Asia (Corchorus capsularis L.). Respecto a las especies de distribución restringida, 19 son endémicas al país (56\% de lo registrado), dos son exclusivas del estado (Heliocarpus parvimontis Gual y Triumfetta acahuizotlensis González-Martínez, J. Jiménez Ram. \& Rios-Carrasco) y tres se comparten con un estado aledaño (Triumfetta heliocarpoides Bullock y T. guerrerensis Gual, Peralta \& N. Diego, con Oaxaca, y T. mexiae C.V. Morton \& Lay, con Michoacán).

En cuanto a las especies endémicas de México, se aprecia que la distribución de $66.6 \%$ es sobre la Vertiente del Pacífico, $11.1 \%$ en la Vertiente del Pacífico-Golfo de México (Veracruz), 5.5\% en la Vertiente del PacíficoSureste de México (Tabasco), 5.5\% en la Vertiente del Pacífico-Centro de México (México, Morelos y Puebla), y el resto (5.5\%) en la Vertiente del Pacifico-Norte y Centro-Golfo-Sureste de México (básicamente en bosques templados). Con relación a la distribución geopolítica en el estado, y considerando las 32 especies, se tiene que los municipios que registran mayor riqueza son: Chilpancingo de los Bravo (18), Atoyac de Álvarez y Acapulco de Juárez (10), Eduardo Neri y Zihuatanejo de Azueta (9), Coahuayutla de José María Izazaga y Mochitlán (8), y Coyuca de Benítez, Iguala de la Independencia, Leonardo Bravo y Petatlán (7). Para 53 municipios se registran de una a cinco especies y para 17 no existe registro de colecta. A este último caso corresponden las siguientes regiones fisiográficas: Centro (Chilapa de Álvarez), Norte (General Canuto A. Neri y Pedro Ascencio Alquisiras), Tierra Caliente (Ajuchitlán del Progreso, Cutzamala de Pinzón, San Miguel Totolapan, Tlalchapa y Tlapehuala), Costa Chica (Juchitán y Marquelia) y Montaña (Cochoapa el Grande, Cualác, Huamuxtitlán, Olinalá, Tlacoapa, Tlalixtaquilla de Maldonado y Zapotitlán Tablas). La única región que presenta registros de especies en todos sus municipios es la región Costa Grande (Peralta et al., 2000).

Los tipos de vegetación donde habitan los taxones específicos pertenecen a los siguientes cinco grupos (Cuadro 1): el primero con 13 especies corresponde a bosques templados y tropicales, intermedios como el bosque caducifolio, subcaducifolio, de Pinus, Pinus-Quercus, Quer- 
Cuadro 1: Agrupación de las 32 especies por tipo vegetacion. BG: bosque de galería; BMM: bosque mesófilo de montaña; BP: bosque de Pinus; BP-Q: bosque de Pinus-Quercus; BQ: bosque de Quercus; BTC: bosque tropical caducifolio; BTSC: bosque tropical subcaducifolio; DC: dunas costeras; VS: vegetación secundaria derivada de los bosques mencionados.

\begin{tabular}{|c|c|c|}
\hline Grupo/Especies & Tipos de vegetación & Altitud \\
\hline $\begin{array}{l}\text { Apeiba tibourbou Aubl., Corchorus hirtus L., Heliocarpus occidentalis Rose, H. pallidus Rose, } H . \\
\text { parvimontis Gual, H. terebinthinaceus (DC.) Hochr., Luehea candida (DC.) Mart., Trichospermum } \\
\text { mexicanum (DC.) Baill., Triumfetta coriacea Hochr., T. falcifera Rose, T. galeottiana Turcz., T. } \\
\text { paniculata Hook. \& Arn., T. simplicifolia (Sessé \& Moc.) Fryxell }\end{array}$ & $\begin{array}{l}\text { BTC, BTSC, BP, BP- } \\
\text { Q, BQ, BG, BMM } \\
\text { y VS }\end{array}$ & $0-2600 \mathrm{~m}$ \\
\hline Corchorus aestuans L. y Triumfetta mexiae C.V. Morton \& Lay & BTC, BTSC y VS & $0-1230 \mathrm{~m}$ \\
\hline $\begin{array}{l}\text { Corchorus capsularis L., C. orinocensis Kunth, C. siliquosus L., Triumfetta acracantha Hochr., T. } \\
\text { bogotensis DC. y T. lappula L. }\end{array}$ & BTC y VS & $0-1500 \mathrm{~m}$ \\
\hline Triumfetta acahuizotlanensis González-Martínez, J. Jiménez Ram. \& Rios-Carrasco & BTSC & ca. $800 \mathrm{~m}$ \\
\hline $\begin{array}{l}\text { Tilia americana var. mexicana (Schltdl.) Hardin, Triumfetta brevipes S. Watson, T. columnaris Hochr., } \\
\text { T. goldmanii Rose, T. grandiflora Vahl, T. guerrerensis Gual, S. Peralta \& Diego, T. heliocarpoides } \\
\text { Bullock, T. polyandra Sessé \& Moc. ex DC., T. semitriloba Jacq. y T. speciosa Seem. }\end{array}$ & $\begin{array}{l}\text { BP, BP-Q, BQ, BMM, } \\
\text { BG, DC y VS }\end{array}$ & $0-2500 \mathrm{~m}$ \\
\hline
\end{tabular}

cus, galería y mesófilo de montaña, así como vegetación secundaria derivada de los anteriores, por ejemplo Heliocarpus occidentalis Rose, Luehea candida (DC.) Mart., Trichospermum mexicanum y Triumfetta galeottiana Turcz. El segundo con dos especies corresponde a bosques tropicales (secos), el caducifolio y el subcaducifolio, así como a vegetación secundaria, Corchorus aestuans L. y Triumfetta mexiae. El tercero está conformado por seis especies que habitan sólo en el bosque tropical caducifolio $\mathrm{y}$ vegetación secundaria derivada del anterior bosque, por ejemplo Corchorus orinocensis Kunth, Triumfetta bogotensis (DC.) y T. lappula L. El cuarto consiste de una sola especie (T. acahuizotlanensis González-Martínez, J. Jiménez Ram. \& Rios-Carrasco), registrada sólo en bosque tropical subcaducifolio. Finalmente, el último grupo está formado por 10 especies que habitan los bosques templados e intermedios de Pinus, Pinus-Quercus, Quercus, mesófilo de montaña y de galería, así como vegetación secundaria derivada de estos, por ejemplo Heliocarpus pallidus Rose, Tilia americana var. mexicana, Triumfetta columnaris Hochr. y T. poliandra Sessé \& Moc. ex DC.

Los usos documentados, en general, para las especies en Guerrero son diversos; básicamente se emplean para alimentación animal y humana, como ornamentales, en la construcción de cercas y postes para casas, en la elaboración de artesanías, correas (para amarre), confección de telas y en la medicina tradicional.

Por último, en la lista de especies nativas de México, Villaseñor (2016) registró para el estado nueve especies de Heliocarpus, pero cuatro de ellas en realidad no tienen distribución en la entidad ( $H$. americanus L., $H$. appendiculatus Turcz., $H$. donnellsmithii Rose y $H$. mexicanus (Turcz.) Sprague), pues su distribución en el país corresponde a la zona sureste (Campeche, Chiapas, Oaxaca, Quintana Roo, Tabasco y Yucatán), a la región del centro (Hidalgo, Puebla y San Luis Potosí) y a la del Golfo (Veracruz) respectivamente. Por otro lado, la quinta especie, $H$. velutinus Rose, es tratada en este trabajo como sinónimo de $H$. pallidus, y finalmente las cuatro restantes registradas acertadamente para el estado son: $H$. pallidus, $H$. parvimontis, H. terebinthinaceus denominado por él -terebinthaceus-, y H. velutinus). El mismo autor reporta tres especies de Trichospermum en la región de estudio; sin embargo, T. galeottii (Turcz.) Sprague corresponde a un sinónimo de $T$. mexicanum y la distribución de $T$. lassetianum (Hochr.) Dorr es restringida al sureste mexicano (Chiapas, Oaxaca, Quintana Roo y Tabasco) (Dorr, 2011). Otra especie también registrada en la entidad pero 
del género Triumfetta por Villaseñor (2016), es T. discolor Rose; no obstante su distribución corresponde a la Vertiente del Pacífico (Durango, Nayarit, Oaxaca, Sinaloa y Sonora), sin registros para Guerrero.

\section{Descripciones}

Malvaceae Juss., Gen. PI. 271. 1789.

Subfamilia Grewioideae Dippel, Handb. Laubholzk. 3: 56. 1893. (como Grewieae).

Árboles, arbustos o hierbas, ocasionalmente sufrútices, dioicos, hermafroditas, ginomonoicos o raramente monoicos, con pubescencia de tricomas simples, estrellados, escamas o nectarios formados por grupos de tricomas glandulares con ubicación variada; hojas alternas, simples, pecioladas, estípulas deciduas o persistentes, láminas frecuentemente asimétricas, enteras o lobadas, ápice acuminado o agudo, margen serrado, crenado o dentado, base redondeada, truncada, cordada, ocasionalmente oblicua, suaves a coriáceas, palmatinervadas o pinnatinervadas, glabras o pubescentes; inflorescencias en cimas o panículas, algunas veces en dicasios o generalmente reducidas a flores solitarias o en pares, axilares, terminales u opuestas a las hojas, brácteas adnadas o no al pedúnculo, o ausentes; flores actinomorfas, hermafroditas o unisexuales, pediceladas, epicáliz presente o ausente, cáliz con (3-)5 sépalos, valvados o imbricados, libres o ligeramente connados en la base, glabros o con tricomas simples o estrellados, algunas veces acrescentes, corola con (3-4)-5 pétalos, usualmente color amarillo o verdoso, menos frecuente color lila, violeta o morado, ocasionalmente ausentes, libres, a veces con glándulas en la base, generalmente glabros, ocasionalmente barbados, imbricados, convolutos o valvados en prefloración, estambres 5 a numerosos, en ocasiones petaloides o reducidos en las flores pistiladas, filamentos con la base nectarífera (Trichospermum), ligeramente connados en la base (Apeiba), agrupados en 5-10 falanges (Luehea), o adnados al ginóforo formando un androginóforo corto (Corchorus), algunas veces el androceo y gineceo están insertos en una extensión del eje floral o gonó- foro (Heliocarpus y Triumfetta), pero en este último las glándulas son esféricas o alargadas, cubiertas por un anillo disciforme o urcéolo, apical, membranáceo, ciliado o casi obsoleto (Triumfetta lappula), anteras ditecas, dorsifijas, basifijas o versátiles, con dehiscencia longitudinal, conectivo algunas veces con apéndices, gineceo sincárpico, carpelos 2-10, ovario súpero, a veces semi-ínfero, oblongo, obcónico, piriforme, globoso depreso o compreso, 1-10 locular, placentacion axial, óvulos comúnmente numerosos en cada lóculo o, rara vez 1-2, estilo simple, estigma bífido, lobado, dentado o capitado; frutos capsulares, leñosos o no, con espinas en Apeiba y Triumfetta, cerdas en Heliocarpus, sin espinas en Corchorus y Trichospermum, septicidas, loculicidas, drupas carnosas o secas, sámaras o folículos, indumentados o glabros, a veces espinosos; semillas 1 a muchas en cada lóculo, cúbicas, globosas, discoidales, obovoides, ovoides, piriformes, subglobosas a compresas, semirollizas, piriformes, ocasionalmente aladas o elipsoidales, con o sin cilios.

\section{Clave para identificación de los géneros de la subfamilia Grewioideae}

1a. Flores con epicáliz; cápsulas 5-angulosas, 5-valvadas Luehea Willd.

1b. Flores sin epicáliz; cápsulas globosas, compresas, depresas, obloides, ovoides, elipsoidales, piriformes, cilíndricas, obcónicas, subglobosas, subclavadas ... 2

2a. Corolas color lila o violeta; cápsulas con semillas ciliadas Trichospermum Blume

2b. Corolas color amarillo o blanco; semillas no ciliadas ... 3

3a. Cápsulas leñosas, 70-80 mm de diámetro, con espinas 10-15 mm de largo; ovario 8-10 lóculos Apeiba Aubl.

3b. Cápsulas no leñosas, de menos de $10 \mathrm{~mm}$ de diámetro, con o sin espinas o cerdas 5-10 mm de largo; ovario 2-5 lóculos 4

4a. Cápsulas sin espinas Corchorus L.

4b. Cápsulas con espinas o cerdas, 5-10 $\mathrm{mm}$ de largo ... 5

5a. Cápsulas lateralmente comprimidas, con cerdas marginales; flores tetrámeras, rara vez pentámeras

Heliocarpus L. 
5b. Cápsulas ovoides, globosas, subglobosas, elipsoidales, cubiertas en toda su superficie por espinas glabras, pilosas o plumosas; flores pentámeras

Triumfetta L.

Apeiba Aubl., Hist. P1. Guiane 1: 537. 1775.

TIPO: Apeiba tibourbou Aubl.

Árboles o arbustos hermafroditas; tallos con lenticelas, pubescencia de tricomas simples y estrellados o glabrescentes; hojas pecioladas, estípulas triangulares, generalmente persistentes, láminas ovadas o elípticas, ápice agudo o acuminado, margen entero o finamente aserrado, base cordada, algunas veces oblícua, palmatinervadas, estrellado-pubescentes, coriáceas; inflorescencias en panículas, terminales u opuestas a las hojas; bráctea foliácea no adnada al pedúnculo; flores sin epicáliz, cáliz 4-5 sépalos, libres o ligeramente connados en la base, oblongo-lanceolados, ápice acuminado, con tricomas simples y estrellados adaxialmente, corola con 4-5 pétalos libres, color amarillo, espatulados u ovados, ápice redondeado, glabros, estambres numerosos, ligeramente connados en la base, filamentos cortos, vilosos o pubescentes con tricomas simples en la base, anteras basifijas, con un apéndice membranáceo estéril en el ápice, estaminodios no petaloides, gineceo 10-carpelar; ovario súpero, globoso, ligeramente depreso, 8-10 locular, híspido a pubescente, estilo rollizo, estigma dentado; frutos capsulares, leñosos, obloides o globosos, 35-40 $\mathrm{mm}$ de largo, 70-80 $\mathrm{mm}$ de diámetro, con espinas 10-15 mm de largo, semillas globosas o piriformes, numerosas por lóculo, sin cilios, envueltas por un arilo negro.

Género con distribución neotropical, conformado por siete a 10 especies (Standley y Steyermark, 1946; Robyns, 1964; Mabberley, 1987). En México está registrada una especie, la cual es característica de estadios sucesionales en la regeneración de bosques tropicales subcaducifolios y perennifolios.

Apeiba tibourbou Aubl., Hist. P1. Guiane 1: 538. t. 213. 1775. TIPO: SOUTH AMERICA. Caiennae \& Gui- anae in campis, s.f., J. B. C. F. Aublet s.n. (TIPO: BM). Fig. 1.

Árboles, 6-20 m de alto; hojas con peciolos 2-4 cm de largo, densamente pilosos a estrellado-pubescentes; estípulas lanceoladas, $1.5-2.5 \mathrm{~cm}$ de largo, $0.5-1 \mathrm{~cm}$ de ancho, láminas 15-32 cm de largo, 6-16.5 cm de ancho, ápice acuminado, margen denticulado, base simétrica o asimétrica, cordada, haz estrellado-pubescente, envés densamente estrellado-pubescente; inflorescencias paniculadas opuestas a las hojas, 7-11 cm de largo; pedúnculos 2.5-3 cm de largo, bráctea triangular, $1.6 \mathrm{~cm}$ de largo, $0.5 \mathrm{~cm}$ de ancho, densamente estrigoso-pubescente; flores $35-40 \mathrm{~mm}$ de diámetro, pedicelos 5-15 mm de largo, sépalos 15-25 mm de largo, 6 $\mathrm{mm}$ de ancho, haz y envés con tricomas simples y estrellados; corola con pétalos mas cortos que los sépalos, 1.5-2 $\mathrm{mm}$ de largo, ca. $6 \mathrm{~mm}$ de ancho; estambres numerosos, 6-9 $\mathrm{mm}$ de largo, filamentos $4 \mathrm{~mm}$ de largo, anteras $4 \mathrm{~mm}$ de largo, ovario $3 \mathrm{~mm}$ de largo, $4.5 \mathrm{~mm}$ de ancho, estilo $10 \mathrm{~mm}$ de largo; frutos $30-45 \mathrm{~mm}$ de largo, $70-80 \mathrm{~mm}$ de diámetro; semillas 10-20 mm de largo.

Distribución: México (Chiapas, probablemente Guerrero, Nayarit, Oaxaca, Veracruz), Centroamérica y N de Sudamérica.

Tipo de vegetación y altitud: elemento de los bosques de Quercus, tropical caducifolio, subcaducifolio y perennifolio, así como de acahual y vegetación secundaria; 60-1650 m s.n.m.

Fenología: florece de julio a septiembre, fructifica de noviembre a enero.

Nombres comunes: achota (Gro), papachote, peine de mico, peinemico (Oax).

Usos: la madera se emplea para la construcción de casas, de la corteza se extrae fibra para tejidos diversos; aparentemente su mucílago sirve para curar heridas; su madera blanca y suave, resulta útil como pulpa para papel. 

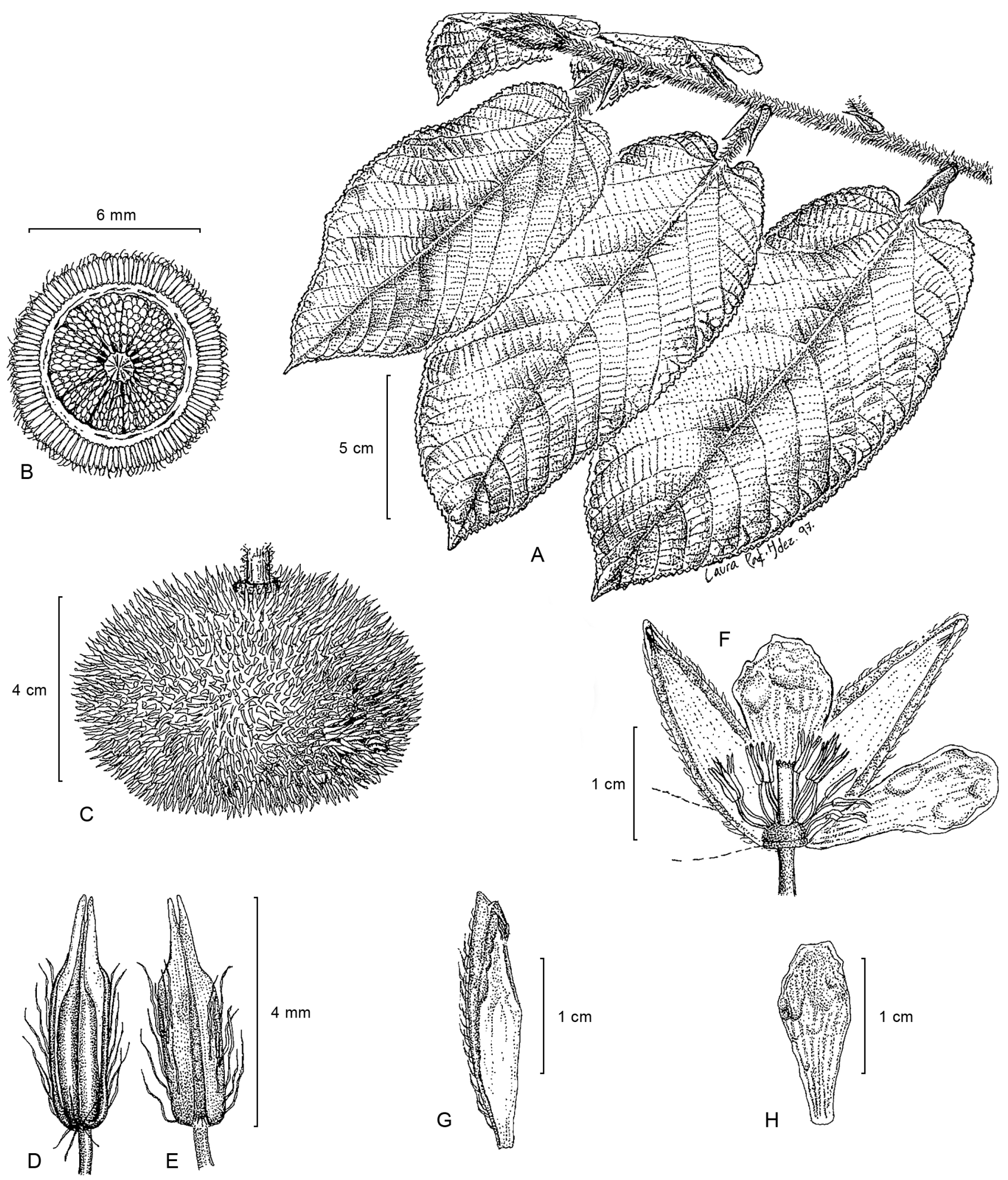

Figura 1: Apeiba tibourbou Aubl. A. rama con hojas; B. corte transversal de fruto; C. vista externa del fruto; D. antera vista frontal; E. antera vista dorsal; F. detalle de la flor mostrando los estambres y el gineceo; G. sépalo; H. pétalo. Basados en I. Calzada y S. Anta 15487 (MEXU). 
Ejemplares examinados: MÉXICO. Oaxaca, municipio Matías Romero Avendaño, $3 \mathrm{~km}$ al sur de Mogoñe, J. A. Solis Magallanes 248 (MEXU). Municipio San José Chiltepec, carretera Tuxtepec - Oaxaca, Sierra de Juárez, G. Martinez 925 (CIIDIR, MEXU). Municipio San Juan Bautista Tuxtepec, Agua Escondida, ejido Benito Huáreaz, Brigada Dioscóreas 1867 (MEXU); Chiltepec and vecinity, G. Martínez 61 (MEXU); Loma Alta, F. Miranda 9177 (MEXU); ejido Benito Juárez, T. D. Pennington y J. Sarukhán 9065 (MEXU); presa Miguel Alemán, Temascal, R. Tórres 2395 (MEXU). Municipio San Juan Lalana, al NE del poblado Santiago Jalahui, I. Calzada y S. Anta 15487 (MEXU). Municipio Santa María Chimalapa, cerca del río Negro, Distrito de Juchitán, S. Acosta 1916 (CIIDIR); río Otates hacia Santa María Chimalapa, R. Tórres y J. L. Villaseñor 5206 (CIIDIR, MEXU); 2 km al SO de Santa María Chimalapa, sobre camino a Lázaro Cárdenas y Mezquite, T. Wendt et al. 3358 (MEXU).

Discusión: Pennington y Sarukhán (1968) citan a esta especie con el nombre común de achota para el estado, con distribución en la vertientes del Golfo y del Pacífico (incluyen Guerrero en su mapa de distribución); los mismos autores en 2012 (tercera edición de su obra) no incluyen Guerrero en el mapa de su distribución, pero siguen conservando el nombre común de achota. Por estas razones, a pesar de que en los herbarios consultados no se encontraron especímenes que permitieran certificar su presencia en el estado, se incluyó en este tratamiento. La descripción se basó en la literatura y se completó revisando ejemplares del estado de Oaxaca. En cuanto a su categoría de conservación se considera como no evaluada (NE).

Corchorus L., Sp. P1. 1: 529. 1753.

=Antichorus L., Syst. Nat. ed. 12: 264. 1767.

TIPO: Corchorus olitorus L.

Arbustos, subarbustos o hierbas, anuales, erectos o decumbentes, hermafroditas; tallos con tricomas estrellados, estrigosos, pilosos o hirsutos, a veces glabrescentes o glabros; hojas pecioladas, estípulas subuladas o filiformes, persistentes, láminas ovadas, oblongas, elípticas a lanceoladas, ápice agudo o acuminado, margen serrado, crenado o dentado, a veces los dientes basales prolongados en 2 largas caudas, base cuneada, obtusa o redondeada, rara vez oblicua, 3-nervadas, glabras, pilosas, estrigulosas, hirsutas o pubescentes, papiráceas; inflorescencias en dicasios, raramente solitarias, axilares u opuestas a las hojas; flores subsésiles o con pedicelo glabro o pubescente; epicáliz ausente; cáliz con 5 sépalos lanceolados, ovados u oblanceolados, cuculados en botón, ápice acuminado, rara vez apendiculado, glabros o pubescentes; corola con 5 pétalos, color amarillo, obovados, obtrulados o espatulados, glabros, convolutos, ápice redondeado, rara vez acuminado; estambres 5-40, filamentos adnados al ginóforo formando un androginóforo corto algunas veces no evidente, anteras dorsifijas, extrorsas; gineceo 2-5 carpelar; ovario súpero, globoso, oblongo, rara vez obcónico, seríceo, puberulento, estrigoso, hirsuto, híspido o piloso, 2-5 lóculos, sésil sobre el androginóforo, óvulos numerosos por lóculo, estigma lobado; frutos capsulares, no leñosos, loculicidas, color verde o pardo oscuro, cilíndricos, obcónicos, globosos, aplanados, rara vez angulosos, de menos de $10 \mathrm{~mm}$ de diámetro, ápice acuminado a obtuso, a veces dentado, coriáceos, glabros, pilosos, hirsutos, estrigosos o adpreso pubescentes, sin espinas; semillas numerosas, color negro, pardo oscuro o pardo claro o verde, piriformes, cúbicas o semirrollizas, muricadas o lisas, sin cilios.

Es el único género de la subfamilia Grewioideae con especies de hábito herbáceo o sufruticoso. Incluye aproximadamente 40 especies, con distribución pantropical (Cronquist, 1981; Mabberley, 1987; Heywood, 1993). Las especies de este género en México son propias de vegetación secundaria, generalmente son arvenses y ruderales, aunque se les ha colectado en bosque tropical caducifolio y de galería. En el país se han registrado siete especies (Colmenero et al., 2010), de las cuales cinco están en Guerrero. 
Clave para la identificación de especies de Corchorus

1a. Ovario 5 lóculos; cápsulas rugosas; tallos glabros .... C. capsularis $\mathrm{L}$.

1b. Ovario 2-4 lóculos; cápsulas lisas; tallos pilosos, estrigosos o hirsutos 2

2a. Sépalos apendiculados en el ápice; cápsulas angulosas, ápice con 3-4 dientes bífidos ....... C. aestuans L.

2b. Sépalos no apendiculados en el ápice; cápsulas no angulosas, ápice sin dientes o si presentes, no bífidos 3

3a. Ovarios escabrosos; cápsulas aplanadas, ápice obtuso, con 4 dientes C. siliquosus $\mathrm{L}$.

3b. Ovarios pilosos o híspidos; cápsulas cilíndricas, ápice acuminado, sin dientes .. 4

4a. Pétalos obtrulados; cápsulas densamente hirsutas ..... C. hirtus $\mathrm{L}$.

4b. Pétalos obovados o espatulados; cápsulas glabras o adpreso-pubescentes C. orinocensis Kunth

Corchorus aestuans L., Syst. Nat. ed. 10. 2: 1079. 1759. TIPO: JAMAICA. P. Browne s.n. (lectotipo: LINN), designado por Fawcett y Rendle, 1926. Figs. 2, 3.

Hierbas sufruticosas, 0.1-1.5 m de alto; tallos pilosos o hirsutos; hojas con peciolos, 0.8-3.5 cm de largo, pilosos o hirsutos, estípulas color rojizo, 2-8 $\mathrm{mm}$ de largo, subuladas, láminas ovadas, $1.5-8 \mathrm{~cm}$ de largo, $1.5-5 \mathrm{~cm}$ de ancho, ápice acuminado, base obtusa, estrigulosas en el margen y en los nervios de haz y envés; flores 6-8 $\mathrm{mm}$ de diámetro, sépalos cuculados, 3-8 mm de largo, 1.5-4 $\mathrm{mm}$ de ancho, apendiculados en ápice, glabros; pétalos obovados, 2-3.5 mm de largo, 1-2 $\mathrm{mm}$ de ancho, ápice redondeado, androginóforo no evidente; estambres 20-30, gineceo 3-4 carpelos, ovario seríceo, 3-4 lóculos, con 1-2 hileras de óvulos por lóculo; frutos color verde, 3-4 angulosos, 15-40 mm de largo, ápice con 3-4 dientes bífidos, cada ángulo con 2 costillas, lisos, pilosos; semillas color pardo claro, cúbicas, $1 \mathrm{~mm}$ de largo, $1 \mathrm{~mm}$ de ancho, muricadas.
Distribución: Estados Unidos de América, México (Campeche, Colima, Chiapas, Guerrero, Jalisco, Michoacán, Nayarit, Oaxaca, Sinaloa, Tabasco, Veracruz), Antillas, Colombia y Perú. Se ha reportado en Europa e India (Brizicky, 1965).

Tipo de vegetación y altitud: elemento del bosque tropical caducifolio y subcaducifolio, así como en vegetación secundaria; 0-750 m s.n.m.

Fenología: florece y fructifica de septiembre a noviembre.

Usos: en Estados Unidos de América (Islas Vírgenes), Centroamérica (Guatemala) y Sudamérica (Perú) las hojas y tallos jóvenes son consumidos como alimento y utilizados en la medicina tradicional (Standley y Steyermark, 1946; Robyns, 1964; Brizicky, 1965). En Ghana y la India se ha empleado para combatir enfermedades como gonorrea, neumonía, infecciones estomacales y de vías urinarias (Bhandari, 1978; USDA, 2017). En Guerrero no se ha registrado ningún uso.

Ejemplares examinados: MÉXICO. Guerrero, municipio Acapulco de Juárez, El Arenal, laguna de Tres Palos, N. Diego 4308 (FCME, IEB); Los Amates, orilla de laguna Tres Palos, N. Diego 4635 (FCME); El Podrido, orilla de laguna Tres Palos, S. Gil 261 (FCME); Plan de Los Amates, M. Gual 657 (ENCB, FCME, IEB, MEXU). Municipio Atoyac de Álvarez, pueblo de Zacoalpan a laguna de Mitla, L. Lozada 206 (FCME). Municipio Benito Juárez, Llano Real, laguna de Mitla, L. Lozada 737 (FCME); camino entre El Tomatal y El Cerrito, laguna de Mitla, L. Lozada 1087 (FCME). Municipio Chilpancingo de los Bravo, Chilpancingo de los Bravo, colonia Los Manantiales, E. A. Zeferino 12 (FCME). Municipio Coyuca de Benítez, Las Lajas, al S del poblado de Coyuca, $M$. Gual 654 (ENCB, FCME, IEB, MEXU); Las Salinas, a 3 km al E de Coyuca, R. Gutiérrez 143 (FCME); El Bordonal, L. Rodríguez 38 (FCME), 172 (FCME); $1 \mathrm{~km}$ al NO del Carrizal, Laguna de Mitla, A. Valenzuela 17 (FCME); 

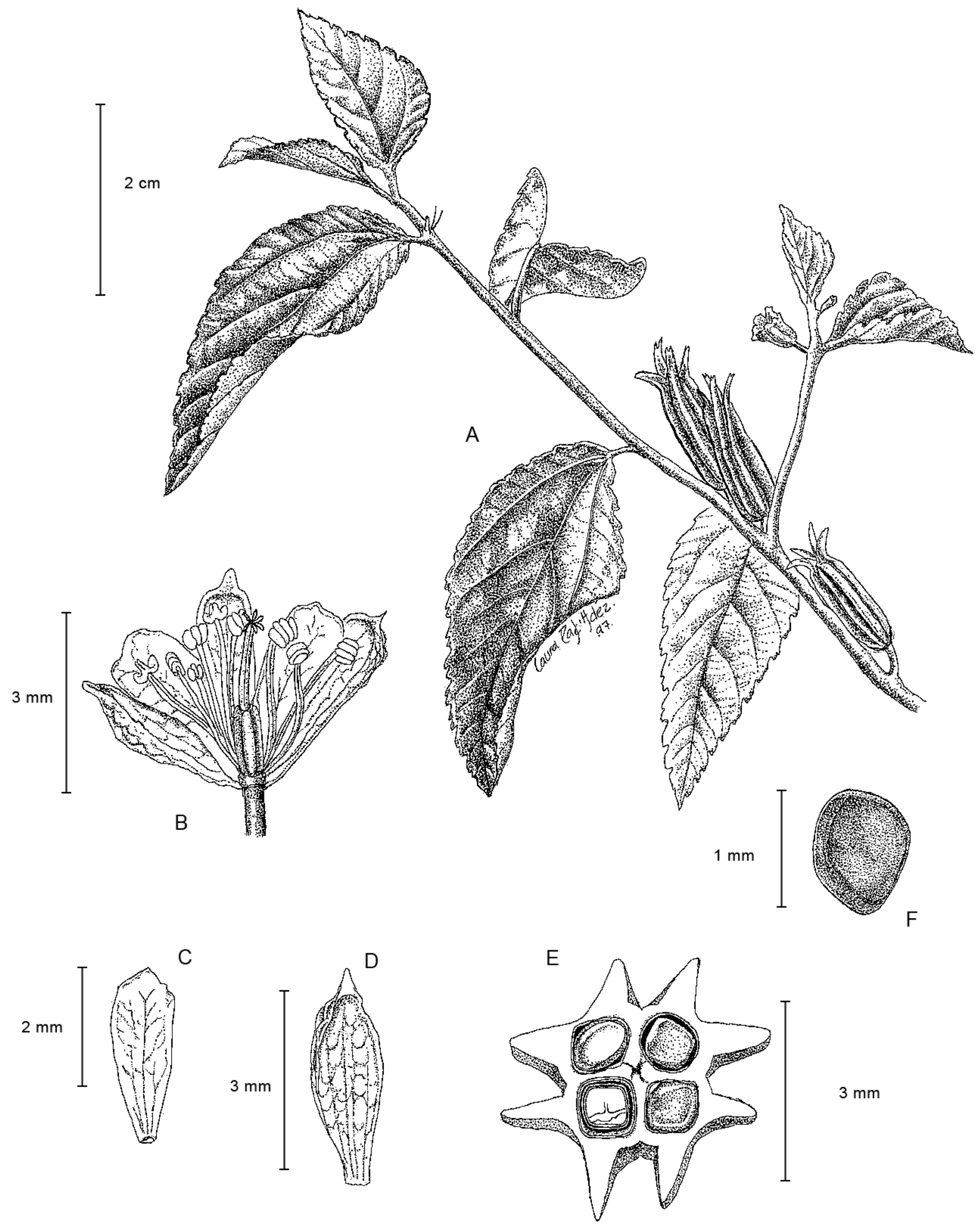

Figura 2: Corchorus aestuans L. A. rama con flor y frutos; B. detalle de la flor; C. pétalo; D. sépalo con apéndice en el ápice; E. corte transversal del fruto; F. semilla. Basados en M. Gual 673 (FCME). 


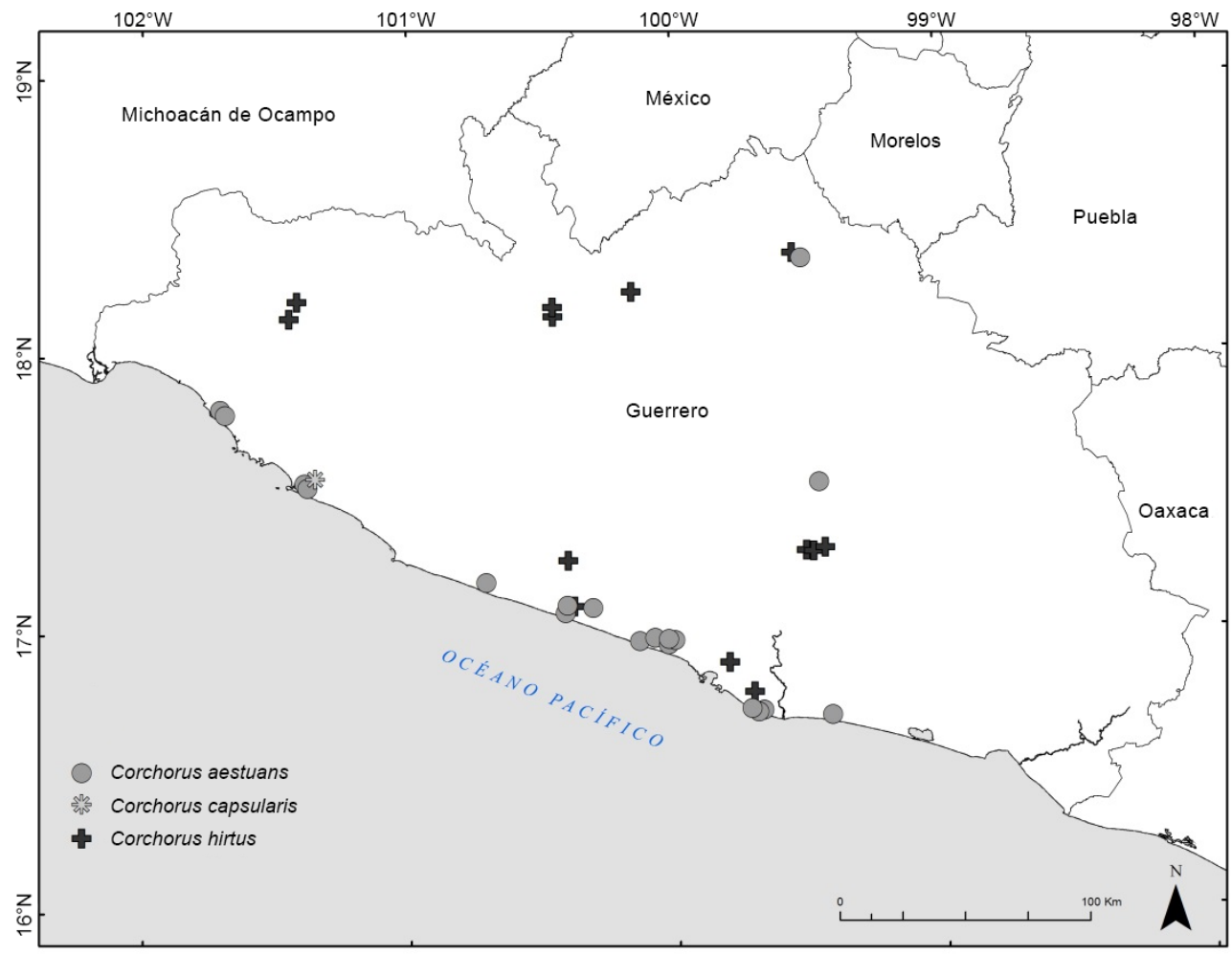

Figura 3: Distribución conocida de Corchorus aestuans L. (О), C. capsularis L. (䊝) y C. hirtus L. (\$).

Isla Montosa, C. Verduzco 303 (FCME, IEB). Municipio Iguala de la Independencia, Iguala, A. Almazán 154 (FCME, UAGC). Municipio Leonardo Bravo, La Pastora, km 181 del camino Atoyac de Álvarez a Xochipala, Laboratorio de Biogeografia 673 (MEXU). Municipio Petatlán, laguna Potosí, N. Diego y M. Castro 7426 (FCME); orillas de laguneta El Carrizal, $2 \mathrm{~km}$ antes de Barra Potosí, M. Gual 651 (ENCB, FCME, IEB, MEXU); orillas de laguneta El Carrizal, $1.5 \mathrm{~km}$ antes de Barra Potosí, $M$. Gual 652 (ENCB, FCME, IEB, MEXU). Municipio San Marcos, $5 \mathrm{~km}$ antes de la laguna de Tecomate, G. Campos 206 (FCME, IEB). Municipio Tecpan de Galeana, aproximadamente a $1 \mathrm{~km}$ al $\mathrm{S}$ de El Carrizal, base oriental de Cerro Japón, F. Lorea 5323 (FCME, IEB). Municipio La Unión de Isidoro Montes de Oca, desviación a La Majagua, carretera Zihutanejo - Lázaro Cárdenas, M. G. Campos 2161 (FCME, IEB); $4 \mathrm{~km}$ al NO del poblado Troncones, M. Gual 673 (ENCB, FCME, MEXU); $3 \mathrm{~km}$ al NE de la Majahua, A. Hanan 207 (FCME, IEB).
Discusión: en cuanto a su categoría de conservación esta especie se considera como preocupación menor (LC).

Corchorus capsularis L., Sp. Pl. 1: 529. 1753. TIPO: Ceylan, s.l., s.f., s.c., s.n. (lectotipo: LINN-LINNHS957-2). Fig. 3.

Subarbustos, $1.5 \mathrm{~m}$ de alto; tallos glabros; hojas con peciolos 0.9-1.6 cm de largo, estípulas color rojizo, $6 \mathrm{~mm}$ de largo, láminas lanceoladas, 4-10 cm de largo, 1.4-3.3 $\mathrm{cm}$ de ancho, ápice largamente acuminado, base cuneada o redondeada, con los dientes basales prolongados formando 2 caudas, haz estrigoso en los nervios, envés glabro; flores $5 \mathrm{~mm}$ de diámetro, sépalos cuculados, no apendiculados, $3 \mathrm{~mm}$ de largo, $1 \mathrm{~mm}$ de ancho, envés estriguloso, pétalos obovados o espatulados, $3 \mathrm{~mm}$ de largo, $1.2 \mathrm{~mm}$ de ancho, ápice redondeado; androginóforo festonado; estambres 25 , filamentos $1.5 \mathrm{~mm}$ de largo; gineceo 5-carpelar, ovario glo- 
boso u obcónico, seríceo, 5 lóculos, con 2 hileras de óvulos por lóculo; frutos pardos, globosos u obcónicos, 12-15 $\mathrm{mm}$ de largo, 10-13 mm de diámetro, ápice obtuso, ligeramente cinco acostillados, rugosos; semillas color pardo oscuro, piriformes, $3 \mathrm{~mm}$ de largo, $2 \mathrm{~mm}$ de ancho, lisas.

Distribución: especie introducida en México (Guerrero) de plantas provenientes de India y Unión de Myanmar (Birmania) (Brizicky, 1965).

Tipo de vegetación y altitud: vegetación secundaria de bosque tropical caducifolio; ca. 10 m s.n.m.

Fenología: florece y fructifica en noviembre.

Usos: no se conocen en el área.

Ejemplar examinado: MÉXICO. Guerrero, municipio Petatlán, Laguneta El Carrizal, camino a laguna Potosí, N. Diego y R. Oviedo 6659 (ENCB, FCME, IEB, MEXU).

Discusión: la presencia de C. capsularis en la costa occidental de México puede deberse a la influencia humana. Los viajes navieros de China ("Nao de China") y Filipinas ("Galeón de Manila") hacia Acapulco, así como las ferias comerciales que se desarrollaban en este mismo puerto en el siglo XVIII han sido documentados desde la antigüedad (González, 1989) pudieron ser éstas la vía para su llegada a América. Sin embargo, su distribución esporádica y tan restringida sugieren una introducción mucho más reciente al continente, probablemente por el intercambio de granos, vegetales y ganado por vía marítima desde Asia (Gual-Diaz et al., 2008). Es una planta escasa en el estado y en cuanto a su categoría de conservación se considera como no evaluada (NE).

Corchorus hirtus L., Sp. Pl. ed. 2. 747. 1762. TIPO: America meridionali. Lámina de C. Plumier, Pl. Amer. 93: pl. 103, fig. 2. 1757. (lectotipo: no localizado), designado por Bornstein, 1989. Fig. 3.
Hierbas perennes o sufruticosas, $8-25 \mathrm{~cm}$ de alto; tallos estrigosos o hirsutos; hojas con peciolos $0.8-1.5 \mathrm{~cm}$ de largo, híspidos o hirsutos, estípulas color rojo en el ápice, 3-12 mm de largo, láminas oblongo lanceoladas, 1.5-8 $\mathrm{cm}$ de largo, 1-4.5 cm de ancho, ápice largamente acuminado, base obtusa, hirsutas o estrigosas en el margen y nervios de haz y envés; flores $10 \mathrm{~mm}$ de diámetro; sépalos no apendiculados, ligeramente cuculados, 5-10 mm de largo, 1-8 mm de ancho, adaxialmente estrigosos, pétalos obtrulados, 3-7 mm de largo, 2-5 mm de ancho, ápice acuminado; androginóforo no evidente; estambres 20-40; gineceo 2-carpelar, ovario seríceo, 2-locular, híspido, con 1-2 hileras de óvulos por lóculo, frutos color verde, cilíndricos, no angulosos, 15-45 $\mathrm{mm}$ de largo, ápice acuminado, sin dientes, dehiscentes por 2 valvas, densamente hirsutos, semillas no vistas (ni registradas en literatura).

Distribución: Estados Unidos de América (sur), México (Chiapas, Guanajuato, Guerrero, Jalisco, Michoacán, Nayarit, Nuevo León, Oaxaca, Puebla, Querétaro, San Luis Potosí, Sinaloa, Sonora, Tabasco, Tamaulipas, Veracruz, Yucatan, Quintana Roo), Centroamérica, Antillas y Sudamérica (Perú). Se ha reportado su presencia en India (Brizicky, 1965).

Tipo de vegetación y altitud: bosques de Pinus, galería, tropical caducifolio, y vegetación secundaria; 10 1230 m s.n.m.

Fenología: florece y fructifica en septiembre y octubre.

Usos: no se conocen en el área.

Ejemplares examinados: MÉXICO. Guerrero, municipio Acapulco de Juárez, Punta Gorda, orilla de la laguna Tres Palos, N. Diego 4939 (FCME); Parque Nacional El Veladero (colonia Independencia), N. Noriega 682 (FCME). Municipio Arcelia, El Limón, Campo Morado, R. Cruz 6391 (FCME). Municipio Benito Juárez, camino entre El Tomatal y El Cerrito, laguna de Mitla, L. Lozada 1085 (FCME). Municipio Chilpancingo de los Bravo, 
Rincón Viejo, H. Kruse 568 (ENCB, FCME); camino al Rincón de la Vía, C. Verduzco 367 (FCME). Municipio Coahuayutla de José María Izazaga, El Aguacate, 3.93 $\mathrm{km}$ al S, J. Calónico y M. Antonio 15860 (FCME); El Aguacate, $7.1 \mathrm{~km}$ al S, J. Calónico y M. Antonio 16341 (FCME); El Aguacate, $5.21 \mathrm{~km}$ al S, J. Calónico y $M$. Antonio 16383 (FCME); Primer Campo, $4.47 \mathrm{~km}$ al O, J. Calónico S. y M. Antonio 16526 (FCME), 16534 (FCME). Municipio Iguala de la Independencia, Iguala, A. Almazán 70 (FCME, UAGC). Municipio Mochitlán, camino al poblado Tepexintla, H. Flores 557 (FCME).

Discusión: es una planta escasa en el estado y en cuanto a su categoría de conservación se le ubica como preocupación menor (LC).

Corchorus orinocensis Kunth, Nov. Gen. Sp. 5: 337. 1821. non C. orinocensis Stand1., 1933. TIPO: VENEZUELA. Crescit ad ripam fluminis Orinoci, s.f., F. H. A. Humboldt y A. J. Bonpland s.n. (holotipo: P-P00679623!). Fig. 4.

ECorchorus secundiflorus Sessé \& Moc. TIPO: MÉXICO. Lámina, 1787-1803, M. Sessé y J. M. Mociño s.n. (holotipo: G-DC, isotipo: MA).

三Corchorus secundiflorus Moc. \& Sessé ex DC. Prodr. 1: 504. 1824. TIPO: no localizado.

三 Corchorus biflorus Sessé \& Moc. Fl. Mexic. 2: 131. 1894. TIPO: no localizado.

Hierbas o arbustos, erectos, 0.3-1 m de alto; tallos estrigosos o glabrescentes; hojas con peciolos, 0.1-3 $\mathrm{cm}$ de largo, estrigosos o puberulentos, estípulas color rojizo en el ápice, 3-5 mm de largo, láminas oblongolanceoladas, 2.5-6.5 cm de largo, 1-4 cm de ancho, ápice acuminado, base obtusa, rara vez con los dientes basales prolongados formando dos caudas, estrigulosas en el margen y nervios de haz y envés; flores ca. $10 \mathrm{~mm}$ de diámetro; sépalos no apendiculados, ligeramente cuculados, 3-5 mm de largo, ápice acuminado, estrigulosos adaxialmente; pétalos obovados o espatulados, ca. $5 \mathrm{~mm}$ de largo, ápice redondeado, androginóforo no evidente; estambres 20-35; gineceo 2-carpelar, ovario densamente seríceo, 2-locular, con una hilera de óvulos por lóculo; fruto color verde, cilíndrico y levemente curveado, no anguloso, 40-50 mm de largo, caudado-acuminado, sin dientes, dehiscentes en 2 valvas, glabros o adpresopubescente; semillas color negro, semirrollizas, $1 \mathrm{~mm}$ de largo y ancho, superficie muricada.

Distribución: Estados Unidos de América, México (Chiapas, Guanajuato, Guerrero, Michoacán, Morelos, Nuevo León, Puebla, Sinaloa, Sonora, Tabasco, Tamaulipas, Veracruz, Yucatán), Centroamérica, Antillas, Sudamérica (Perú). Se ha reportado su presencia en la India (Robyns, 1964).

Fenología: florece y fructifica de mayo a noviembre.

Nombre común: jarilla.

Usos: no se conocen en el área.

Ejemplares examinados: MÉXICO. Guerrero, municipio Acapulco de Juárez, cerro de Cacahuatepec, $N$. Diego 5009 (FCME); Punta Gorda, orilla de la laguna de Tres Palos, M. Gual 4939 (FCME). Municipio Chilpancingo de los Bravo, ladera $\mathrm{S}$ del cerro El Tigre al $\mathrm{N}$ de Petaquillas, E. Velázquez 2282 (FCME). Municipio Coyuca de Benítez, Las Lajas, al S del poblado de Coyuca, M. Gual 653 (ENCB, FCME, IEB, MEXU); cerro al SE de la laguna de Coyuca, M. Gual 656 (ENCB, FCME, IEB, MEXU). Municipio Iguala de la Independencia, terrenos de la Escuela Superior de Agricultura, A. Almazán 184 (FCME, MEXU, UAGC); laguna de Tuxpan, a la orilla de la laguna, E. Pérez y R. M. Fonseca 10 (FCME, IEB, MEXU). Municipio Leonardo Bravo, La Pastora, km 181 del camino Atoyac, E. Pérez 5008 (FCME), 5009 (FCME).

Tipo de vegetación y altitud: bosque tropical caducifolio y vegetación secundaria; 10-800 m s.n.m. 


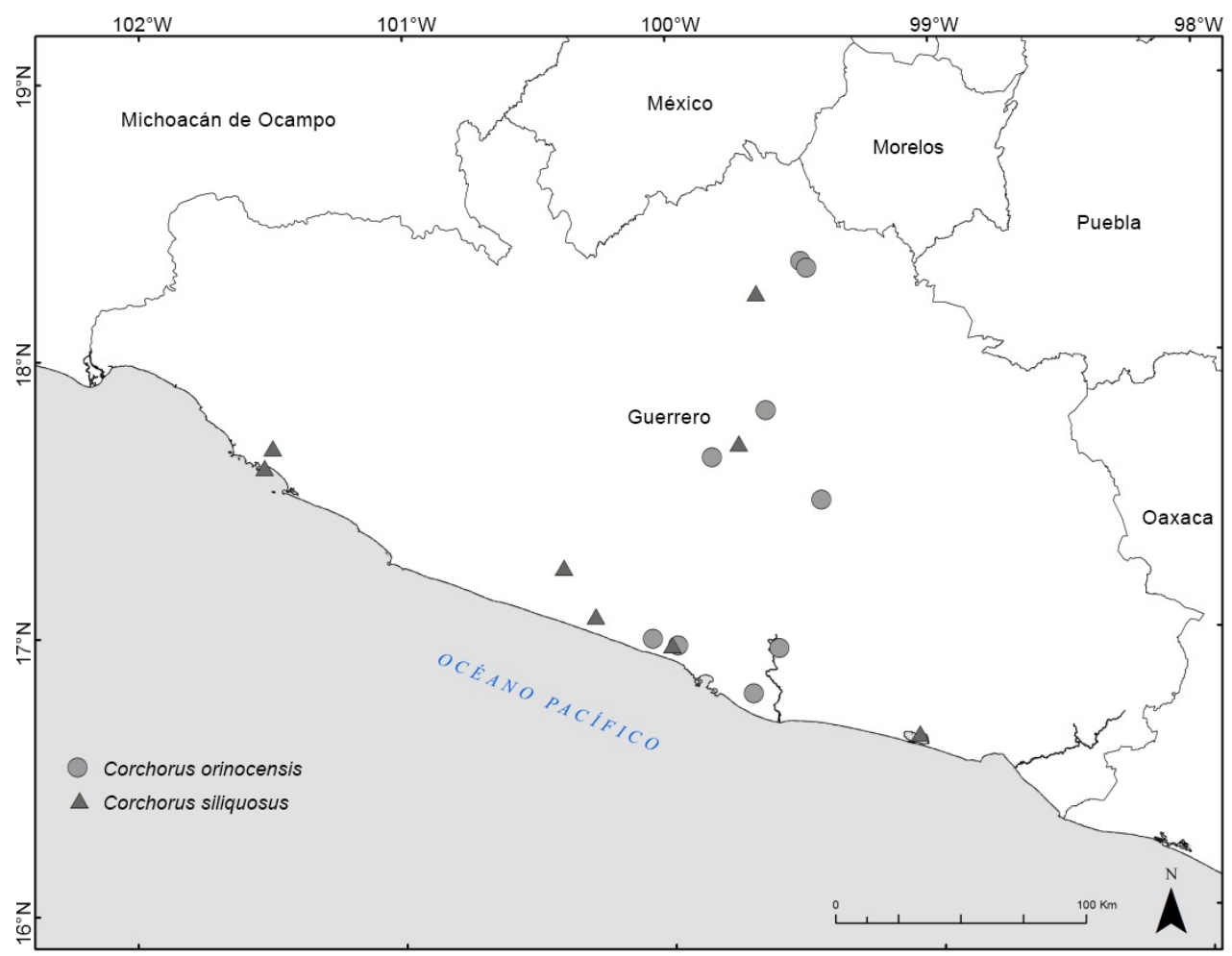

Figura 4: Distribución conocida de Corchorus orinocensis Kunth (○) y C. siliquosus L. (A).

Discusión: respecto a la identidad de Corchorus secundiflorus, Fryxell (2001), en la revisión de Tiliaceae para la Flora Novo-Galiciana, la considera como sinónimo de $C$. siliquosus, basándose en las láminas de la Colección Torner compiladas por White et al. (1998). Sin embargo, con base a Colmenero et al. (2010) se considera que se trata de un sinónimo de $C$. orinocensis, por el fruto 2-valvado en comparación con otra lámina de la misma colección para C. siliquosus, donde se aprecian los cornículos (dientes) del fruto que caracterizan a esta otra especie. Respecto a C. biflorus Sessé \& Moc., descrita en Flora Mexicana (Sessé \& Mocino, 1893), y tomando en cuenta las mismas características del fruto (2-valvado, sin cornículos o dientes) también se trata de un sinónimo de C. orinocensis. En la mayor parte de los herbarios mexicanos existe una confusión, puesto que se han identificado ejemplares de dos o tres valvas con este nombre. Es una planta escasa en el estado y en cuanto a su categoría de conservación se le ubica como preocupación menor (LC).
Corchorus siliquosus L., Sp. P1. 529. 1753. TIPO: JAMAICA (TIPO: no designado). Fig. 4.

$\equiv$ Corchorus trinervis Moc. \& Sessé, Pl. Nov. Hisp. 88. 1888. TIPO: MÉXICO. Lámina: 1787-1803, M. Sessé y J. M. Mociño s.n. (Colección Torner), (holotipo: G-DC).

Hierbas o arbustos, 0.4-1.5 m de alto; tallos con una franja de tricomas adpresos; hojas con peciolos, 1.5-3 $\mathrm{cm}$ de largo, estrigosos, estípulas color rojizo, $2 \mathrm{~mm}$ de largo, láminas ovadas o lanceoladas, 3-6 cm de largo, 1-3 $\mathrm{cm}$ de ancho, ápice largo acuminado, base oblícua o cuneada, nervios estrigosos en haz y envés; flores $8 \mathrm{~mm}$ de diámetro, sépalos no apendiculados, ligeramente cuculados, $5 \mathrm{~mm}$ de largo, $3 \mathrm{~mm}$ de ancho, ápice sin apéndices, estrigulosos adaxialmente; pétalos espatulados, 3-5 mm de largo, 2-3 mm de ancho, ápice redondeado; androginóforo no evidente; estambres 30-40(-60); gineceo 2-carpelar; ovario puberulento, 2-locular o bilocular, 1-2 hileras 
de óvulos por lóculo; frutos color verde, aplanados, no angulosos, 15-40 mm de largo, ápice obtuso, con 4 pequeños dientes, hirsutos; semillas color verde, semirrollizas, $1 \mathrm{~mm}$ de largo, $1 \mathrm{~mm}$ de ancho, lisas.

Distribución: Estados Unidos de América, México (Campeche, Colima, Chiapas, Guerrero, Hidalgo, Jalisco, Michoacán, Morelos, Nayarit, Oaxaca, Puebla, Querétaro, Quintana Roo, San Luis Potosí, Sinaloa, Tabasco, Tamaulipas, Veracruz, Yucatán), Centroamérica, Antillas, Sudamérica (Perú). Se ha reportado su presencia en India (Brizicky, 1965).

Tipo de vegetación y altitud: bosque tropical caducifolio; 0-1500 m s.n.m.

Fenología: florece y fructifica en marzo.

Usos: no se conocen en el área.

Ejemplares examinados: MÉXICO. Guerrero, municipio Atoyac de Álvarez, El Salto, N. Diego 3952 (FCME); colonia Vicente Guerrero, laguna de Mitla, $L$. Lozada 298 (FCME). Municipio Cocula, Cocula, E. A. López 7364 (FCME, UAGC). Municipio Coyuca de Benítez, El Bordonal, D. Quiroz 187 (FCME, IEB). Municipio Florencio Villarreal, Chautengo, al $\mathrm{S}$ del poblado, $R$. M. Fonseca 1636 (FCME). Municipio Leonardo Bravo, El Naranjo, Chilpancingo, V. García 2902 (FCME). Municipio Zihuatanejo de Azueta, en el camino que va del caserío La Vainilla al Calabazalito, C. Gallardo et al. 72 (FCME, MEXU); playa La Ropa, bahía de Zihuatanejo, G. Castillo y P. Zamora 6305 (MEXU).

Discusión: en cuanto a los ejemplares Tipo de esta especie de parte del Proyecto de Tipificación de Linnaean Society of London, Jansen-Jacobs y Meijer (1995) indicaron 691.6-LINN como el Tipo pero es una colección de Browne, recibida por Linnaeus en 1758, por lo que no es el material original para el nombre. Del mismo modo, aunque 691.7-LINN fue tratado por Fryxell (2001) como el tipo, esta colección carece del número relevante de Species Plantarum (Sp. Pl. 1) siendo una adición post-1753 al herbario; tampoco se considera un material original para el nombre. Es una planta escasa en el estado y en cuanto a su categoría de conservación se le ubica como preocupación menor (LC).

Heliocarpus L., Sp. Pl. ed. 1. 448. 1753.

$\equiv$ Adenodiscus Turcz., Bull. Soc. Imp. Naturalistes Moscou 19: 504. 1846.

TIPO: Heliocarpus americanus L.

Árboles o arbustos, hermafroditas o ginomonoicos; tallos con lenticelas color blanco, algunas veces con corteza exfoliante y color rojizo, pubescencia de tricomas simples y estrellados, glabrescentes; hojas alternas, con peciolos más cortos que las láminas, estípulas filiformes o triangulares, deciduas, láminas ovadas o 3-lobadas, ápice acuminado, agudo o caudado, margen irregularmente serrado, dentado o eroso, con o sin dientes glandulares basales, base redondeada, cordada, cuneada, subcordada, redondeada o atenuada, papiráceas, membranáceas, coriáceas o semicoriáceas, 3-7 nervadas, glabras o estrelladopubescentes; inflorescencias en panículas laxas, conformada por dicasios, las ramas apicales cimosas, terminales o axilares, rara vez con brácteas foliáceas, no adnadas al pedúnculo, pedunculadas, flores hermafroditas o pistiladas, tetrámeras rara vez pentámeras, pediceladas, epicáliz ausente; cáliz con 4-5 sépalos libres, ápice acuminado, algunas veces con apéndices, pubescentes en la parte abaxial, las hermafroditas con 4-5 pétalos color blanco o amarillo, espatulados u obtrulados, acuminados, estambres 12-60, libres o en un gonóforo, anteras lineares, introrsas, gineceo 2-carpelar; ovario súpero, sésil sobre el gonóforo o con un ginóforo, ligeramente compreso lateralmente, marginalmente ciliado, 2-4 locular, densamente estrellado-pubescente, estilo rollizo, estigma bilobado algunas veces papiloso; las pistiladas apetalas, estambres y estaminodios ausentes; frutos capsulares, lateralmente comprimidos, no leñosos, secos, indeiscentes, ovados, 
elípticos, circulares, obovados, de menos de $10 \mathrm{~mm}$ de diámetro, con 2-3 hileras de cerdas marginales, 5-10 mm de largo, plumosas, cuerpo pubescente o glabro, algunas veces ligeramente rugoso, indehiscente, semillas 2-4 por fruto, comprimidas, sin cilios.

Género neotropical con aproximadamente 11 especies (Lay, 1949; Robyns, 1964). En México están registradas todas las especies, de las cuales cuatro están presentes en Guerrero. El nombre genérico proviene del prefijo griego Helio=Sol, en referencia a la forma del fruto (Standley y Steyermark, 1946). En México las especies de este género son propias de vegetación secundaria derivada de distintos tipos de bosques tropicales y templados.

Algunas especies del género se utilizan en Centroamérica; con la corteza se elabora una fibra fuerte y durable, la madera es utilizada en la construcción de interiores de casas habitación y de pequeñas embarcaciones, así como para la obtención de pulpa para papel (Standley, 1923; Lay, 1949; Mabberley, 1987). En México presenta también importancia en la medicina tradicional; la corteza de algunas especies se utiliza como cicatrizante y antinflamatorio (Aguilar et al., 1994); también se ha mencionado el uso de Heliocarpus appendiculatus y H. pallidus en la elaboración de papel amate (Peters et al., 1987).

\section{Clave para la identificación de especies de Heliocarpus}

1a. Hojas 5-7 nervadas, base redondeada o cuneada, rara vez cordada o subcordada

1b. Hojas 3 nervadas, base cordada, raramente subcordada en láminas jóvenes 3

2a. Láminas de las hojas color verde oscuro, margen dentado o serrado, con 3 pares de dientes basales glandulares, haz escasamente estrellado-pubescente, tricomas simples, papiráceas; pétalos 4; frutos circulares u obovados; tallos con corteza exfoliante ......... H. occidentalis Rose

2b. Láminas de las hojas color verde claro, margen eroso, con la mayoría de los lóbulos (dientes) glandulares, haz densamente estrellado-pubescente sin tricomas simples, ligeramente aterciopeladas; pétalos 5; frutos ovados; tallos sin corteza exfoliante H. parvimontis Gual

3a. Láminas de las hojas color verde, escasa y cortamente estrellado-pubescentes en el envés; cáliz con 4 sépalos; estambres 20; frutos ovados, con cerdas, 3 $\mathrm{mm}$ de largo ......... H. terebinthinaceus (DC.) Hochr.

3b. Láminas de las hojas color blanquecino; densamente estrellado-tomentosas en el envés; cáliz con 5 sépalos; estambres 30-40; frutos elipsoidales, con cerdas, $2 \mathrm{~mm}$ de largo H. pallidus Rose

Heliocarpus occidentalis Rose, Contr. U.S. Natl. Herb. 5: 127. 1897. TIPO: MÉXICO. Guerrero, Acapulco and vicinity, E. Palmer 440 (isotipo: MO, sintipo: US-US00098472!); TIPO: MÉXICO. Guerrero, Acapulco and vicinity, E. Palmer 986 (sintipo: USUS00520158!, isosintipo: MO). Fig. 5.

$\equiv$ Heliocarpus laevis Rose, Contr. U.S. Natl. Herb. 8: 317. 1905. TIPO: MÉXICO. Jalisco, Bolaños, J. N. Rose 2860 (holotipo: US, isotipos: F-F0073967!, K-K000381204!; MO-MO194191!).

Árboles y arbustos, hermafroditas, 1-8 $\mathrm{m}$ de alto; tallos con corteza exfoliante color rojo, ramas jóvenes densamente estrellado-pubescentes, ferrugíneas; hojas color verde oscuro, peciolos 3-7.5 cm de largo, abundante y cortamente estrellado-pubescentes, estípulas filiformes, 3-4 mm de largo, estrellado-pubescentes, láminas ovadas a ampliamente ovadas, rara vez 3-lobadas, $6-16.5 \mathrm{~cm}$ de largo, 3.5-10.5 cm de ancho, ápice acuminado o caudado, margen dentado, a veces finamente serrado, base cuneada o redondeada, raramente subcordada o cordada, con tres pares de dientes basales glandulares, 5(7) nervadas, haz escasamente estrellado-pubescente y tricomas simples, envés con tricomas estrellados cortos y largos, papiráceas; inflorescencias terminales, rara vez axilares, 7-14 $\mathrm{cm}$ de largo, pedúnculos $2-2.5 \mathrm{~cm}$ de largo, rara vez con brácteas foliáceas, $2.5 \mathrm{~cm}$ de largo, $1.5-2 \mathrm{~cm}$ de ancho, estrellado-pubescentes; flores con cáliz 4-6 sépalos, ovados o lineares, $5 \mathrm{~mm}$ de largo, 1-1.5 mm de ancho, ápice 


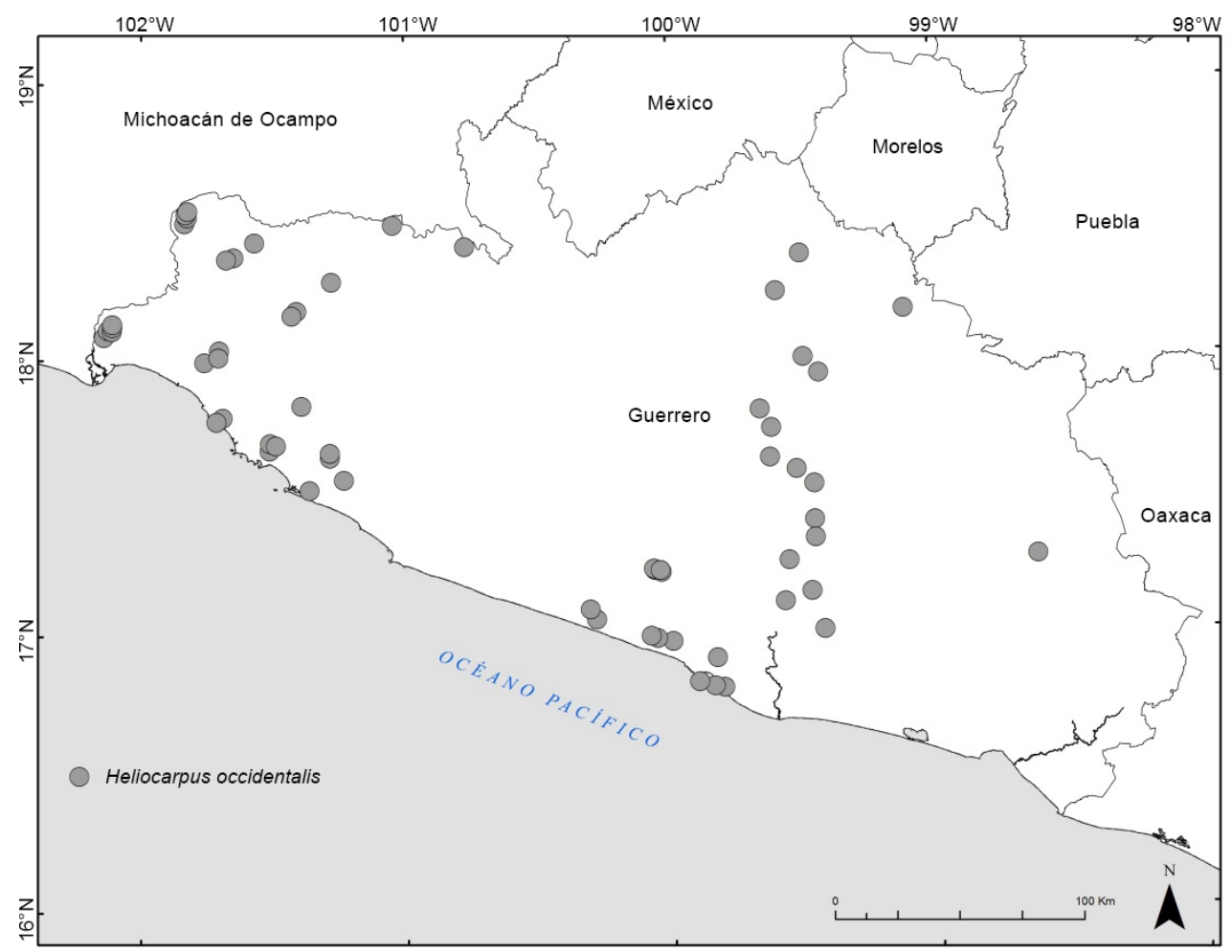

Figura 5: Distribución conocida. Heliocarpus occidentalis Rose (○).

con apéndice de menos de $1 \mathrm{~mm}$ de largo, lado abaxial pubescente, corola con 4 pétalos, color verdoso o blanco, espatulados, 2.5-6 mm de largo, 1.5-2 $\mathrm{mm}$ de ancho, ápice retuso o redondeado, androginóforo, $0.5 \mathrm{~mm}$ de largo, estambres 30-40, ovario obovado, $0.5 \mathrm{~mm}$ de largo, estilo $0.5 \mathrm{~mm}$ de largo, estigma papiloso; frutos circulares $\mathrm{u}$ obovados, 4-13 mm de largo, 5-9 $\mathrm{mm}$ de ancho, con cerdas color rojizo, 3-6 mm de largo, pedicelos ferrugíneos, 5-6 mm de largo, densamente estrellado-pubescentes; semillas 2 por fruto, color pardo oscuro, ovadas, compresas, 2-2.5 $\mathrm{mm}$ de largo.

Distribución: especie endémica de México (Colima, Guerrero, Jalisco, México, Michoacán, Nayarit, Oaxaca, Sinaloa).

Tipo de vegetación y altitud: bosque tropical caducifolio y subcaducifolio, de galería y vegetación secundaria; 0-1250 m s.n.m.
Fenología: florece de septiembre a diciembre y fructifica de octubre a marzo.

Nombres comunes: calagua, calagua roja, calahualaga, calahuate, calahue.

Usos: en el estado de Michoacán, la corteza se usa para obtener "sicuas" o cordeles rústicos, que se utilizan para amarrar el zacate o caña de maíz, para formar los mogotes y para tejer los techos de las chozas. No existe información sobre usos en Guerrero.

Ejemplares examinados: MÉXICO. Guerrero, municipio Acapulco de Juárez, El Palmito, orilla de la laguna Tres Palos, N. Diego 4768 (FCME); La Venta, cerro Las Peñas, frente al cerro El Peregrino, H. Kruse 2305 (FCME); $2.5 \mathrm{~km}$ al O de Puerto Marqués, W. López 561 (MEXU); Parque Nacional El Veladero, colonia Primero de Mayo, N. Noriega 227 (FCME), 296 (FCME); Isla Ro- 
queta, J. Oseguera 59 (FCME); Acapulco, L. Paray 1824 (ENCB); final de la Escénica, L. Wolfgang 423 (MEXU). Municipio Atenango del Río, cerro La Víbora, $1 \mathrm{~km}$ al E de Santa Cruz, O. Delgado 816 (FCME). Municipio Atlamajalcingo del Monte, S. D. Koch y P. A. Fryxell 83970 (ENCB). Municipio, Atoyac de Álvarez, $5 \mathrm{~km}$ al NO de la desviación a El Camalote, J. C. Martínez-Soto y E. Martínez 5932 (MEXU). Municipio Benito Juárez, El Camalote, laguna de Mitla, L. Lozada 768 (FCME). Municipio Chilpancingo de los Bravo, a $3 \mathrm{~km}$ de Acahuizotla, dirección $\mathrm{S}$ (camino de terracería hacia la planta eléctrica), J. Almazán y G. Zamudio 43 (FCME); $0.5 \mathrm{~km}$ al SO de la desviación a Mazatlán, carretera México a Acapulco, L. Lozada 1317 (FCME); Tierras Prietas, J. Maldonado 1059 (FCME); Chilpancingo, S. Melitón 1059 (FCME); Soyatepec a Ocotito, C. Verduzco 456 (FCME). Municipio Coahuayutla de José María Izazaga, La Higuerita, 1.3 km al N, J. Calónico 16111 (FCME); La Corba, 7.88 km al NE, J. Calónico 17577 (FCME); La Corba, $5.46 \mathrm{~km}$ al N, J. Calónico 17597 (FCME); La Higuera, $1.92 \mathrm{~km}$ al NE, J. Calónico 17889 (FCME); La Corba, $0.29 \mathrm{~km}$ al E, J. Calónico 18755 (FCME); La Corba, $5.53 \mathrm{~km}$ al NE, J. Calónico 18852 (FCME); El Maguey, $1.61 \mathrm{~km}$ al N, J. Calónico 19195 (FCME), 19204 (FCME). Municipio Cocula, Xonacastla, J. Santana 416 (FCME). Municipio Coyuca de Benítez, $3 \mathrm{~km}$ al SO de San Isidro (cerro), $G$. Coello 119 (FCME); Las Lajas, cerro al SE de laguna de Coyuca, M. Gual 655 (ENCB, FCME, IEB, MEXU); 1.5 km al SO de la subestación eléctrica, L. Meza 112 (FCME); Las Lajas, cerro al SE de laguna de Coyuca, D. Quiroz 428 (FCME); $2 \mathrm{~km}$ al SO de San Isidro, L. Rodríguez 464 (FCME). Municipio Eduardo Neri, barranca Acatitlán, Xochipala, M. Gual 339 (ENCB, FCME, MEXU). Municipio Iguala de la Independencia, Tuxpan, $3 \mathrm{~km}$ al NE del poblado, G. Ocampo et al. 150 (FCME). Municipio Juan R. Escudero, Tierra Colorada, falda E del cerro de granito, H. Kruse 2153 (FCME), 2304 (FCME). Municipio Petatlán, camino a los Llanos de la Puerta, Camalote, G. Campos 1418 (FCME); laguna de San Valentín, N. Diego 5222 (FCME); microondas La Roca, márgenes de la laguna de San Valentín, N. Diego 5598 (FCME); 2 km al N de Petatlán hacia La Ceiba, M. Gual 437 (ENCB, FCME, MEXU), 438 (ENCB, FCME, MEXU); $15 \mathrm{~km}$ al NO de Petatlán, camino al Camalote, E. Martínez 5147 (ENCB, FCME). Municipio Pungarabato, Los Cajones, $21 \mathrm{~km}$ al NE de Ciudad Altamirano, carretera a Huetamo, J. L. Contreras 683 (FCME). Municipio Tecoanapa, Pochotillo, Costa Chica, A. Millán 108 (FCME). Municipio Tepecoacuilco de Trujano, Ahuehuepan, J. Amith y J. Rojas 539 (FCME); San Agustín Oapan, Kowayoh (donde está la serpiente), J. Rojas et al. 242 (FCME). Municipio La Unión de Isidoro Montes de Oca, $2.4 \mathrm{~km}$ al SE de La Majahua por el camino de terracería, A. Díaz et al. 287 (FCME); $2.5 \mathrm{~km}$ al N el poblado La Unión, M. Gual 410 (ENCB, FCME, MEXU); $11.5 \mathrm{~km}$ al $\mathrm{N}$ de La Unión, camino a Coahuayutla, M. Gual 645 (ENCB, FCME, IEB, MEXU); $4 \mathrm{~km}$ al $\mathrm{N}$ de La Unión, camino a Coahuayutla, M. Gual 647 (ENCB, FCME, IEB, MEXU); $1.5 \mathrm{~km}$ al NO de Troncones, J. Paisano 97 (FCME). Municipio Zihuatanejo de Azueta, $2 \mathrm{~km}$ al SO del caserío La Vainilla, en el mirador del parque ecológico, C. Gallardo et al. 149 (FCME); $200 \mathrm{~m}$ al NO del caserío La Vainilla, C. Gallardo et al. 340 (FCME); $2.5 \mathrm{~km}$ al N de Zihuatanejo, Cerro Viejo, M. Gual 525 (ENCB, FCME, MEXU); Terreros, $\mathrm{km} 25$ carretera que entronca Zihuatanejo a Ciudad Altamirano, F. Lorea 3743 (FCME). Municipio Zirándaro, Guayameo, $2.14 \mathrm{~km}$ al SO, J. Calónico 19370 (FCME); $13 \mathrm{~km}$ al NO de Zirándaro, G. Campos 948 (FCME).

Discusión: en cuanto a su categoría de conservación esta especie se considera como preocupación menor (LC), está ampliamente representada en el estado.

Heliocarpus pallidus Rose, Contr. U.S Natl. Herb. 5: 128. 1897. TIPO: MÉXICO. Guerrero, Acapulco and vicinity, E. Palmer 157 (lectotipo: US-US00098473!, isolectotipos: F, K, US), designado por Fryxell, 2001. Figs. 6, 7.

$\equiv$ Heliocarpus velutinus Rose, Contr. U.S. Natl. Herb. 8: 317. 1905. TIPO: MÉXICO. Morelos, near Yaute- 

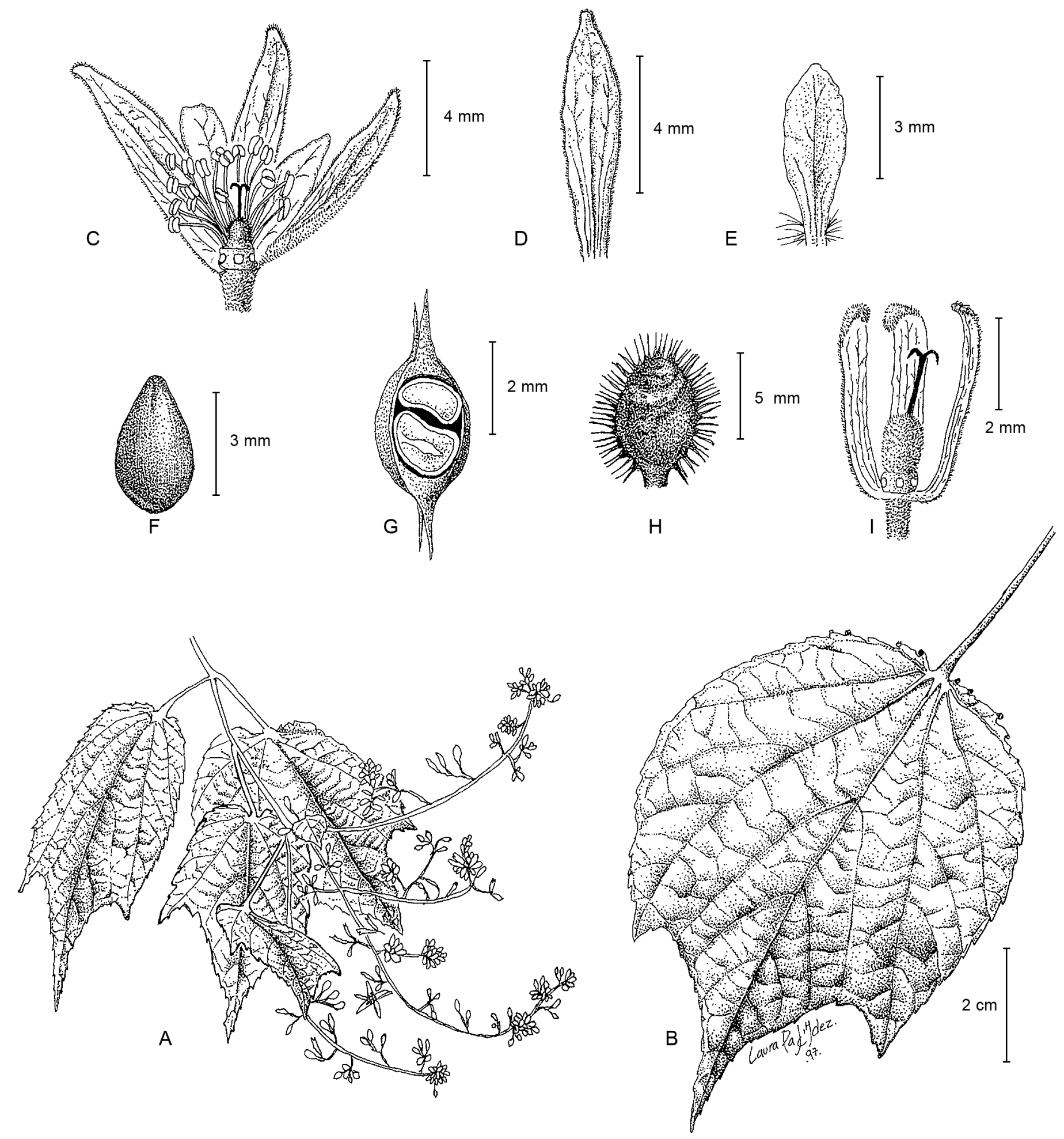

Figura 6: Heliocarpus pallidus Rose A. rama con hojas e inflorescencia; B. hoja con detalle de la venación y dientes basales con cuatro pares de glándulas; C. detalle de la flor; D. sépalo; E. pétalo; F. semilla; G. corte transversal de fruto; H. vista externa del fruto con cerdas; I. detalle de la flor femenina desprovista de los pétalos. Basados en E. Moreno y M. Luna 841 (FCME). 


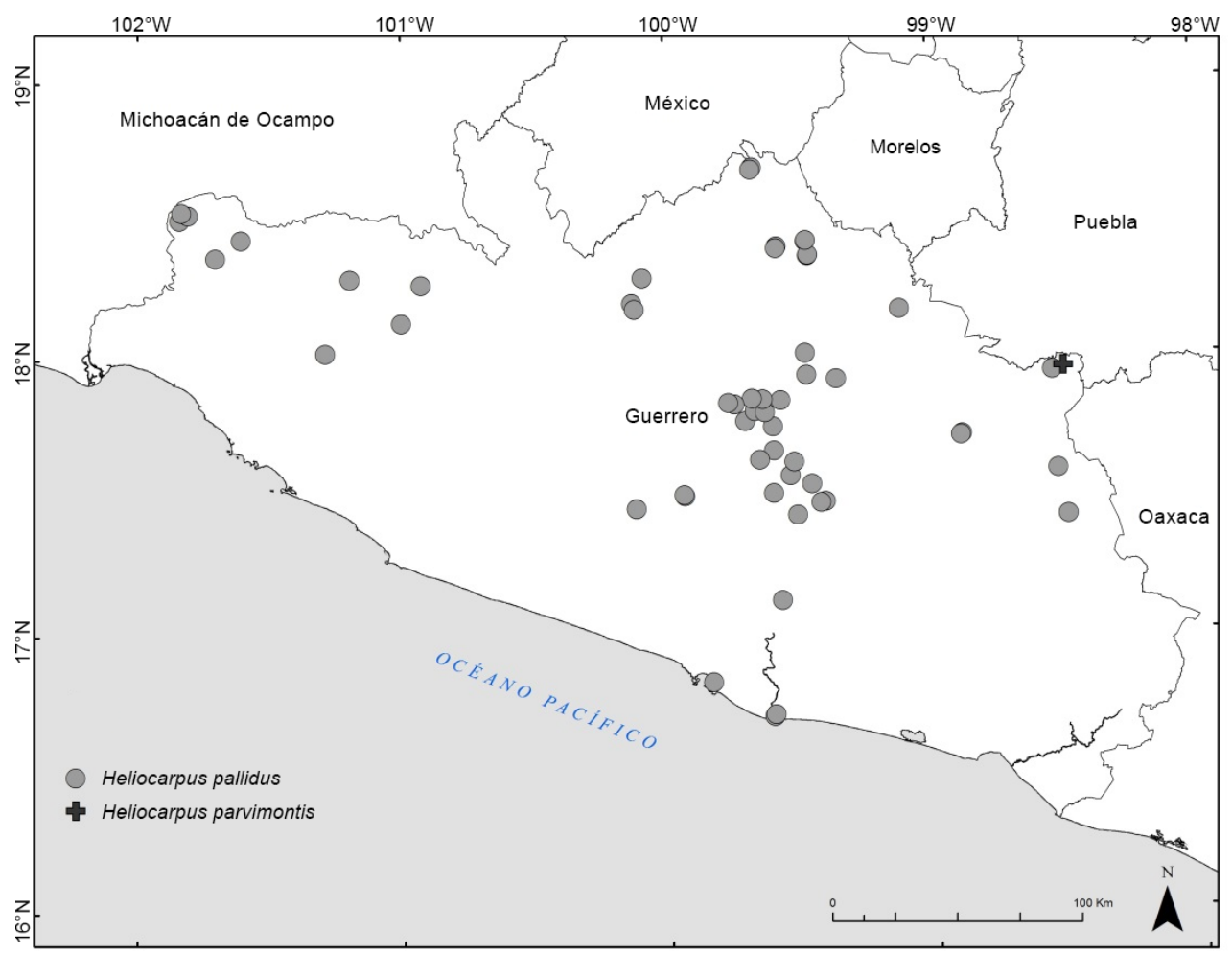

Figura 7: Distribución conocida de Heliocarpus pallidus Rose (○) y H. parvimontis Gual (\$).

pec, C. G. Pringle 8694 (holotipo: US, isotipos: BMBM000795087!, MO-MO194194!).

Árboles, ginomonoicos, 3-6 m de alto; tallos con ramas jóvenes abundante y cortamente estrellado-pubescentes; hojas con peciolos, $3.5-9 \mathrm{~cm}$ de largo, abundante y cortamente estrellado-pubescentes, estípulas deciduas, láminas blanquecinas (haz y envéz), 3-lobadas rara vez enteras, ampliamente ovadas, $6-16 \mathrm{~cm}$ de largo, $5-14.5 \mathrm{~cm}$ de ancho, ápice largo acuminado, margen dentado mucronado, base cordada, los 4-8 dientes basales con glándula apical, semicoriáceas o membranáceas, 3-nervadas, nervios laterales con uno o dos nervios secundarios, haz escasa y cortamente estrellado-pubescente, principalmente en los nervios, envés densamente estrellado-tomentoso; inflorescencias terminales, $4.5-16 \mathrm{~cm}$ de largo, pedúnculos 3-5 cm de largo, densamente estrellado-pubescentes; flores hermafroditas con cáliz de 5 sépalos color blanquecino, estrechamente oblongos, 4-6 $\mathrm{mm}$ de largo, $1 \mathrm{~mm}$ de ancho, ápice con apéndice, 0.4-0.6 mm de largo, lado abaxial estrellado-tomentoso; corola con pétalos color blanco, espatulados, rara vez obtrulados, 3.5-5.5 $\mathrm{mm}$ de largo, ápice cortamente acuminado, $5 \mathrm{~mm}$ de largo; androginóforo $0.5 \mathrm{~mm}$ de largo; estambres $30-40$, filamentos 1.5-2.5 mm de largo; ovario ovado, 1-2 $\mathrm{mm}$ de largo, pubescencia ferrugínea, estilo 1-2 $\mathrm{mm}$ de largo, estigma papiloso; flores pistiladas con cáliz, $7.5 \mathrm{~mm}$ de largo, 1-1.5 mm de ancho, densamente estrellado-tomentosas, androginóforo ausente, corola y ovario (vestigial) similares a las flores hermafroditas pero más pequeños; fruto color pardo claro, elipsoide, $5 \mathrm{~mm}$ de largo y ancho, con 2 hileras de cerdas, $2 \mathrm{~mm}$ de largo, estrellado-pubescente, cuerpo densamente estrellado-pubescente; semillas 2 por fruto, color pardo oscuro, piriformes, $3 \mathrm{~mm}$ de largo.

Distribución: especie endémica de México (Colima, Guerrero, Jalisco, México, Michoacán, Morelos, Nayarit, Oaxaca, Puebla). 
Tipo de vegetación y altitud: bosque tropical caducifolio, Quercus, Pinus-Quercus, y vegetación secundaria (matorral); así como en ecotonía entre bosque tropical caducifolio y de Quercus; 1200-2050 m s.n.m.

Fenología: florece de junio a noviembre y fructifica de octubre a diciembre.

Nombres comunes: abrojo blanco, alagua, calagua, calahuate blanco, coqueto, guazima, tempazuchilt del monte.

Usos: la madera se utiliza para la elaboración de papel, postes, vigas, polines y se obtiene leña, sus árboles se utilizan como sombra, y en su corteza crecen hongos comestibles.

Ejemplares examinados: MÉXICO. Guerrero, municipio Acapulco de Juárez, Las Huertas, entre el río Papagayo y laguna Tres Palos, N. Diego 4733 (FCME); El Palmito, orilla de la laguna Tres Palos, N. Diego 4750 (FCME); La Venta, cerro Las Peñas, frente a El Peregrino, H. Kruse 1746 (FCME); carretera escénica, L. Wolfgang 406 (MEXU). Municipio Alpoyeca, camino Tlapa a Huamuxtitlán, puente El Salado, E. Martínez et al. 2643 (IEB). Municipio Ahuacuotzingo, Coazintla, $2 \mathrm{~km}$ al S, R. Gutiérrez y J. L. Marín 83 (FCME). Municipio Arcelia, Filo del Círculo, $4.81 \mathrm{~km}$ al SO del campamento minero de Campo Morado, R. Cruz y R. Contreras 6114 (FCME); La Lucha, Campo Morado, A. Ponce et al. 681 (FCME). Municipio Atenango del Río, cerro La Víbora, a $1 \mathrm{~km}$ al E de Santa Cruz, O. Delgado 792 (FCME). Municipio Atlixtac, $4 \mathrm{~km}$ adelante de Atlixtac por carretera Chilpancingo a Chichihualco, 4.VI.1980, F. Lorea et al. s.n. (FCME). Municipio Atoyac de Álvarez, cañada $93 \mathrm{~km}$ delante de La Laguna, sobre carretera Xochipala - Filo de Caballos, A. Aquino 49 (FCME). Municipio Chilpancingo de los Bravo, $6 \mathrm{~km}$ adelante de la desviación por la brecha que va a Azinyahualco, M. Blanco et al. 587 (ENCB, MEXU), 588 (ENCB, MEXU); camino a Coapango (vivero de F. V. G.) al O de Chilpancingo, M. Blanco et al. 713 (MEXU); Chilpancingo, colonia
Ignacio Manuel Altamirano, C. Flores 13222 (FCME); Petaquillas, $3 \mathrm{~km}$ al S en Salto Valadez, H. Kruse 2870 (FCME), 19700831-197 (FCME); Salto Valadez, $H$. Kruse 197000802-195 (FCME); Chilpancingo, colonia La Trinchera, J. Maldonado 3573 (FCME). Municipio Coahuayutla de José María Izazaga, La Corba, $5.46 \mathrm{~km}$ al N, J. Calónico 17296 (FCME); La Corba, $4.92 \mathrm{~km}$ al NE, J. Calónico 17772 (FCME); El Pantano, $3.5 \mathrm{~km}$ al SE, $J$. Calónico 17844 (FCME); La Corba, $5.53 \mathrm{~km}$ al NE, $J$. Calónico 18811 (FCME), 18859 (FCME); La Corba, 4.74 $\mathrm{km}$ al NE, J. Calónico 18934 (FCME), 18939 (FCME), 18945 (FCME); El Zopilote, $3.25 \mathrm{~km}$ al NE, J. Calónico 19024 (FCME); El Pantano, $5.01 \mathrm{~km}$ al S, J. Calónico 19052 (FCME), 19061 (FCME). Municipio Coyuca de Catalán, Manchón, Distrito de Mina, G. B. Hinton 11267 (ENCB). Municipio Eduardo Neri, Ahuelican, J. Amith y J. Rojas 366-A (FCME); Cañón del Zopilote, H. Bravo 4976 (MEXU); Xochipala, B. E. Carreto 1885 (FCME); Amatitlán, $2 \mathrm{~km}$ al SE, camino a Carrizalillo, R. Cruz y M. E. García 695 (FCME); a $2 \mathrm{~km}$ de Xochipala, por la carretera a Filo de Caballo, R. M. Fonseca 74 (FCME); 3.5 km al NE de Xochipala, M. Gual 404 (FCME); $10 \mathrm{~km}$ al O de Mezcala, M. Gual 449 (ENCB, FCME, MEXU); El Palmar, 2 km al N, J. Jiménez y M. Luna 1056 (FCME); Carrizalillo, $8 \mathrm{~km}$ al O, M. Martínez 788 (FCME); Amatitlán, $3.4 \mathrm{~km}$ al E, camino a Carrizalillo, M. A. Monroy 575 (FCME); Mezcala, $14 \mathrm{~km}$ al SO, M. A. Monroy 684 (FCME); cerro Papalotepec, Xochipala, S. Peralta y $C$. Villegas 106 (FCME, MEXU). Municipio General Heliodoro Castillo, $8 \mathrm{~km}$ antes de El Jilguero, camino a Puerto de El Gallo, $48 \mathrm{~km}$ al SO de Filo de Caballos, J. C. Martínez-Soto y E. Martínez 5818 (FCME). Municipio Huitzuco de los Figueroa, $3 \mathrm{~km}$ al NO de San Francisco Ozomatlán, A. Vargas 111 (FCME). Municipio Iguala de la Independencia, SE de Iguala, B. Estela 70 (FCME); $6.5 \mathrm{~km}$ al N de Chilpancingo por carretera a Iguala, $S$. D. Koch et al. 79611 (ENCB); $11 \mathrm{~km}$ al N de Iguala, por autopista a México, S. D. Koch et al. 79650 (ENCB); Microondas Tuxpan, cerro El Jumil, al NE de Iguala, $P$. Tenorio 17219 (MEXU). Municipio Leonardo Bravo, $10 \mathrm{~km}$ adelante de Xochipala, carretera Casas Verdes a Filo de 
Caballo, 8.IX.1980, V. AIF y R. AIF s.n. (FCME, MEXU). Municipio Taxco de Alarcón, 15 miles north of Taxco, $P$. A. Fryxell 1132 (ENCB, MEXU); $4 \mathrm{~km}$ al $\mathrm{N}$ de Nuevo Mezcaltepec, cerro El Encinar, carretera Taxco a Iguala, M. Jiménez 36 (FCME). Municipio Tepecoacuilco de Trujano, entre Oapan y San Marcos Oacatzingo, J. Amith y J. Rojas 366 (FCME). Municipio Tlapa de Comonfort, 3 $\mathrm{km}$ al E de Alpoyecancingo, I. Calzada y C. Toledo 16253 (FCME), 16255 (FCME). Municipio Xochihuehuetlán, cañada Las Pozas, lado SO del Xilotzin, Jilotepec, E. Moreno y M. Luna 841 (FCME). Municipio Zihuatanejo de Azueta, El Limoncito, 3 a $4 \mathrm{~km}$ al $\mathrm{N}$ de Real de Guadalupe, F. González-Medrano 6556 (IEB), 6557 (IEB). Municipio Zirándaro, Pláceres del Oro, $7.03 \mathrm{~km}$ al NO, $J$. Calónico 12806 (FCME); Guayameo, $5.06 \mathrm{~km}$ al E, $J$. Calónico 12964 (FCME), 12984 (FCME).

Discusión: en cuanto a su categoría de conservación esta especie se considera como preocupación menor (LC), está ampliamente representada en el estado.

Heliocarpus parvimontis Gual, Rev. Mex. Biodiv. 80: 283-286. 2009. TIPO: MÉXICO. Guerrero, cerro Xilotzin, $3.25 \mathrm{~km}$ al NNE de Jilotepec, E. Moreno y $M$. A. Monroy 581 (holotipo: MEXU-MEXU01372853!, isotipos: FCME!, MEXU-MEXU01042381!). Fig. 7.

Arbustos, hermafroditas, $1.5-3 \mathrm{~m}$ de alto; tallos densamente estrellado-pubescentes, glabrescentes, corteza no exfoliante; hojas con peciolos, $1-1.5 \mathrm{~cm}$ de largo, densamente estrellado-pubescentes, estípulas filiformes en la base del peciolo, ca. $3 \mathrm{~mm}$ de largo, deciduas, láminas color verde claro, ovadas o angostamente ovadas, $3-8 \mathrm{~cm}$ de largo, 2-5 cm de ancho, ápice acuminado, margen eroso, con la mayoría de los lóbulos (dientes) glandulares, base cuneada o ligeramente subcordada, 5-7 nervadas, haz densamente estrellado-pubescente con brazos cortos y largos y sin tricomas simples, envés con indumento abundante de tricomas estrellados con brazos largos (dando una apariencia blanquecina), ligeramente aterciopeladas; inflorescencias terminales o axilares, $5-11 \mathrm{~cm}$ de largo, brácteas foliá- ceas, lanceoladas, ca. $20 \mathrm{~mm}$ de largo, con características similares a las de las hojas; flores con 5 sépalos lanceolados, 4.5-6 mm de largo, apéndices 1-2 mm de largo, lado abaxial cortamente estrellado-pubescentes; corola con 5 pétalos, obovados, $2 \mathrm{~mm}$ de largo, ápice asimétrico y denticulado, escasamente estrellado-pubescentes en la base; androginóforo, $5 \mathrm{~mm}$ de largo; estambres aproximadamente 50 , filamentos $5 \mathrm{~mm}$ de largo; ovario ovado, 2-locular, cada lóculo con 2 óvulos, $5 \mathrm{~mm}$ de largo, marginalmente ciliado, estrellado-pubescente; estilo 2-5 $\mathrm{mm}$ de largo; estigma papiloso; fruto ovado, 8-9 $\mathrm{mm}$ de largo, 0.6-0.7 mm de ancho, estrellado-pubescente, cerdas $3 \mathrm{~mm}$ de largo, ocasionalmente presentes en las superficies ventral y dorsal; semillas 2 por fruto, color pardo claro en la madurez, obovadas, 3-5 $\mathrm{mm}$ de largo, $3 \mathrm{~mm}$ de ancho, 1 por lóculo.

Distribución: especie endémica de México (Guerrero).

Tipo de vegetación y altitud: en bosque tropical caducifolio y zonas de ecotonía entre éste y el de Quercus; 1480-1590 m s.n.m.

Fenología: florece y fructifica en octubre.

Usos: no se conocen en el área.

Ejemplares examinados: MÉXICO. Guerrero, municipio Xochihuehuetlán, cerro Xilotzin, $3.25 \mathrm{~km}$ al NNE de Jilotepec, E. Moreno y M. A. Monroy 581 (MEXU); loc. cit., E. Moreno et al. 1060 (MEXU), 1061 (MEXU), 1062 (MEXU), 1063 (ENCB, IEB, MEXU).

Discusión: por su distribución reducida y escasa recolecta en el estado (sólo localidad tipo), así como por el impacto en los tipos de vegetación que actualmente ocupa (fragmentados y reducidos por la expansión urbana), se le considera como peligro crítico (CR). Desafortunadamente, no se cuenta con información que permita evaluar el grado de impacto en las poblaciones de esta especie y sobre otras con las que comparte el hábitat. 
Heliocarpus terebinthinaceus (DC.) Hochr., Annuaire

Conserv. Jard. Bot. Genève 18: 125. 1914. Fig. 8.

= Grewia terebinthinaceus DC., Cat. Pl. Horti Monsp. 114. 1813. TIPO: El material considerado como tipo de G. terebinthinacea es: "DC. hort. monsp. ined. t. 44", una ilustración basada en una planta cultivada de origen desconocido.

$\equiv$ Heliocarpus nelsonii Rose, Contr. U.S. Natl. Herb. 5(3): 128. 1897. TIPO: MÉXICO. Oaxaca, Valley of Oaxaca, E. W. Nelson 1243 (holotipo: US, isotipo: NYNY00415453!).

$\equiv$ Heliocarpus reticulatus Rose, Contr. U.S. Natl. Herb. 5(3): 128. 1897. TIPO: MÉXICO. Jalisco, hills near Guadalajara, C. G. Pringle 1791 (holotipo: US, isotipos: F, K-K000381211!, MO-MO194195!, NY, US).

$\equiv$ Heliocarpus microcarpus Rose, Contr. U.S. Natl. Herb. 8: 316. 1905. TIPO: MÉXICO. Morelos, about Cuernavaca, C. G. Pringle 8719 (holotipo: US, isotipos: F, K-K000381212!, MO-MO194195!).

Árboles o arbustos, ginomonoicos, 5-10 m de alto; tallos de corteza no exfoliante, ramas jóvenes estrelladopubescentes, glabrescentes; hojas con peciolos, 4.5-6.5 $\mathrm{cm}$ de largo, densamente estrellado-pubescentes, estípulas deciduas, láminas verdes, 3-lobadas, ampliamente ovadas, 9-22 cm de largo, 6.5-19 cm de ancho, ápice acuminado, margen dentado-mucronado o finamente serrado, dientes basales con 4-6 pares de glándulas, rara vez ausentes, base cordada, 3-nervadas, nervios laterales con 1-2 nervios secundarios, escasa y cortamente estrelladopubescentes en el envés, de consistencia semicoriácea; inflorescencias terminales, $8-20 \mathrm{~cm}$ de largo, pedúnculos 3-7 cm de largo, densamente estrellado-pubescentes; flores hermafroditas, cáliz de 4 sépalos lineares, $2.5 \mathrm{~mm}$ de largo, ápice con apéndice, $1 \mathrm{~mm}$ de largo, lado abaxial estrellado-pubescente, corola con 4 pétalos color blanco, $1.5 \mathrm{~mm}$ de largo, $0.5 \mathrm{~mm}$ de ancho, glabros, androginóforo $0.5 \mathrm{~mm}$ de largo, estambres 20, filamentos $2 \mathrm{~mm}$ de largo, estaminodios $1 \mathrm{~mm}$ de largo; ovario ovado, $0.5 \mathrm{~mm}$ de largo, estilo $0.5 \mathrm{~mm}$ de largo, estigma papiloso, flo- res pistiladas de cáliz con 1 apéndice, $0.4 \mathrm{~mm}$ de largo, androginóforo ausente, estilo $1 \mathrm{~mm}$ de largo; fruto color pardo, ovado, 7-10 mm de largo, 6-9 mm de ancho, densamente estrellado-pubescente, con cerdas, $3 \mathrm{~mm}$ de largo, algunas veces con espinas, 1-2 $\mathrm{mm}$ en el cuerpo del fruto; semillas 2 por fruto, color pardo claro, piriformes, $2 \mathrm{~mm}$ de largo.

Distribución: México (Colima, Chiapas, Guanajuato, Guerrero, Jalisco, México, Michoacán, Morelos, Nayarit, Oaxaca, Puebla, Querétaro) y Centroamérica.

Tipo de vegetación y altitud: bosque de galería, Quercus, Pinus-Quercus, tropical caducifolio, matorral xerófilo y vegetación secundaria; 500-2000 m s.n.m.

Fenología: florece de agosto a octubre y fructifica de agosto a diciembre.

Nombres comunes: árbol de cuetla, calahuate, coahuilahua, conotle, cuetlo, cuhualaga, jonotle, ndácua vali, tripa de judas.

Usos: en el estado se le utiliza como forraje para chivos, de su follaje se alimentan unas larvas llamadas "cuetlas" las cuales son consumidas por los habitantes localmente; la cáscara del tallo se usa para apostemas. En Oaxaca, se consume en infusión para tratamiento del paño, acné, gastritis y enfermedades estomacales asociadas a agentes microbianos, así como planta forrajera en tiempo de secas. En general, la corteza es correosa y se ha utilizado en sus áreas de distribución para amarrar diversos objetos.

Ejemplares examinados: MÉXICO. Guerrero, municipio Ahuacuotzingo, Ajuatetla, reserva campesina, D. Aparicio 94 (FCME); loc. cit., F. Casarrubias 505 (FCME); loc. cit., C. Godinez 5 (FCME); loc. cit., T. Hernández 49 (FCME, MEXU). Municipio Alcozauca de Guerrero, Alcozauca a Ixcuinatoyac, J. Viveros y F. A. Casas 216 (ENCB); barranca del Agua Salada, J. Viveros y 


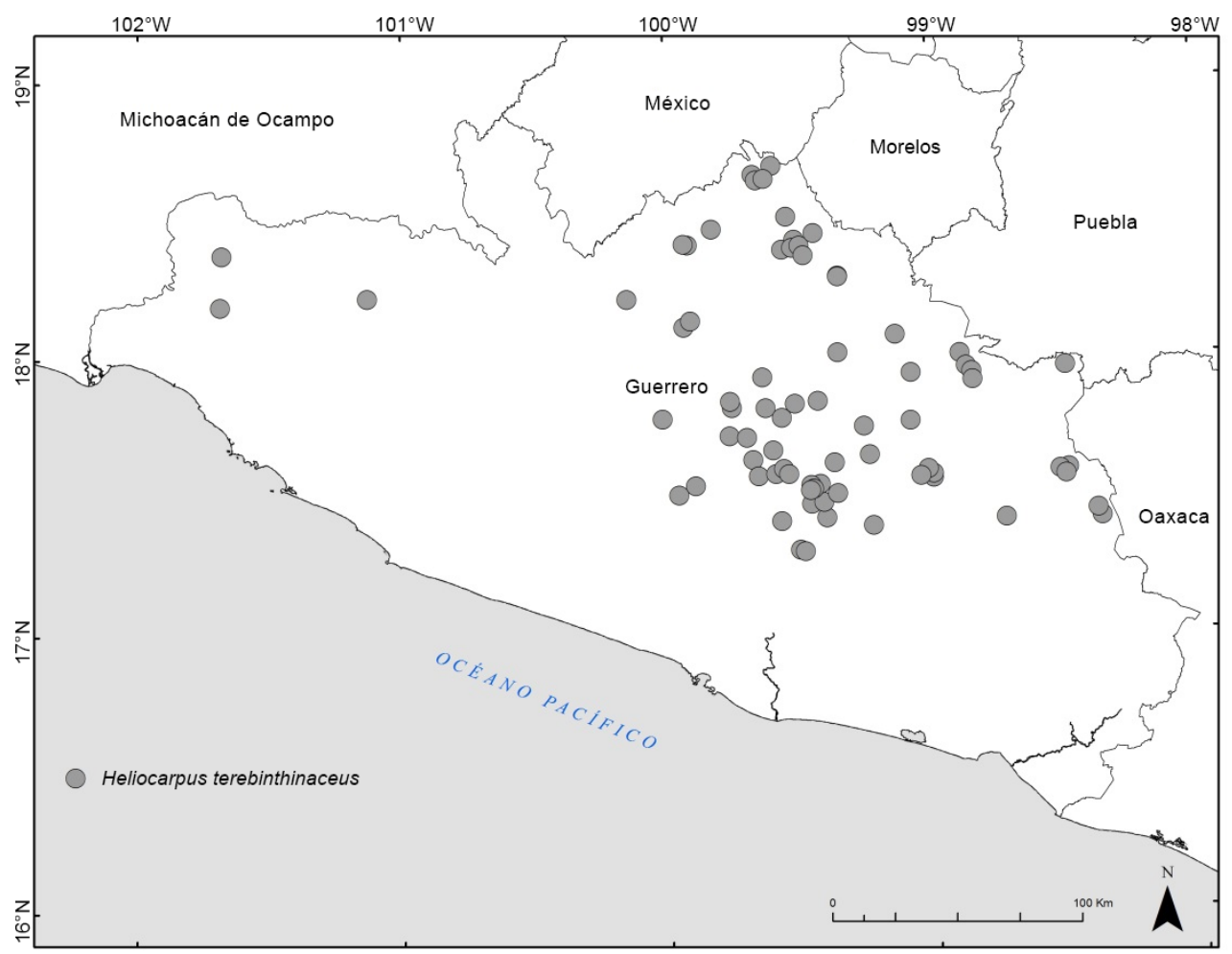

Figura 8: Distribución conocida de Heliocarpus terebinthinaceus (DC.) Hochr. (O).

F. A. Casas 280 (ENCB, MEXU), 358 (ENCB, MEXU). Municipio Alpoyeca, $3 \mathrm{~km}$ al NO de Tecoyo, J. Calónico 480 (FCME); Alpoyeca, $1.5 \mathrm{~km}$ al O de Tecoyo, J. Calónico 726 (FCME), 2237 (FCME); $1.5 \mathrm{~km}$ al N de Tecoyo, $J$. Calónico 2182 (FCME). Municipio Apaxtla, cerro de las Trincheras, 5.X.1981, R. Fernández et al. s.n. (FCME); 10 $\mathrm{km}$ al NO de Tlatzcala (ladera del río), 4.X.1981, S. García s.n. (FCME). Municipio Arcelia, cañada El Limón, Campo Morado, R. Cruz 6447 (FCME). Municipio Atenango del Río, $5 \mathrm{~km}$ al $\mathrm{O}$ de Atenango del Río, rumbo a Iguala, $A$. $G$. Trápaga y A. G. Monzón 78 (FCME). Municipio Atlixtac, Santa Isabel, $0.3 \mathrm{~km}$ al ONO, F. Guerrero 265 (FCME); Santa Isabel, $0.36 \mathrm{~km}$ al NO, I. Limón 72 (FCME); Petatlán, $2.3 \mathrm{~km}$ al NO, Y. Martínez 291 (FCME); afueras de Petatlán, L. Mendizábal 132 (FCME); Petatlán, 1.89 km al NO, S. Saucedo 234 (FCME), 235 (FCME). Municipio Buenavista de Cuéllar, $0.5 \mathrm{~km}$ al SO de Los Amates sobre El Cañón, C. Catalán y C. Sánchez 525 (FCME); al N de Los Pilinques, G. Santana 98 (FCME). Municipio Chil- pancingo de los Bravo, al $\mathrm{S}$ de Chilpancingo (Jardín Botánico), A. Barrera 51 (ENCB); Chilpancingo, $5 \mathrm{~km} \mathrm{S,} M$. Blanco et al. 141 (ENCB); a $1 \mathrm{~km}$ de la entrada a la presa El Molino, hacia Chilpancingo, ladera NO, L. Cervantes 94 (FCME); cerro de Los Bueyes, al N de Chilpancingo, J. Chavelas 2872 (ENCB); Rancho de la Vírgen, G. González 21 (MEXU); camino a Amojileca, $1 \mathrm{~km}$ antes del poblado, sobre la carretera, M. Gual 658 (ENCB, FCME, IEB, MEXU); $3 \mathrm{~km}$ después del poblado de Amojileca, sobre la carretera a Omiltemi, M. Gual 661-a (ENCB, FCME, IEB, MEXU); Rincón de La Vía, H. Kruse 680 (FCME), 760 (FCME); cerro El Fresno, H. Kruse 2301 (FCME); $1 \mathrm{~km}$ al SO de Cruz de Ocote, F. Lorea 3655 (FCME); Los Cañones, L. C. Rodríguez 402 (FCME). Municipio Coahuayutla de José María Izazaga, $9.98 \mathrm{~km}$ al N de Coahuayutla, J. Calónico 11897 (FCME); $11 \mathrm{~km}$ al N de Colmenares, camino a La Unión, J. C. Martínez-Soto y E. Martinez 1984 (ENCB). Municipio Copalillo, 2 km hacia el crucero Olinalá - Xixila - Papalutla, J. Calónico 
132 (FCME); 14 km al SE de Papalutla, crucero Olinalá Xixila - Papalutla, J. Calónico 328 (FCME); $6 \mathrm{~km}$ al NE de Zicapa, Las Trancas, G. Campos 240 (FCME); $6 \mathrm{~km}$ al NO de Zicapa, L. F. Limón 135 (FCME); 13 km al SE de Papalutla, crucero Olinalá - Xixitla - Papalutla, M. Martínez 856 (FCME); crucero Olinalá - Xixitla - Papalutla, a $14 \mathrm{~km}$ de Papalutla, A. Rincón 47 (FCME). Municipio Copanotoyac, Potoichan, 10-12 km carretera Tlapa, $R$. Fragoso y J. Santana 1474 (FCME). Municipio Cuetzala del Progreso, Chilacachapa, E. A. López-Huicochea 12503 (FCME). Municipio Eduardo Neri, Cañón del Zopilote, $H$. Bravo 4976 (MEXU); El Palmar, $2.5 \mathrm{~km}$ al NE, J. Calónico 1478 (FCME); $2.1 \mathrm{~km}$ al SE de Amatitlán, carretera Amatitlán a Carrizalillo, R. Cruz y M. E. García 77 (FCME); Puerto de los Tepetates, $3 \mathrm{~km}$ al SO de Amatitlán, $R$. Cruz 554 (FCME); 2 km de la carretera de Mezcala camino de terracería, B. González 1089 (FCME); Tres Cruces, J. Maldonado 617 (FCME, UAGC); barranca El Salado, Xochipala, S. Peralta 280 (FCME, MEXU); Ameyaltepec, cerro Cacalotepec, J. Rojas et al. 331 (FCME). Municipio General Heliodoro Castillo, Huautla, $12.3 \mathrm{~km}$ al S, J. Calónico 12313 (FCME); 8 km antes de El Jilguero, camino a Puerto Gallo, J .C. Martínez-Soto y E. Martínez 5018 (ENCB). Municipio Huitzuco de los Figueroa, Huitzuco, G. González 54 (MEXU). Municipio Iguala de la Independencia, Cañón de la Mano, entre Los Amates y El Naranjo, $10 \mathrm{~km}$ al $\mathrm{N}$ de Iguala por el ferrocarril, $C$. Catalán y F. Terán 447 (MEXU); arriba del Puente Campuzano (Iguala), F. Miranda 3936 (MEXU); Iguala, C. G. Pringle 10069 (ENCB); Tuxpan $5 \mathrm{~km}$ al N del poblado, ladera del cerro El Jumil, F. Terán 184 (FCME). Municipio Ixcateopan de Cuauhtémoc, Ixcateopan, $10 \mathrm{~km}$ al O, M. Martínez 2066 (FCME). Municipio Leonardo Bravo, $6 \mathrm{~km}$ del entronque que va al poblado, B. González 1414 (FCME); mina La Natividad, $4 \mathrm{~km}$ de El Naranjo, E. Hernández s.n. (FCME). Municipio Malinaltepec, Tilapa, $A$. Galeana 1079 (FCME). Municipio Mártir de Cuilapan, La Esperanza, reserva campesina, N. Diego 6839-a (FCME); loc. cit., E. Teyuco 215 (FCME). Municipio Mochitlán, Mazatlán, $3 \mathrm{~km}$ al N de Salto de Valadez, H. Kruse 2118 (FCME), 2265 (FCME). Municipio Pilcaya, La Concep- ción, $21 \mathrm{~km}$ al SE, J. Calónico 6049 (FCME); $1 \mathrm{~km}$ al SE camino a Tetipac, $R$. Cruz 1521 (FCME); $3 \mathrm{~km}$ al SE, camino a Tenoxiotitlán, R. Cruz 1548 (FCME); El Mogote, 2 $\mathrm{km}$ antes de El Mirador, M. Martínez 1978 (FCME). Municipio Quechultenango, a $2 \mathrm{~km}$ al $\mathrm{S}$ de Quechultenango, por camino de herradura a Tlayolapa, A. Núñez 964 (FCME). Municipio Taxco de Alarcón, Juliantla, $2 \mathrm{~km}$ al SE, rumbo a Tlamaczapa, J. Calónico 6146 (FCME); $2.5 \mathrm{~km}$ al SO de Acuitlapan, camino a Taxco, F. Lorea 3221 (FCME). Municipio Teloloapan, 7 miles $\mathrm{W}$ of Teloloapan (45 miles W of Iguala), P. A. Fryxell 610 (MEXU); at km 73.9, $9.5 \mathrm{~km}$ (by road) of the Teloloapan, H. Iltis et al. 3037 (ENCB). Municipio Tepecoacuilco de Trujano, $14 \mathrm{~km}$ al S de San Miguel, cabecera SSE de barranca San Marcos, $6 \mathrm{~km}$ al SO de camino, J. Amith y G. Hall 892 (FCME); ladera S de Zapotitlán, E. Domínguez et al. 309 (FCME). Municipio Tixtla de Guerrero, de Atliaca a Tixtla, N. Herrera 18 (UAGC); $5 \mathrm{~km}$ al O de Tixtla, sobre carretera Chilpancingo a Tixtla, 2.XI.1983, G. Lozano s.n. (FCME); $5 \mathrm{~km}$ al O de Tixtla sobre carretera Chilpancingo a Tixtla, G. Lozano 374 (FCME). Municipio Xochihuehuetlán, Jilotepec, cañada de Tecoapano, E. Moreno 698 (FCME). Municipio Zirándaro, Los Alacranes, $10 \mathrm{~km}$ al SO, J. Calónico 12108 (FCME). Municipio Zitlala Topiltepec, reserva campesina, N. Diego y H. Ordóñez 7161 (FCME); dirección a el poblado de Xocolmani adelante de la cuadrilla Chocotla, M. Gual 5910 (FCME); loc. cit., C. Miranda 121 (FCME); loc. cit., B. Toazinque 196 (FCME).

Discusión: su categoría de conservación es de preocupación menor (LC), está bien representada en el estado y en el país. El ejemplar H. Bravo 4976 (MEXU-19765) es asignado por el colector igualmente a otra colecta diferente que corresponde a la especie Heliocarpus pallidus (H. Bravo 4976, MEXU-19747).

Luehea Willd., Ges. Naturf. Freunde Berlin Neue Schriften 3: 410. 1801.

=Alegria DC., Prodr. 1: 516. 1824.

TIPO: Luehea speciosa Willd. 
Árboles o arbustos, hermafroditas; tallos con lenticelas blancas, estrellado-pubescentes, glabrescentes; hojas con peciolos cortos, estípulas lanceoladas o asimétricas, estrellado-pubescentes, deciduas, láminas elípticas, ovado oblongas u obovadas, ápice agudo o acuminado, margen dentado o serrado, base truncada, redondeada, oblícua o ligeramente cordada, 2-5 nervadas, estrelladopubescentes, de consistencia membranácea a coriácea; inflorescencias en cimas o panículas, axilares o terminales, algunas veces reducidas a flores solitarias o apareadas, con epicáliz de numerosas bracteolas persistentes; cáliz con 5-6 sépalos, libres, algunas veces corto connados, oblongo lanceolados, acuminados, base con glándulas carnosas, pubescencia de tricomas simples y estrellados; corola con 5-6 pétalos color blanco, espatulados, ápice redondeado, pubescencia de tricomas simples y estrellados; estambres numerosos, con los filamentos connados en la base, agrupados en 5-10 falanges, estaminodios presentes, anteras oblongas, versátiles, extrorsas; gineceo, 5-carpelar; ovario súpero, piriforme, 5-locular, con abundante pubescencia de tricomas simples y estrellados, óvulos numerosos por lóculo; estilo simple, rollizo; estigma capitado o 5-lobado; frutos cápsulas leñosas, no cilíndricas, 5-angulosas, 5-valvadas, pedicelos glabrescentes; semillas numerosas, aladas en un lado.

Género neotropical con aproximadamente 20 especies (Robyns, 1964; Good, 1974; Mabberley, 1987). En México se han registrado tres especies, una de las cuales se encuentra en Guerrero. Las especies de este género son componentes del bosque tropical subcaducifolio y perennifolio. En Centroamérica se ha reportado uso artesanal; con los frutos se elaboran "molinillos" y con su corteza se realizan cordones temporales (Standley, 1923; Standley y Steyermark, 1946). En Brasil se le ha dado uso medicinal, para curar la lepra y algunos tumores (USDA, 2017).

Luehea candida (DC.) Mart., Nov. Gen. Sp. 1: 102. 1826. TIPO: Fl. Mex. Ic. Ined.

= Alegria candida DC., Prodr. 1: 517. 1824. TIPO: MÉXICO. M. Sessé y J. M. Mociño s.n. (lectotipo: M. Sessé y
J. M. Mociño, III. Hunt Institute 6331.0558; isolectotipos: F-F0044566F!, F-F0044567F!), lectotipo designado por McVaugh, 2000. Figs. 9, 10.

Árboles o arbustos, 4-12 m de alto; hojas con peciolos, 0.5-1.5 cm de largo, estrellado-pubescentes, estípulas asimétricas, color verde amarillo, 8-10 $\mathrm{mm}$ de largo, haz glabro, envés con tricomas estrellados, deciduas, láminas ovadas a elípticas, algunas veces ampliamente obovadas, rara vez asimétricas, 4-22 cm de largo, 2.5-13 $\mathrm{cm}$ de ancho, ápice acuminado, base oblicua, cordada o redondeada, haz con tricomas estrellados, envés tomentoso, tricomas estrellados; inflorescencias $6-16 \mathrm{~cm}$ de largo; flores 50-120 mm de diámetro, pedicelos 20-30 $\mathrm{mm}$ de largo, estrellado-pubescentes, epicáliz de bracteolas lanceoladas, 25-50 mm de largo, haz con abundantes tricomas estrellados cortos y largos, concentrados sobre la costa, envés con abundantes tricomas estrellados cortos; sépalos 5-6, 25-40 mm de largo, 15-20 mm de ancho, ligeramente cuculados en botón, haz con tricomas simples y cortos en la base, envés con tricomas simples y estrellados; pétalos 30-50 mm de largo, 15-30 $\mathrm{mm}$ de ancho, ambas superficies con tricomas simples y estrellados; ovario $25-30 \mathrm{~mm}$ de largo, densamente pubescente con tricomas cortos y estrellados, con 2 hileras de óvulos por lóculo; estilo ensanchándose hacia el ápice, 15-20 mm de largo, con tricomas estrellados, cortos, frutos 45-60 $\mathrm{mm}$ de largo, 25-30 $\mathrm{mm}$ de ancho, acuminados, rara vez obtusos, cubiertos con tricomas cortos y estrellados; semillas color pardo claro, $15 \mathrm{~mm}$ de largo incluyendo el ala, $5 \mathrm{~mm}$ de ancho, ala $10 \mathrm{~mm}$ de largo, papirácea.

Distribución: México (Chiapas, Colima, Guerrero, Jalisco, Michoacán, Nayarit, Sinaloa, Oaxaca, Tabasco, Veracruz, Yucatán), Centroamérica, Sudamérica ( $\mathrm{N}$ de Colombia y Venezuela).

Tipo de vegetación y altitud: bosque tropical caducifolio, subcaducifolio, de Quercus, y vegetación secundaria (ruderal y acahual); 0-1060 m s.n.m. 


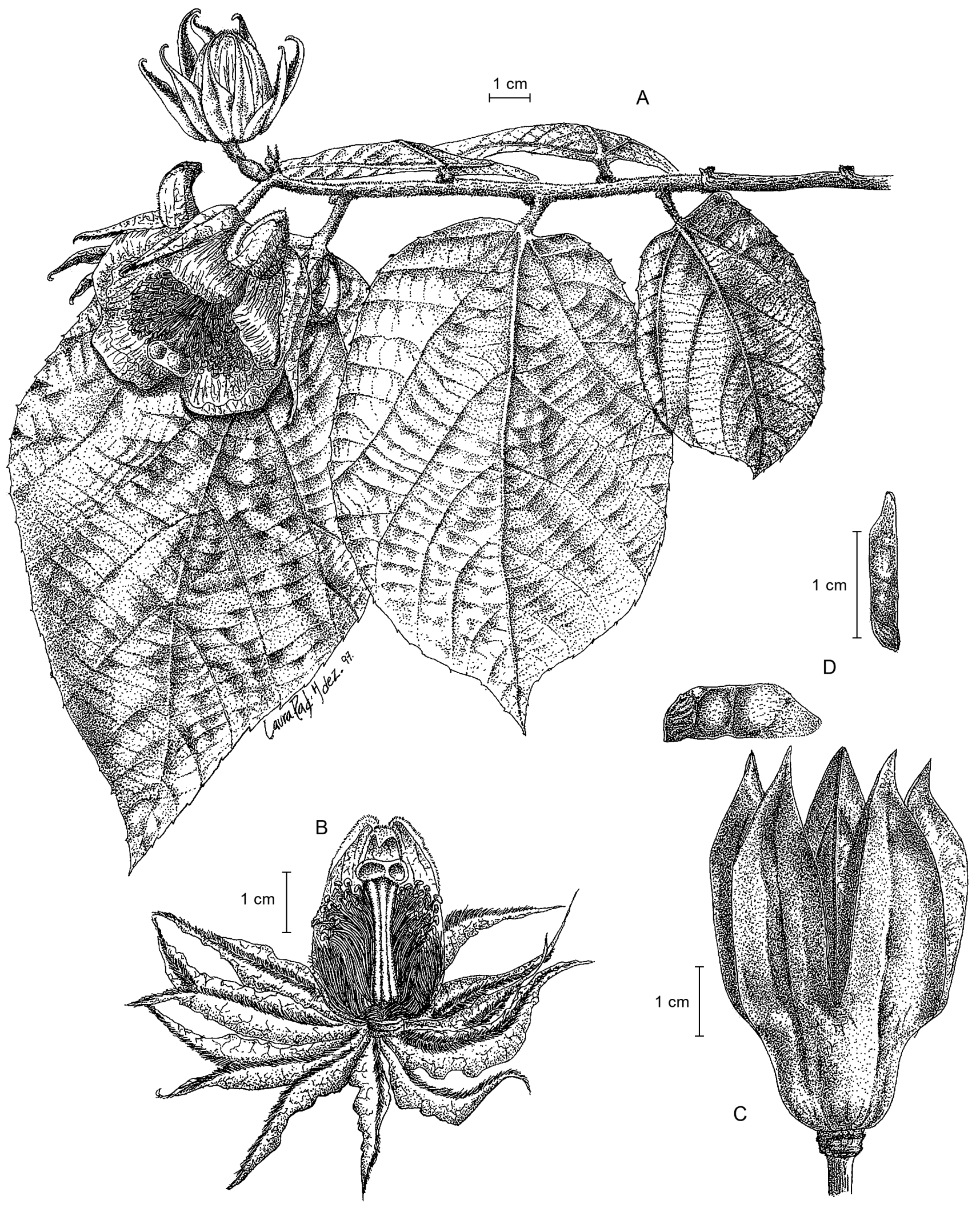

Figura 9: Luehea candida (DC.) Mart. A. rama con hojas, flor y botón; B. detalle de la flor; C. fruto dehiscente y semilla; D. semilla alada en vista lateral. A. basada en A. Peláez 35 (FCME); B, C y D en J. Almazán y G. Zamudio 358 (FCME). 


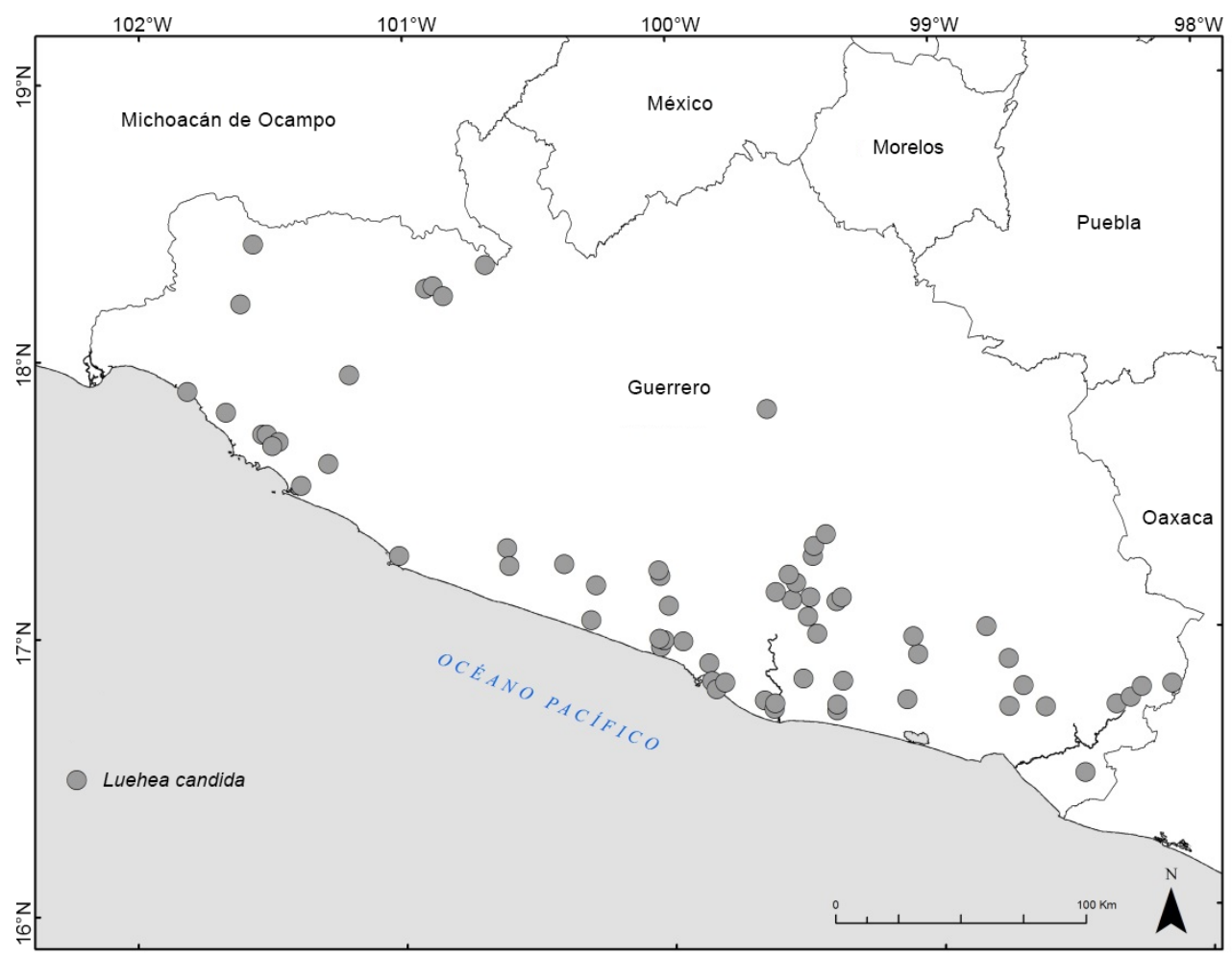

Figura 10: Distribución conocida de Luehea candida (DC.) Mart. (O).

Fenología: florece y fructifica en febrero, marzo, mayo y noviembre.

Nombres comunes: algodoncillo, cardoncillo, murciélago.

Usos: la madera es muy resistente, se utiliza en la construcción de vigas y postes, así como en la fabricación de cabos de hacha y otras herramientas, y llega a emplearse también como leña. Con la corteza se elaboran cuerdas rústicas temporales para amarres. También se ha citado su uso medicinal y su flor la consume el venado.

Ejemplares examinados: MÉXICO. Guerrero, municipio Acapulco de Juárez, La Estación, laguna Tres Palos, N. Diego 4422 (ENCB, FCME, IEB, MEXU); La Huerta, entre el río Papagayo y laguna Tres Palos, $N$. Diego 4737 (ENCB, FCME, IEB, MEXU); direction of Acapulco, hwy 95, 34.2 mile rocky slope, J. Freeland y
L. Spetzman 168 (MEXU); cerro de La Hacienda (laguna Tres Palos), S. Gil 127 (ENCB, FCME, IEB, MEXU); viveros El Huayacán, La Poza, W. López 900 (ENCB, FCME, MEXU), 954 (ENCB, FCME, MEXU); along the dirt road side, Santiago Acatepec, road to Tamarindo, 8 km from Mexico, hwy 200 miles, Acapulco and San Marcos, J. S. Miller y P. Tenorio 569 (MEXU); carretera a Puerto Marqués, F. Miranda 4332 (MEXU); on road to Zihuatanejo, H. E. Moore y C. E. Wood 4710 (MEXU); Parque Nacional El Veladero, N. Noriega 71 (ENCB, FCME, IEB, MEXU); final de la escénica, Acapulco, $L$. Wolfgang 622 (MEXU). Municipio Atoyac de Álvarez, El Cerrito, laguna de Mitla, L. Lozada 1105 (FCME, IEB); 1 $\mathrm{km}$ de El Quemado, J. E. Salmones 9 (FCME); E1 Salto, 3 km de Mexcaltepec, N. Turrubiante 196 (FCME). Municipio Ayutla de los Libres, Tierra Blanca, O. Guadarrama 128 (FCME); loc. cit., T. Oble 28 (FCME); loc. cit., G. Ocampo 128 (FCME); Ayutla, E. Pérez 2 (ENCB, FCME, IEB, MEXU). Municipio Azoyú, Azoyú, A. Almazán 1777 
(FCME, UAGC). Municipio Chilpancingo de los Bravo, Jolotichán, O. Arroyo 12802 (FCME); Rancho Viejo, $H$. F. Belmont 23 (FCME); Rincón de la Vía, H. Kruse 272 (ENCB, FCME); Agua de Obispo, 24.VI.1982, N. Diego s.n. (FCME); loc. cit., R. Gutiérrez 18 (FCME), 83 (FCME). Municipio Coahuayutla de José María Izazaga, Amatepec, $8.84 \mathrm{~km}$ al SE, J. Calónico 13028 (FCME); El Maguey, $2.76 \mathrm{~km}$ al NO, J. Calónico 14968 (FCME). Municipio Coyuca de Benítez, $2 \mathrm{~km}$ al SE de San Isidro, G. Coello 359 (FCME); al E de Atoyaquillo, 11.XI.1979, R. M. Fonseca y R. Vilchis s.n. (FCME); $3 \mathrm{~km}$ de Coyuca, L. Meza 69 (FCME); $2 \mathrm{~km}$ al SO de San Isidro, D. Quiroz 114 (FCME); cerro de Don Neto, L. C. Rodríguez 118 (ENCB, FCME, IEB, MEXU); $4 \mathrm{~km}$ al SE de Coyuca, $L$. C. Rodríguez 506 (FCME). Municipio Coyuca de Catalán, $4 \mathrm{~km}$ al NO de Placeres del Oro, rumbo a El Puerto, O. García et al. 125 (FCME); a $5 \mathrm{~km}$ al NO de Placeres del Oro, J. C. Soto y J. Refugio 911 (MEXU); carretera Altamirano a Zihuatanejo, a $22 \mathrm{~km}$ al SO de Coyuca de Catalán, J. C. Soto y L. Cortés 2296 (ENCB). Municipio Cuajinicuilapa, a $9 \mathrm{~km}$ de la desviación a Punta Maldonado, G. Campos 83 (FCME), 146 (FCME). Municipio Eduardo Neri, Xochipala, A. Gómez 1582 (FCME). Municipio Florencio Villarreal, carretera Cruz Grande, a $3 \mathrm{~km}$ de la desviación a El Capulín, G. Campos 158 (FCME); loc. cit., G. Gaxiola 97 (FCME). Municipio Juan R. Escudero, $16 \mathrm{~km}$ de Tierra Colorada por terracería, rumbo al Tabacal, J. Almazán 349 (FCME); Xolapa, margen del río Papagayo, rumbo al Puente Quebrado, J. Almazán y G. Zamudio 358 (FCME); $3 \mathrm{~km}$ adelante de Villa Guerrero (Pajaritos), rumbo a El Terrero, R. M. Fonseca 17 (ENCB, FCME, IEB, MEXU); El Zapote, J. Maldonado 6806 (FCME), 7221 (FCME); Tierra Colorada, Puente Papagayo, L. Wolfgang 142 (MEXU); a $17 \mathrm{~km}$ de Tierra Colorada a El Tabacal, 19.IX.1981, G. Zamudio y J. Almazán s.n. (FCME); El Zapote, M. Zaragoza 57 (FCME). Municipio Mochitlán, Mochitlán, L. Lozada 18 (FCME); a $23 \mathrm{~km}$ al SE de Acahuizotla por camino de herradura a San Roque, A. Núñez 708 (FCME). Municipio Ometepec, barranca Honda, A. Peláez 30 (FCME). Municipio Petatlán, cerro Huamilule, margen de laguna Potosí, N. Diego y A. Beltrán 6029 (FCME); $47 \mathrm{~km}$ al SE de Petatlán, $C$. D. Johnston 116779 (ENCB); a 10 km al NO de Petatlán camino a El Camalote, J. C. Soto 599 (MEXU). Municipio San Luis Acatlán, 8 km de Potrerillos del Rincón, hacia San Luis Acatlán, V. C. Aguilar 1437 (FCME); Los Magueyes, desviación hacia Colotepec sobre la carretera Tierra Colorada a Ayutla de los Libres, V. C. Aguilar 1501 (ENCB, FCME, IEB, MEXU); Yoloxóchitl, J. Amith et al. 1843 (FCME); cerro de El Burro a $1500 \mathrm{~m}$ al SSE de Jolotichán, A. Cruz 14 (FCME); loc. cit., C. Ramírez 11 (FCME). Municipio San Marcos, Las Mesas, Costa Chica, A. Almazán 133-A (FCME, UAGC); $5 \mathrm{~km}$ al $\mathrm{S}$ de San Marcos, R. M. Fonseca 1760 (ENCB, FCME, IEB, MEXU); $2 \mathrm{~km}$ al SO de Vista Hermosa, L. Lozada 1352 (FCME, MEXU); aproximadamente $2 \mathrm{~km}$ después de San Miguel, rumbo al ejido Tierra Colorada, E. Velázquez 537 (ENCB, FCME, IEB, MEXU). Municipio Tecpan de Galeana, El Arroyo Grande, camino Tecpan - Los Balcones, N. Diego 2836 (FCME); El Pusumiche, 3 km del entronque de la brecha a Corinte con la carretera Tecpan de Galeana a Zihuatanejo, P. Tenorio 1050 (MEXU). Municipio La Unión de Isidoro Montes de Oca, tramo de terracería El Entronque a El Petatillo, E. Guizar y L. Pimentel 2820 (ENCB, FCME, IEB, MEXU); Las Juntas del Poblado, cerca de la desviación del camino a La Majahua, F. Morales 168 (FCME). Municipio Xochistlahuaca, $6 \mathrm{~km}$ de Xochistlahuaca dirección Ometepec, G. Gaxiola 496 (FCME); Plan de Guadalupe, río Verde, R. M. Fonseca 2675 (FCME); Arroyo Guacamayas, 1.5 km al NE de Xochistlahuaca, A. Peláez 30 (FCME), 35 (FCME). Municipio Zihuatanejo de Azueta, $19 \mathrm{~km}$ al NE de Vallecitos de Zaragoza, carretera Zihuatanejo a Ciudad Altamirano, G. Campos 1330 (FCME); a $300 \mathrm{~m} \mathrm{~N}$ del caserío La Vainilla, rumbo a El Calabazalito, G. Gallardo et al. 122 (FCME); al N del caserío La Vainilla, camino a El Calabazito, C. Gallardo et al. 497 (ENCB, FCME, IEB, MEXU); sobre el camino a Ciudad Altamirano, $M$. Gual 512 (ENCB, FCME, IEB, MEXU); camino a Ciudad Altamirano, $2.5 \mathrm{~km}$ por la desviación a El Calabazito, M. Gual 649 (ENCB, FCME, IEB, MEXU), 650 (ENCB, FCME, IEB, MEXU). 
Discusión: en cuanto a su categoría de conservación esta especie se ubica como preocupación menor (LC), está ampliamente representada en el estado.

Trichospermum Blume, Bijdr. Fl. Ned. Ind. 56. 1825.

= Belotia A. Rich., Dict. Univ. Hist. Nat. 2: 539. 1842. TIPO: Trichospermum javanicum Blume

Árboles o arbustos, dioicos, rara vez hermafroditas; tallos estrellado-pubescentes; hojas pecioladas, estípulas subuladas, densamente estrellado-pubescentes, deciduas, láminas elípticas u ovado-lanceoladas, ápice agudo, obtuso, redondeado o acuminado, margen serrulado, base redondeada u obtusa, rara vez oblícua, 3-7-nervadas, membranáceas a subcoriáceas, densamente estrellado-pubescentes, domacios frecuentes en las axilas de los nervios; inflorescencias en cimas, panículas o umbelas, axilares o terminales, bráctea no adnada al pedúnculo o ausente; flores unisexuales, epicáliz ausente; cáliz de 5 sépalos libres, color verde rosado, ligeramente cuculados en botón, oblongos, ápice acuminado, densamente estrellado-pubescentes; corola con 5 pétalos, color lila o violeta, espatulados o ligulados, ápice redondeado, truncado, rara vez emarginado, base con una glándula redondeada o lobada, escasamente estrellado-pubescentes; flores estaminadas con estambres numerosos, filamentos libres con la base densamente velutina, anteras subglobosas, versátiles, extrorsa, pistilodio rudimentario; flores pistiladas con estaminodios no petaloides, ocasionalmente anteríferos; gineceo, 2-carpelar, ovario súpero, oblongo, 2-locular, sésil sobre el androginóforo, estrellado-pubescente, con numerosos óvulos por lóculo; estigma lobado; frutos capsulares color verde, verde amarillento, pardo casi negro, obovoides a depresos, ápice mucronado o rostrado, comprimidos lateralmente con dehiscencia loculicida, coriáceos, densamente estrellado-pubescentes, sin espinas o cerdas; semillas numerosas, color pardo oscuro, discoidales o elipsoidales, ciliadas.

Género tropical con 25 a 40 especies, distribuidas en América y Asia (Robyns, 1964; Mabberley, 1987;
Dorr, 2011). En México se han registrado dos especies, sólo una en Guerrero (Dorr, 2011). Por la consistencia suave de la madera, estas especies se han utilizado para la construcción de balsas y otros objetos, además de la corteza se elaboran cordones para amarre (Standley, 1923).

Trichospermum mexicanum (DC.) Baill. Hist. Pl. 4: 179. 1872. Figs. 11, 12.

EGrewia mexicana DC., Prodr. 1: 510. $1824 \equiv$ Belotia mexicana (DC.) K. Schum. Engler \& Prantl, Nat. Pflanzenfam. 3(6): 28. 1890 = Belotia grewiifolia A. Rich. R. de la Sagra, Hist. Phys. Cuba, Pl. Vasc.: 209, t. 21. 1841 (1845), as "grevicefolia" nom. illeg. TIPO: MÉXICO. Ex. Nov. Hispania, Lagasca y Segura M. 86 (holotipo: GDCG00209186).

= Trichospermum insigne (Baill.) Kosterm., Reinwardtia 6(3): 279. 1962 = Belotia insignis Baill., Adansonia 10: 182. 1872. TIPO: MÉXICO. Guerrero, near Acapulco, $A$. B. Ghiesbreght 356 (holotipo: P-P02143089, isotipo: FF0073951F).

Árboles, 2-17 m de alto; tallos con corteza fisurada y lenticelas, ramas jóvenes estrellado-pubescentes, glabrescentes; hojas con peciolos, 1.5-3 cm de largo, con un engrosamiento cerca de la base de la lámina, estípulas color rojizo, ca. $1 \mathrm{~cm}$ de largo, láminas ovado elípticas, 5-17 cm de largo, 6-7.5 cm de ancho, con tricomas simples y estrellados en haz y envés; inflorescencias 2.5-8 $\mathrm{cm}$ de largo, pedúnculos $1.5-3 \mathrm{~cm}$ de largo, densamente estrellado-pubescentes; flores 20-30 mm de diámetro; pedicelos $5 \mathrm{~mm}$ de largo; sépalos 1-15 mm de largo, $3 \mathrm{~mm}$ de ancho, densamente estrellado-pubescentes en ambas superficies; pétalos 10-16 mm de largo, $4 \mathrm{~mm}$ de ancho, truncados en el ápice, estrellado-pubescentes en la base de ambas superficies; flores estaminadas con androginóforo grueso, festonado, densamente estrellado-pubescente, filamentos 5-10 $\mathrm{mm}$ de largo, anteras $1 \mathrm{~mm}$; pistilodio $1 \mathrm{~mm}$ de largo, estilo 1-2 mm de largo, estigma papiloso; flores pistiladas con estaminodios presentes, rara vez con estambres, filamentos $1 \mathrm{~mm}$ de largo; ovario 4-5 mm de 

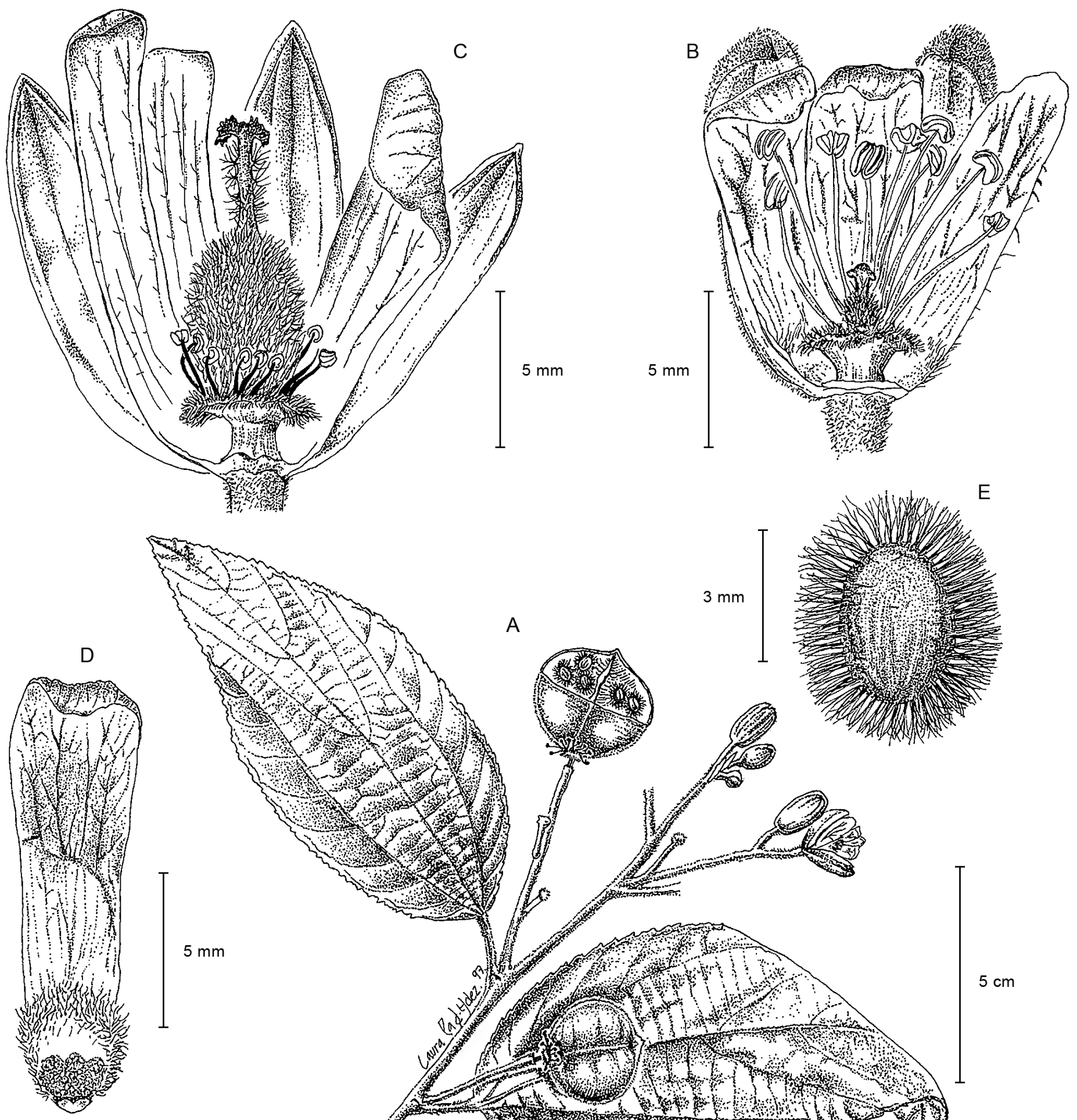


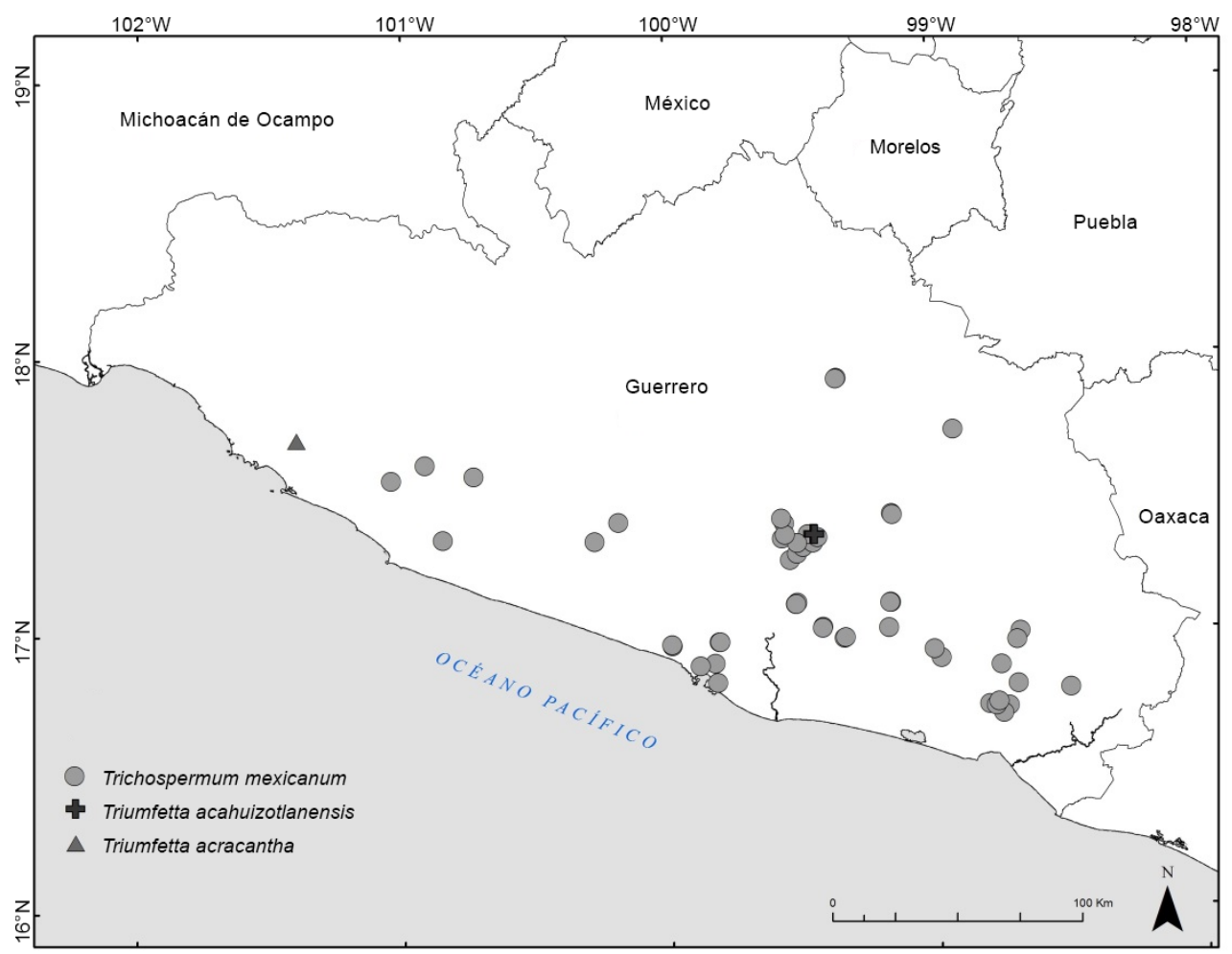

Figura 12: Distribución conocida de Trichospermum mexicanum (DC.) Baill. (O), Triumfetta acahuizotlanensis González-Martínez, J. Jiménez Ram. \& Rios-Carrasco (\$) y T. acracantha Hochr. (4).

largo, densamente estrellado-pubescente; estilo $3 \mathrm{~mm}$ de largo, estigma bilobado papiloso; fruto $13-20 \mathrm{~mm}$ de largo, 10-25 $\mathrm{mm}$ de ancho, 5-10 $\mathrm{mm}$ de grueso; semillas 5 $\mathrm{mm}$ de largo, 4-3 $\mathrm{mm}$ de ancho, superficie corrugada, cilios, $2 \mathrm{~mm}$ de largo.

Distribución: especie endémica de México (Colima, Jalisco, México, Guerrero, Michoacán, Nayarit, Puebla, Oaxaca, Sinaloa).

Tipo de vegetación y altitud: bosque de PinusQuercus, galería, tropical caducifolio y subcaducifolio, y vegetación secundaria (pastizal); 150-2600 m s.n.m.

Fenología: florece y fructifica de noviembre a junio.

Nombres comunes: algodoncillo, coasanate, flor de gallina, flor de María, jonote, majahua, palo rosa.
Usos: no se conocen en el área.

Ejemplares examinados: MÉXICO. Guerrero, municipio Acapulco de Juárez, Acapulco, C. U. Múñoz 10681 (FCME); Parque Nacional El Veladero, colonia Palma Sola, N. Noriega 423 (FCME, IEB), 456 (FCME, IEB); Acapulco, Sierra, L. Paray 2349 (ENCB, MEXU). Municipio Atoyac de Álvarez, $1 \mathrm{~km}$ al NE del Cacao, E. Graw 73 (FCME); El Ranchito, F. Morales 520 (FCME). Municipio Ayutla de los Libres, Ahuacachahue, M. Gregorio 97 (FCME); La Concordia, J. L. Marín 33 (FCME), 1485 (FCME); a $1 \mathrm{~km}$ de Coapinola por el camino a $\mathrm{La}$ Concordia, J. L. Marín 42 (FCME, IEB). Municipio Azoyú, a $2 \mathrm{~km}$ al NO de Jolotichán, C. Aguilar 28 (FCME); $2.5 \mathrm{~km}$ al NO de Xolatichama, $1800 \mathrm{~m}$ al S de Jolotichán, A. Cruz 28 (FCME); ladera N Cerro del Burro, $1800 \mathrm{~m}$ al $\mathrm{S}$ de Jolotichán, 16.XI.1980, R. E. González s.n. (FCME); $2 \mathrm{~km}$ al S de Jolotichán, camino Marquelia a Agua Zar- 
ca a San Luis Acatlán, E. Martínez y B. Morales 3412 (ENCB, FCME, IEB, MEXU); ladera $\mathrm{N}$ en la base del cerro del Burro a $1800 \mathrm{~m}$ al S de Jolotichán, 16.XI.1980, J. Mejía s.n. (FCME); por el arroyo a $500 \mathrm{~m}$ al S de Jolotichán, 16.XI.1980, C. Pérez s.n. (FCME). Municipio Chilpancingo de los Bravo, Agua de Obispo, M. A. Bello 5 (FCME, UAGC); loc. cit., G. Díaz 375 (FCME); 3 km al N de Agua de Obispo, G. Díaz 890 (FCME); poblado La Cumbre, siguiendo el camino a El Guayabo, H. Flores 131 (ENCB, FCME, IEB, MEXU); Agua de Obispo, siguiendo el camino al río Apetlaca, H. Flores 210 (FCME); Acahuizotla, adelante de Chilpancingo, entre Acahuizotla y Palo Blanco (brecha), T. Germán y V. Funk 618 (FCME, MEXU); $3 \mathrm{~km}$ al $\mathrm{N}$ de Agua de Obispo, M. Jiménez 890 (FCME, MEXU); Agua de Obispo, A. E. Juárez 3 (FCME); Rincón de La Vía, H. Kruse 133 (FCME); Agua de Obispo, H. Kruse 875 (FCME); cerro El Fresno, cima, H. Kruse 2279 (FCME); camino al Ocotito a Jaleaca, km 3, E. Martínez y O. Téllez 151 (ENCB, FCME, IEB, MEXU); Agua de Obispo, sobre la carretera Chilpancingo a Tierra Colorada, A. Núñez 791 (FCME); Soyatepec, Cerro de La Vaca, L. C. Rodríguez 321 (ENCB, FCME, IEB, MEXU); Los Cajones, L. C. Rodríguez 432 (ENCB, FCME, IEB, MEXU); 4 km al N de Rincón de La Vía, hacia Acahuizotla, J. Rojas et al. 344 (FCME); km 18 carretera Ocotito - Zoyatepec, R. de Santiago y R. Fragoso 842 (FCME); barranca de El Toro, C. Verduzco 291-B (FCME); $1 \mathrm{~km}$ antes de Agua de Obispo, L. Wolfgang 2634 (MEXU); Agua de Obispo, sobre la carretera Chilpancingo a Tierra Colorada, G. Zamudio 375 (FCME). Municipio Coyuca de Benítez, embarcadero, D. C. Barriento 7092 (FCME). Municipio Cuautepec, San Agustín Cuilutla, N. Herrera 43 (MEXU). Municipio Huitzuco de los Figueroa, $3.2 \mathrm{~km}$ al O de San Francisco Ozomatlán, I. Vaca y A. VargasPérez 227 (FCME). Municipio Igualapa, a $3 \mathrm{~km}$ delante de Quetzalapa, A. Núñez 461 (FCME). Municipio Juan R. Escudero, Tepeguaje, Cerro alto Tepeguaje, H. Kruse 2590 (FCME). Municipio Malinaltepec, Tilapa, $A$. Galeana 1086 (FCME). Municipio Petatlán, ejido Corrales, Costa Grande, entre El Varillal y El Mameycito, A. Almazán 401 (FCME, UAGC); camino Llanos de la Puerta a
Camalote, G. Campos 1431 (FCME); La Guayabera, 3 $\mathrm{km}$ al ONO, paraje La Estrella, F. Madariaga et al. 848 (FCME). Municipio Quechultenango, camino a las grutas de Juxtlahuaca, $5 \mathrm{~km}$ al NE de Colotlipa, M. Zamora 5274 (ENCB, FCME, IEB). Municipio San Luis Acatlán, Yoloxóchitl, J. Amith y R. de Santiago 1817 (FCME), 1828 (FCME); $8 \mathrm{~km}$ de Potrerillos del Rincón hacia Iliatengo, G. Campos 1958 (FCME); Horcasitas, J. González y C. Catalán 70 (UAGC), 78 (UAGC); km 18 del camino de San Luis Acatlán a Iliatenco, F. Lorea 2823 (FCME). Municipio Tecoanapa, Ochoapa, L. Abarca 6935 (FCME); Pochotillo, Costa Chica, R. Clemente 95 (FCME); Las Ánimas, L. J. Cruz 9 (FCME); 1 km después de Cruz Quemada, dirección Ayutla, A. Núñez 143 (FCME); Ochoapa, 3.III.1990, B. Rendón et al. s.n. (FCME); Las Ánimas, $A$. Y. Ortega 689 (FCME). Municipio Tecpan de Galeana, Bajitos de La Laguna, E. Álvarez 540 (FCME). Municipio Xalpatláhuac, a $5 \mathrm{~km}$ al E de Los Saucitos, dirección Xalpatláhuac, A. Núñez 444 (FCME). Sin localidad precisa, Sierra Madre, H. Kruse 875 (ENCB).

Discusión: de acuerdo a Dorr (2011) el tipo de Grewia mexicana concuerda con el material asignado a Trichospermum insigne en Flora Novo-Galiciana (Fryxell, 2001), ya que presenta láminas ampliamente ovadas, con ápices agudos, envés con pubescencia densa y uniforme de tricomas estrellados, con sépalos y pétalos ca. $10 \mathrm{~mm}$ de largo y cápsulas $16-18 \mathrm{~mm}$ de ancho $\times 24-28 \mathrm{~mm}$ de largo. Dorr (2011) considera que es una especie mexicana muy distinta del material de Trichospermum mexicanum recolectado en Cuba, la cual tiene láminas ovadas con ápices acuminados a largos acuminados, envés con escasa pubescencia estrellado-tomentosa, sépalos y pétalos 4-6 mm de largo, y cápsulas 8-10 mm de largo $\times 10(-12) \mathrm{mm}$ de ancho; se concuerda con Dorr, que dicho nombre debe ser aplicado a la especie endémica del oeste y sur de México que se cita con frecuencia pero incorrectamente como T. insigne.

El número de colecta 875 de $H$. Kruse se lo asignó a dos colectas diferentes de la misma especie, una con 
localidad Agua de Obispo y la otra en la Sierra Madre. En cuanto a su categoría de conservación esta especie se considera como preocupación menor (LC), está ampliamente representada en el estado.

Triumfetta L., Sp. Pl. ed. 1. 444. 1753.

TIPO: Triumfetta lappula L.

Árboles, arbustos o hierbas sufruticosas, hermafroditas, andromonoicos o ginodioicos; tallos con o sin corteza exfoliante, ferrugíneos, color rojizo, densamente estrellado-pubescentes o glabrescentes; hojas pecioladas; estípulas filiformes, frecuentemente deciduas, con pubescencia simple o estrellada, láminas 3-lobadas, equiláteras, rara vez inequiláteras, margen irregularmente serrado, biserrado o dentado, frecuentemente con 3-5 pares de dientes basales, con o sin glándulas, base obtusa, cuneada, cordada o semicordada, coriáceas, semicoriáceas, suaves, ásperas, 3-7 nervadas, con tricomas simples y estrellados, escabrosas o velutinas; inflorescencias en cimas, terminales, axilares u opuestas a las hojas, a veces con brácteas no adnadas al pedúnculo; flores hermafroditas y unisexuales, pediceladas; epicáliz ausente; cáliz color verde, algunas veces con tonalidades color rojizo; sépalos 5, lanceolados, linear lanceolados, oblongos, obovados, en ocasiones constreñidos en la parte media, ápice acuminado, con apéndices simples o trífidos, algunas veces ausentes; corola con 5 pétalos o ausentes, color amarillo o blanco, espatulados, obovados, ápice redondeado, agudo, asimétrico o dentado; gonóforo presente, con 5 glándulas esféricas o alargadas, cubiertas por un anillo generalmente membranáceo o urceolo, ciliado, casi obsoleto en T. lappula; estambres 15-70, filamentos filiformes, anteras oblongas, estaminodios no petaloides o ausentes en flores pistiladas; gineceo 2-5 carpelos, ovario ovoide o elipsoidal, súpero, sésil, 2-4 lóculos, cubierto por espinas hialinas, rectas o falcadas, estilo rollizo; estigma agudo, 2-5 lobados o denticulados; óvulos 2 por lóculo, pistilodios presentes en flores estaminadas; frutos capsulares, no leñosos, generalmente globosos, ovoides, subglobosos o elipsoidales, de menos de $1 \mathrm{~cm}$ de diámetro, indehiscentes, ocasionalmente con dehiscencia loculicida, cubiertos en toda la superficie por espinas, $1-10 \mathrm{~mm}$ de largo, falcadas o rectas, glabras, pilosas, plumosas o con pubescencia de tricomas estrellados, ápice de las espinas con espínulas hialinas, rectas o uncinadas; semillas color pardo oscuro, pardo claro o blanquecinas, ovoides o piriformes, sin cilios.

Género pantropical, con aproximadamente 150 especies, distribuidas en África, Australia y en América tropical (Lay, 1950; Cronquist, 1981; Mabberley, 1987; Fryxell, 1998; 2001). Según Meijer (2001) existen alrededor de 50 especies en la región Neotropical, la mayoría en México. En México existen 35 especies (Fryxell, 1998; Gual-Díaz, 2011), 18 de las cuales se encuentran en Guerrero.

El nombre genérico se asignó en honor a John Baptiste Triumfetti (Lay, 1950; Rendle, 1971). Las especies de este género habitan en diversos tipos de vegetación, desde los templados hasta los cálidos, actuando como elementos de vegetación primaria y/o secundaria.

Varias especies se utilizan como medicinales, por ejemplo Triumfetta lappula es recomendada como desinflamatorio y para infecciones de garganta (Costa Rica, México, Venezuela). Triumfetta rhomboidea Jacq. es conocida por sus propiedades efectivas en el control de quemaduras, inflamaciones, piquetes de arañas y tumores de la piel. Triumfetta semitriloba Jacq. ha sido aprovechada por su propiedad diurética, en el combate de enfermedades tanto venéreas como del hígado (México); además, en Brasil ha sido utilizada como fuente de celulosa para papel y elaboración de tela para ropa (Standley, 1923; Standley y Steyermark, 1946; USDA, 2017).

\section{Clave para la identificación de especies de Triumfetta (flores y frutos)}

1a. Tallos con corteza exfoliante color rojizo T. mexiae C.V. Morton \& Lay

1b. Tallos generalmente sin corteza exfoliante, si presente, sólo ocasionalmente ( $T$. guerrerensis) .......... 2

2a. Hojas inequiláteras (con lados desiguales); frutos con 280 espinas... T. guerrerensis Gual, S.Peralta \& Diego 
2b. Hojas equiláteras; frutos con 250 espinas o menos ... 3

3a. Sépalos constreñidos o ligeramente constreñidos en la parte media ... 4

3b. Sépalos no constreñidos en la parte media ........... 10

4a. Frutos 2-3 lóculos, con espinas 1-3 mm de largo ... 5

4b. Frutos 4(-3) lóculos, con espinas (4-)6-10 mm de largo 9

5a. Sépalos con apéndice apical $5 \mathrm{~mm}$ de largo T. falcifera Rose

5b. Sépalos con apéndice apical 0.5-3 $\mathrm{mm}$ de largo ..... 6

6a. Frutos, 3-5 mm de diámetro, con espinas 1.5-3 $\mathrm{mm}$ de largo, retrorso pilósulas; estambres 20; hojas no coriáceas 7

6b. Frutos 6-10 $\mathrm{mm}$ de diámetro, con espinas $1 \mathrm{~mm}$ de largo, glabras o pubescentes; estambres 25-40; hojas coriáceas o semicoriáceas ... 8

7a. Frutos con 75-100 espinas; pétalos lanceoladas, 3-5 mm de largo; tallos glabros o con tricomas simples .. T. acracantha Hochr.

7b. Frutos con 50-75 espinas; pétalos espatulados a elípticos, 6-10 mm de largo; tallos aracnoide tomentosos T. semitriloba Jacq.

8a. Frutos 6-7 mm de diámetro; espínulas uncinadas; estambres 25-30; hojas semicoriáceas

T. brevipes $\mathrm{S}$. Watson

8b. Frutos 6-10 mm de diámetro; espínulas falcadas; estambres 35-40; hojas coriáceas ... T. coriacea Hochr.

9a. Frutos 4 lóculos, con más de 200 espinas 6-10 mm de largo ............. T. polyandra Sessé \& Moc. ex DC.

9b. Frutos 4(-3) lóculos, con 22-26(-30) espinas 4-6 mm de largo .............................. T. acahuizotlanensis González-Martínez,J.JiménezRam.\&Rios-Carrasco

10a. Frutos 2 o 3 lóculos ............................................... 11

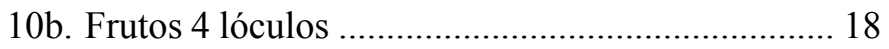

11a. Hojas con margen serrado ..................................... 12

11b. Hojas con margen dentado................................... 16

12a. Flores unisexuales y hermafroditas (plantas andromonoicas, ginodioicas o hermafroditas) ................ 13

12b. Flores hermafroditas (plantas hermafroditas) ....... 15

13a. Plantas ginodioicas o hermafroditas; frutos 2-5 mm de largo, con 20-40 espinas 14 13b. Plantas andromonoicas; frutos $6 \mathrm{~mm}$ de diámetro, con 75 espinas ............. T. paniculata Hook. \& Arn.

14a. Frutos 3-4 mm de diámetro, con 30-40 espinas

T. galeottiana Turcz.

14b. Frutos $2 \mathrm{~mm}$ de diámetro, con 20-25 espinas T. heliocarpoides Bullock

15a. Hojas con base cuneada; pétalos de $25-30 \mathrm{~mm}$ de largo; frutos 5-6 mm de diámetro, dehiscentes, con espinas 4-5 $\mathrm{mm}$ de largo T. grandiflora Vahl

15b. Hojas con base cordada o semicordada; pétalos 15$18 \mathrm{~mm}$ de largo; frutos 6-6.5 mm de diámetro, indehiscentes, con espinas 1-2 mm de largo

T. columnaris Hochr.

16a. Sépalos con apéndice apical, $2 \mathrm{~mm}$ de largo; estambres 25-35; frutos globosos T. bogotensis DC.

16b. Sépalos con apéndice apical, $1 \mathrm{~mm}$ de largo; estambres 15-20; frutos ovoides o elipsoidales 17

17a. Frutos con 25 espinas rectas, espínulas rectas, 1-2 $\mathrm{mm}$ de largo, glabras

.................... T. simplicifolia (Sessé \& Moc.) Fryxell

17b. Frutos con 50 espinas rectas, espínulas uncinadas, 2-3 mm de largo, retrorso pilosas T. lappula L.

18a. Hojas elípticas o angostamente ovadas, no lobadas; cáliz 15-20 mm de largo; frutos 4-5 $\mathrm{mm}$ de diámetro, con espinas 2-3 mm de largo, ligeramente pubescentes ........................................... T. goldmanii Rose

18b. Hojas oblongas o ampliamente ovadas, 3-lobadas; cáliz 25-30 mm de largo; frutos 6-8 $\mathrm{mm}$ de diámetro, con espinas 3-4 mm de largo, plumosas

T. speciosa Seem.

\section{Clave para la identificación de especies de Triumfetta (frutos)}

1a. Espinas falcadas o rectas, espínulas rectas ............. 2

1b. Espinas rectas, espínulas uncinadas ........................ 8

2a. Espinas plumosas ……………………….............. 3

2b. Espinas no plumosas ............................................... 5

3a. Espinas 6-10 $\mathrm{mm}$ de largo T. polyandra Sessé \& Moc. ex DC.

3b. Espinas 3-5 $\mathrm{mm}$ de largo ... 4

4a. Frutos 4-locular T. speciosa Seem. 
4b. Frutos 3-locular T. grandiflora Vahl

5a. Frutos elipsoidales con 25 espinas T. simplicifolia (Sessé \& Moc.) Fryxell

5b. Frutos globosos con más de 25 espinas 6

6a. Espinas pubescentes; frutos de 4 lóculos T. goldmanii Rose

6b. Espinas glabras; frutos 2 lóculos 7

7a. Espinas 75-100, 3-4 mm de largo T. mexiae C.V. Morton \& Lay

7b. Espinas 200, $1 \mathrm{~mm}$ de largo T. coriacea Hochr.

8a. Frutos pubescentes o estrellado-pubescentes ......... 9

8 b. Frutos glabros 17

9a. Frutos estrellado-pubescentes .............................. 10

9b. Frutos pubescentes o pilósulos 14

10a. Frutos 6-6.5 mm de diámetro; espinas $1-2 \mathrm{~mm}$ de largo, glabras o pubescentes .... T. columnaris Hochr.

10b. Frutos de menos de $5 \mathrm{~mm}$ de diámetro; espinas de 2-3 mm de largo, retrorso-pilosas o retoso-pilósulas o bien 4-6 mm, glabras 11

11a. Frutos ovoides, piriforme a elipsoidales ............... 12

11b. Frutos globosos o subglobosos, 3 lóculos 13

12a. Frutos ovoide a elipsoidales, $3 \mathrm{~mm}$ de diámetro, 2 lóculos T. lappula $\mathrm{L}$.

12b. Frutos piriformes, 2-3 mm de diámetro, (3-)4 lóculos T. acahuizotlanensis González-Martínez, J. Jiménez Ram. \& Rios-Carrasco

13a. Frutos globoso, $3 \mathrm{~mm}$ de diámetro

T. acracantha Hochr

13b. Frutos subgloboso $4-5 \mathrm{~mm}$ de diámetro

T. semitriloba Jacq.

14a. Frutos dehiscentes; espinas 4-5 mm de largo

T. grandiflora $\mathrm{Vahl}$

14b. Frutos indehiscentes; espinas 1-3 mm de largo .... 15

15a. Espinas $3 \mathrm{~mm}$ de largo, retrorso-pilosas

T. bogotensis DC.

15b. Espinas 1-2 $\mathrm{mm}$ de largo, glabras 16

16a. Frutos $4 \mathrm{~mm}$ de diámetro; espina $2 \mathrm{~mm}$ de largo ...... T. falcifera Rose

16b. Frutos 6-7 mm de diámetro; espina $1 \mathrm{~mm}$ de largo ... T. brevipes $\mathrm{S}$. Watson

17a. Frutos 6-8.5 mm de diámetro 18 17b. Frutos $2-4 \mathrm{~mm}$ de diámetro 19

18a. Frutos $6 \mathrm{~mm}$ de diámetro; espinas 75

T. paniculata Hook. \& Arn.

18b. Frutos 7.5-8.5 mm de diámetro; espinas más de 280 T. guerrerensis Gual, S. Peralta \& Diego

19a. Frutos 2 mm de diámetro; espinas 20-25 T. heliocarpoides Bullock

19b. Frutos 3-4 mm de diámetro; espinas 30-40 T. galeottiana Turcz.

Triumfetta acahuizotlanensis González-Martínez, J. Jiménez Ram. \& Rios-Carrasco, Phytotaxa 26(3): 273-278. 2016. TIPO: MÉXICO. Guerrero, municipio Mochitlán, Acahuizotla, pasando el río Escondido, $C$. A. González-Martínez y S. Rios-Carrasco 588 (holotipo: FCME, isotipos: FCME). Fig. 12.

Árboles, hermafroditas, 3-7 m de alto; tallos color verde pardusco, los jóvenes con abundantes lenticelas, estrellado-pubescente, tallos maduros color marrón claro a amarillo-blanco, glabrescentes; hojas con peciolos, 1-9 $\mathrm{cm}$, con escasos tricomas estrellados, glabrescentes, estípulas lanceoladas, 4-7 mm de largo, deciduas, láminas equiláteras, subcuadradas, a veces elípticas, 3-lobadas, $3.8-13 \mathrm{~cm}$ de largo, 3.5-11.2 cm de ancho, ápices caudados, margen biserrado, base obtusa o cuneada, coriáceas, 5-7 nervada (a veces 9-nervada, 2 nervios basales discretos) con 2-4 pares de dientes basales glandulares, haz con pelos simples, envés glabros; inflorescencias en cimas, 4-6 címulas, $6.8-20.5 \mathrm{~cm}$ de largo, pedúnculos $0.23-0.84 \mathrm{~cm}$ de largo, brácteas ovada-elípticas o lanceoladas, 2-5.4 de largo, 0.4-1.9 cm de ancho, con características semejantes a las hojas, aunque la base es atenuada o cuneada; flores hermafroditas; cáliz tetrámero, sépalos espatulados o lanceolados, constreñidos debajo de la parte media, 5-5.9 mm de largo, 1.1-1.4 mm de ancho, apéndices apicales, 0.4-0.5 $\mathrm{mm}$ de largo, haz glabro, envés con escasos tricomas estrellados; pétalos espatulados, 3.5-4.2 de largo, 0.8-0.9 mm de ancho, ápice agudo-redondeado o ligeramente oblícuo, márgenes con tricomas hialinos, gonóforo oblongo, ca. 1 $\mathrm{mm}$ de largo, anillo ca. $0.3 \mathrm{~mm}$ de alto, ciliado, estambres 
30, filamentos 2-4.2 $\mathrm{mm}$ de largo; ovario ca. $0.6 \mathrm{~mm}$ de largo, ca. $0.4 \mathrm{~mm}$ de ancho; estilo 1.4-1.7 $\mathrm{mm}$ de largo; estigma bífido; fruto piriforme, (3-)4 lóculos, cuerpo 2-3 $\mathrm{mm}$ de diámetro, indehiscente, cubierto por 22-26(-30) espinas rectas, 4-6 mm de largo, glabras, espínulas uncinadas (falcadas), hialinas; semillas rojo oscuro en la base y negro en los bordes, una por lóculo, raramente 3 .

Distribución: especie endémica de México (Guerrero).

Tipo de vegetación y altitud: bosque tropical subcaducifolio; ca. 800 m s.n.m.

Fenología: florece de septiembre a octubre y fructifica de octubre a enero.

Usos: no se conocen en el área.

Ejemplares examinados: MÉXICO. Guerrero, municipio Chilpancingo de los Bravo, cerca del río, C. A. González-Martínez y Rios-Carrasco 996 (FCME); Acahuizotla, C. A. González-Martínez y Rios-Carrasco 1007 (FCME); adelante del río, L. Lozada y J. Rojas 3707 (FCME). Municipio Mochitlán, pasando el río Escondido, C. A. González-Martínez y Rios-Carrasco 959 (FCME).

Discusión: por su distribución reducida y escasa recolecta en el estado (solo dos municipios), así como el impacto de los tipos de vegetación que actualmente ocupa (fragmentados y reducidos por la expansión urbana), se le considera como peligro crítico (CR). Desafortunadamente, no se cuenta con información que permita evaluar el grado de impacto en las poblaciones de esta especie y sobre otras con las que comparte el hábitat.

Triumfetta acracantha Hochr., Annuaire Conserv. Jard. Bot. Genève 18: 111. 1914. TIPO: MÉXICO. Guerrero, Baqueta, E. Langlassé 505 (holotipo: G-DC, isotipos: GH-GH00052580!, K-K000381785!, USUS00098427!). Fig. 12.
Arbustos, hermafroditas, $1.5 \mathrm{~m}$ de alto; tallos color pardo, con abundantes lenticelas, glabros o finamente pubescentes, sin corteza exfoliante; hojas con peciolos, 4-6 cm de largo, densamente hirsuto a pilosos, estípulas triangulares, densamente hirsuto a pilosas, láminas equiláteras, ovadas u ovado elipticas, ligeramente lobuladas, 8-12 cm de largo, 4-8 cm de ancho, ápice largo acuminado, margen crenado serrado, base redondeada o truncada, no coriáceas, venación palmada, 5-7 nervadas, ambas superficies con escasos tricomas estrellados, casi glabras; inflorescencias en cimas, compuestas de címulas, laxas, de tres flores, usualmente axilares algunas veces terminales, pedúnculos, 0.2-0.3 cm de largo, los pedicelos ca. 0.2 $\mathrm{cm}$ de largo, brácteas elípticas o estrechamente ovadas, $1.7 \mathrm{~cm}$ de largo, $1.2 \mathrm{~cm}$ de ancho, con características similares a las hojas; flores con sépalos ligeramente constreñidos en la parte media, $8-13 \mathrm{~mm}$ de largo, ligeramente pubescentes, con apéndice apical, 2-3 mm de largo, pétalos lanceolados, 3-5 mm de largo, estambres 20, gonóforo ca. $1 \mathrm{~mm}$ de alto, con glándulas esféricas, anillo 0.2 $\mathrm{mm}$ de alto, estilo $6 \mathrm{~mm}$ de largo; estigma 3-lobado; fruto globoso, 3 lóculos, cuerpo $3 \mathrm{~mm}$ de diámetro, finamente estrellado-pubescente, indehiscente, cubierto por 75-100 espinas rectas, 2-2.5 mm de largo, retrorso-pilósulas, espínulas uncinadas; semillas no vistas.

Distribución: especie endémica de México (Colima, Guerrero, Jalisco, Michoacán, Sinaloa).

Tipo de vegetación y altitud: bosque tropical caducifolio y vegetación secundaria; 100-700 m s.n.m.

Fenología: florece y fructifica en septiembre y octubre.

Usos: no se conocen en el área.

Ejemplar examinado: MÉXICO. Guerrero, municipio Petatlán, Baqueta (Vaqueta), E. Langlassé 505 (G-DC).

Discusión: la descripción se basó en la literatura y en su descripción original (Hochreutiner, 1914; Fryxell, 
2001), y se complementó revisando un ejemplar de Jalisco. Por su distribución reducida y escasa recolecta en el estado (solo colecta tipo), así como el impacto en los tipos de vegetación que actualmente ocupa (fragmentados y reducidos por la expansión urbana), se le considera como peligro crítico (CR). Desafortunadamente, no se cuenta con información que permita evaluar el grado de impacto en las poblaciones de esta especie y sobre otras con las que comparten el hábitat.

Triumfetta bogotensis DC., Prodr. 1: 506. 1824. TIPO: COLOMBIA. Santa Fé de Bogotá, S. Mutis s.n. (holotipo: P). nom. nov. basado en $\equiv$ Triumfetta pilosa Kunth, Nov. Gen. Sp. 5: 343. 1823. Fig. 13.

= Triumfetta dumetorum Schltdl., Linnaea 11: 377. 1837. TIPO: MÉXICO. Tlalpujahua, F. W. Keerl y Martius s.n. (sintipo: BR-BR0000005421312!); TIPO: MÉXICO. Veracruz, Jalapam (Jalapa), C. J. W. Schiede 463 (sintipo: HAL-HAL0098396!).

= Triumfetta lindeniana Turcz., Bull. Soc. Imp. Naturalistes Moscou 31: 229. 1858. TIPO: MÉXICO. Veracruz, Jalapa and vicinity, L. J. J. Linden 59 (holotipo: KWKW001000091!, isotipo: MICH-MICH1115341!).

$=$ Triumfetta botteriana Turcz., Bull. Soc. Imp. Naturalistes Moscou 32:260. 1859. TIPO: MÉXICO. s.1., M. Botteri 773 (holotipo: K-K000381786!, isotipo: G-G00357200!). = Triumfetta orizabae Turcz., Bull. Soc. Imp. Naturalistes Moscou 32: 261. 1859. TIPO: MÉXICO. Veracruz, Orizaba, M. Botteri 771 (holotipo: KW-KW001000085!, isotipo: K-K000381787!).

Arbustos, hermafroditas, $0.7-2.5 \mathrm{~m}$ de alto; tallos color pardo, con abundantes lenticelas, hirsutos o pilosos, sin corteza exfoliante; hojas con peciolos, 1-6 cm de largo, densamente hirsutos o pilosos, estípulas triangulares, densamente hirsutas a pilosas, láminas equiláteras, ovadas, elípticas en ramas terminales, $3-12 \mathrm{~cm}$ de largo, 1.6-6 cm de ancho, ápice acuminado, margen dentado, base truncada o semicordada, 3-5 nervadas, haz con escasos tricomas simples, envés estrellado- pubescente; inflorescencias en cimas, axilares, $2 \mathrm{~cm}$ de largo, brácteas ovadas, $1.5 \mathrm{~cm}$ de largo, $1 \mathrm{~cm}$ de ancho, con características semejantes a las hojas; flores con sépalos elípticos, 6-9 $\mathrm{mm}$ de largo, $1 \mathrm{~mm}$ de ancho, no constreñidos en la parte media, con apéndice apical, 2 $\mathrm{mm}$ de largo, pétalos espatulados, $5 \mathrm{~mm}$ de largo, $3 \mathrm{~mm}$ de ancho, ápice redondeado, gonóforo $0.5 \mathrm{~mm}$ de largo, con glándulas elípticas, anillo $0.5 \mathrm{~mm}$ de alto; estambres 25-35, filamentos $7 \mathrm{~mm}$ de largo, ovario, $5 \mathrm{~mm}$ de largo; fruto globoso, 2 lóculos, cuerpo $6 \mathrm{~mm}$ de largo, 3-4 mm de diámetro, pubescente, indehiscente, cubierto por aproximadamente 40 espinas rectas, $3 \mathrm{~mm}$ de largo, retrorso-pilosas, espínulas uncinadas; semillas no vistas (ni registradas en literatura).

Distribución: México (Colima, Guerrero, Jalisco, México, Michoacán, Oaxaca, Tamaulipas, Veracruz, Yucatán), Centroamérica, Antillas y Sudamérica.

Tipo de vegetación y altitud: bosque tropical caducifolio y vegetación secundaria; 10-1150 m s.n.m.

Fenología: florece y fructifica en noviembre.

Usos: no se conocen en el área.

Ejemplares examinados: MÉXICO. Guerrero, municipio Acapulco de Juárez, Las Huertas, entre río Papagayo y laguna de Tres Palos, N. Diego 4728 (FCME). Municipio Coahuayutla de José María Izazaga, El Maguey, $1.61 \mathrm{~km}$ al N, J. Calónico 18097 (FCME). Municipio San Marcos, carretera Acapulco a Pinotepa Nacional, $3 \mathrm{~km}$ al E de San Marcos, S. D. Koch et al. 79338 (MEXU); aproximadamente $2 \mathrm{~km}$ después de San Miguel, rumbo a ejido Tierra Colorada, E. Velázquez 538 (FCME).

Discusión: es una planta escasa, sólo se ha colectado en tres municipios del estado de Guerrero y en cuanto a su categoría de conservación se le ubica en no evaluada (NE), está mejor representada en otros estados del país. 


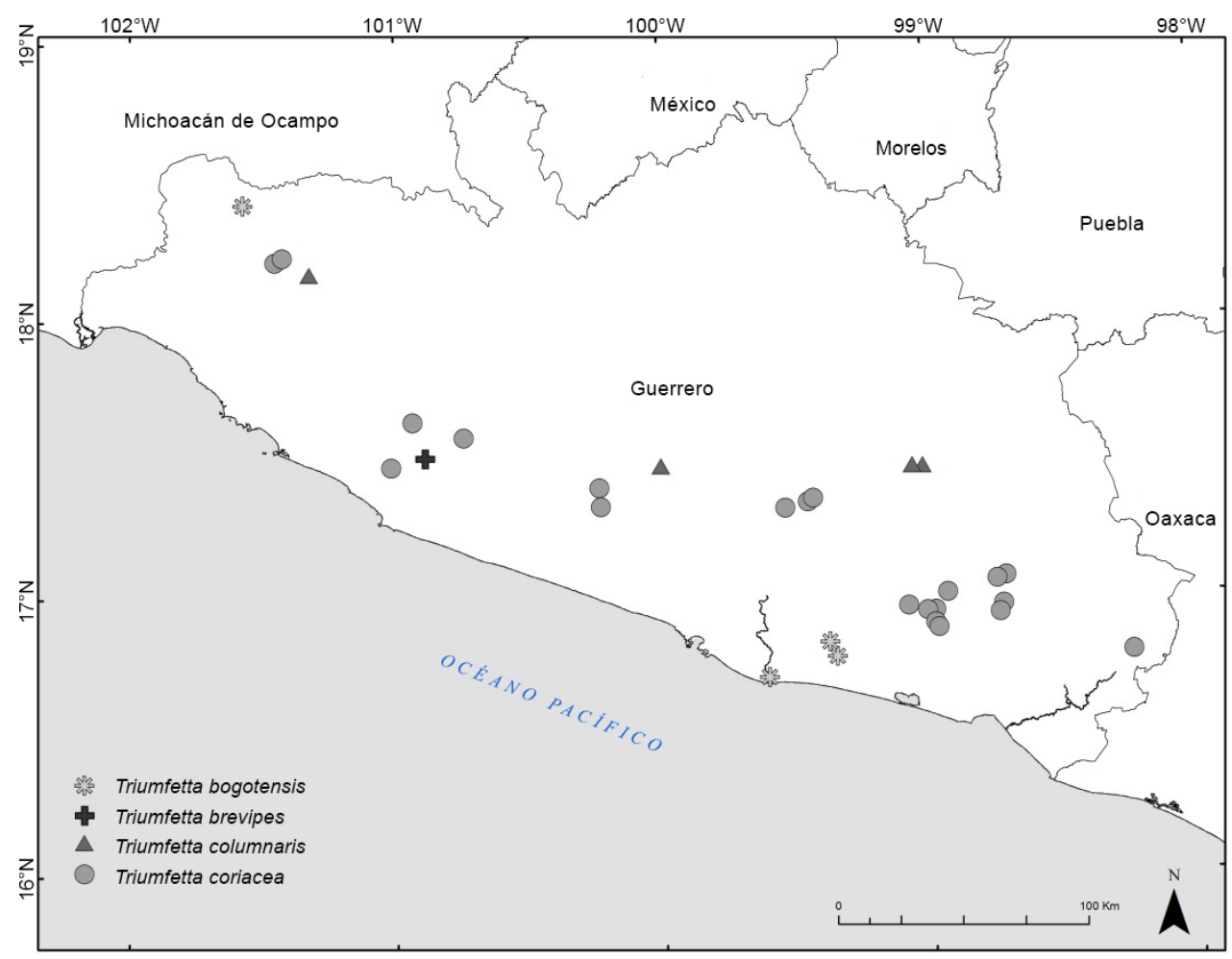

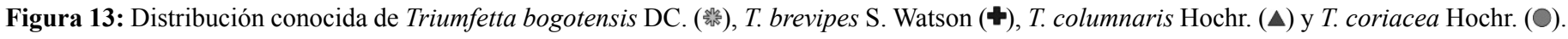

Triumfetta brevipes S. Watson, Proc. Amer. Acad. Arts 22: 400. 1887. TIPO: MÉXICO. Jalisco, río Blanco, E. Palmer 323 (holotipo: GH-GH00052582!, isotipos: GH-GH00052600!, MEXU-MEXU00019677!, NYNY00415569!, US-US00098432!). Fig. 13.

$=$ Triumfetta palmeri S. Watson, Proc. Amer. Acad. Arts 22: 400. 1887. TIPO: MÉXICO. Jalisco, E. Palmer 330 (holotipo: GH, isotipos: K-K000381791!, MOMO309031!, PH-PH00028507!, US-US00098450!).

Arbustos, hermafroditas, $0.5-1 \mathrm{~m}$ de alto; tallos color pardo, con abundantes lenticelas, densamente estrellados-pubescentes, sin corteza exfoliante; hojas con peciolos, 0.2-0.8 cm de largo (rara vez $2 \mathrm{~cm}$ ), láminas equiláteras, ovado elípticas, 4-13 cm de largo, 2-5 cm de ancho, ápice agudo o acuminado, margen irregularmente serrado, base cuneada o truncada, hasta subcordada, de consistencia semicoriácea, 3-7 nervadas, haz estrellado- pubescente, envés estrellado-tomentoso; inflorescencias en cimas, axilares o terminales, brácteas elípticas, 1-1.2 cm de largo, $0.9 \mathrm{~cm}$ de ancho, con características semejantes a las hojas; flores con sépalos oblongos, ligeramente constreñidos en la parte media, 8-16 mm de largo, densamente estrellado-pubescentes, con apéndice apical, 1-1.5 mm de largo; pétalos obovados, 7-10 mm de largo, ápice acuminado, gonóforo ca. $1.5 \mathrm{~mm}$ de largo, con glándulas anchamente oblongas, anillo $0.3 \mathrm{~mm}$ de alto; estambres 25-30, filamentos $1 \mathrm{~cm}$ de largo, ovario $1.5 \mathrm{~mm}$ de largo; fruto globoso, 3 lóculos, cuerpo 6-7 mm en diámetro, pilósulo, indehiscente, cubierto por 75-100 espinas rectas, $1 \mathrm{~mm}$ de largo, glabras o poco pubescentes, espínula uncinada (falcadas); semillas color pardo oscuro, piriformes, 3-3.5 mm de largo, 2.5-3 $\mathrm{mm}$ de ancho, 1-2 por lóculo.

Distribución: especie endémica de México (Durango, Nayarit, Jalisco, Michoacán y Guerrero). 
Tipo de vegetación y altitud: bosque de Quercus; 1400 m s.n.m.

Fenología: florece y fructifica en octubre.

Usos: no se conocen en el área.

Ejemplar examinado: MÉXICO. Guerrero, municipio Tecpan de Galeana, Tierras Blancas, G. B. Hinton 8822 (MO).

Discusión: por su distribución reducida y escasa recolecta en el estado (sólo por una colecta efectuada en 1936), así como el impacto en los tipos de vegetación que actualmente ocupa (fragmentados y reducidos por la expansión urbana), se le considera como peligro crítico (CR). Desafortunadamente, no se cuenta con información que permita evaluar el grado de impacto en las poblaciones de esta especie y sobre otras con las que comparte el hábitat.

Triumfetta columnaris Hochr., Annuaire Conserv. Jard. Bot. Genève 18: 101. 1914. TIPO: MÉXICO. Oaxaca, Tokontepeque (Totontepec), K. T. Hartweg 448 (holotipo: G-DEL, isotipo: NY-NY00415573!). Fig. 13.

= Triumfetta pseudocolumnaris Hochr., Annuaire Conserv. Jard. Bot. Genève 18: 103. 1914. TIPO: MÉXICO. Oaxaca, cordillera, H. G. Galeotti 4151. (holotipo: G-G00357192!).

= Triumfetta columnaroides Bullock, Bull. Misc. Inform. Kew 292. 1937. TIPO: MÉXICO. México. Temascaltepec, G. B. Hinton 4917 (holotipo: K, isotipos: K-K000381215!, LL, MO, NY-NY00415573!, US).

Arbustos, hermafroditas, $1.5-4 \mathrm{~m}$ de alto; tallos color rojizo, con lenticelas blanquecinas, pilosos o glabrescentes, sin corteza exfoliante; hojas con peciolos, 0.5-2 cm de largo, densamente piloso-pubescentes, estípulas no persistentes, láminas equiláteras, ovadas o ligeramente lanceoladas, $2.5-7 \mathrm{~cm}$ de largo, 2-2.5 cm de ancho, ápice largo acuminado, margen serrado, base cordada o semicordada, 5-nervadas, de consistencia suave o ligeramente coriácea, haz y envés con tricomas simples y estrellados, concentrándose en la base de las hojas de ambas superficies; inflorescencias en cimas, terminales o axilares, $5-15 \mathrm{~cm}$ de largo, pedúnculos $2-4.5 \mathrm{~cm}$ de largo, brácteas lanceoladas, $1-1.3 \mathrm{~cm}$ de largo, $0.8 \mathrm{~cm}$ de ancho, con características semejantes a las hojas, flores con sépalos lineares a lanceolados, 20-22 mm de largo, $2 \mathrm{~mm}$ de ancho, no constreñidos en la parte media, con apéndices 1-2 mm de largo; pétalos espatulados, 15-18 $\mathrm{mm}$ de largo, $3 \mathrm{~mm}$ de ancho, ápice redondeado, gonóforo de $1 \mathrm{~mm}$ de largo, con glándulas oblongas, anillo 0.5 $\mathrm{mm}$ de alto, estambres 20, filamentos $15 \mathrm{~mm}$ de largo, ovario $1 \mathrm{~mm}$ de largo, ligeramente estrellado-pubescente; fruto globoso, 3-loculares, cuerpo 6-6.5 mm de diámetro, estrellado-pubescente, indehiscentes, con 75-100 espinas rectas, 1-2 $\mathrm{mm}$ de largo, glabras o pubescentes, espínulas uncinadas; semillas color pardo oscuro, piriformes, 2.3-2.5 mm de largo, 1.8-2 $\mathrm{mm}$ de ancho, 1 o 2 por lóculo.

Distribución: especie endémica de México (Guerrero, Jalisco, México, Michoacán, Morelos, Oaxaca).

Tipo de vegetación y altitud: bosque de Quercus, Pinus-Quercus, mesófilo de montaña y Pinus; 1980-2160 m s.n.m.

Fenología: florece y fructifica en octubre y noviembre.

Usos: no se conocen en el área.

Ejemplares examinados: MÉXICO. Guerrero, municipio General Heliodoro Castillo, puente de La Dama, a $1 \mathrm{~km}$ de Los Bajos, N. Diego et al. 9151 (FCME). Municipio José Joaquín de Herrera, $5 \mathrm{~km}$ al NO de Hueycantenango, sobre el camino de Alcozacán a Hueycantenango, G. Lozano 410 (FCME); $4.5 \mathrm{~km}$ al NW de Huayaltengo, M. Ochoa 114 (FCME). Municipio Zirándaro, Fresnos a Mina, G. B. Hinton 9749 (MEXU). 
Discusión: por su distribución reducida (tres municipios), así como por el impacto en los bosques templados en donde habita, derivado entre otras acciones, por el incremento de las áreas de cultivo o pastoreo, se le considera como vulnerable (VU).

Triumfetta coriacea Hochr., Annuaire Conserv. Jard. Bot. Genève 18: 108. 1914. TIPO: MÉXICO. Guerrero, Sierra Madre, E. Langlassé 815 (holotipo: G-G00357188!, isotipos: G-G00357190!, K, GHGH00052586!). Figs. 13, 14.

Arbustos, hermafroditas, 0.3-6 $\mathrm{m}$ de alto; tallos color rojizo ferrugíneos, con abundantes lenticelas, densamente estrellado-pubescentes, glabrescentes, sin corteza exfoliante; hojas con peciolos, 2-9.5 cm de largo, abundante y cortamente estrellado-pubescentes, estípulas filiformes $0.5 \mathrm{~cm}$ de largo, no persistentes, láminas equiláteras, enteras, rara vez 3-lobadas, ovadas a elípticas, 3.5-17.5 cm de largo, 2.5-13.5 cm de ancho, ápice acuminado, margen biserrado, regularmente 3-5 dientes basales glandulares en su ápice, base obtusa o cuneada, de consistencia coriáceas, 5-nervadas, haz escasamente estrellado-pubescente en toda la superficie, rara vez estrellado-lanoso, envés densamente estrellado-pubescente, rara vez estrellado-estrigoso; inflorescencias en cimas, terminales o axilares, 6-25 cm de largo, pedúnculos 3-14 $\mathrm{cm}$ de largo, brácteas elípticas, $2-2.2 \mathrm{~cm}$ de largo, $0.5 \mathrm{~cm}$ de ancho, con características similares a las hojas; flores con sépalos blanquecinos, lanceolados a linear-lanceolados, constreñidos en la parte media, 18-25 mm de largo, $2 \mathrm{~mm}$ de ancho, haz glabro, envés densa y cortamente estrellado-pubescente, con apéndices, $0.5 \mathrm{~mm}$ de largo; pétalos espatulados, 15-22 $\mathrm{mm}$ de largo, 5-8 $\mathrm{mm}$ de ancho, ápice redondeado; gonóforo 1-1.5 mm de largo, con glándulas elípticas, anillo ca. $1.5 \mathrm{~mm}$ de alto; estambres 35-40, filamentos 14-20 mm de largo, ovario rollizo, ca. $1.5 \mathrm{~mm}$ de largo, densamente cubierto de pequeñas espinas, estilo 15-25 mm de largo, estigma 5-lobado; fruto globoso, 2 lóculos, cuerpo 6-10 $\mathrm{mm}$ de diámetro, glabro, indehiscente, espinas 200, color negro, rectas, $1 \mathrm{~mm}$ de largo, glabras, espínulas falcadas, casi rectas; semillas color pardo oscuro, piriformes, 2.9-3 mm de largo, 2-2.2 $\mathrm{mm}$ de ancho, 1 por lóculo.

Distribución: especie endémica de México (Guerrero, Jalisco, Nayarit, Oaxaca).

Tipo de vegetación y altitud: bosque de Quercus, Pinus, Pinus-Quercus, tropical caducifolio y vegetación secundaria; 200-1550 m s.n.m.

Fenología: florece y fructifica de marzo a mayo, así como en octubre y noviembre; raramente en enero y febrero.

Usos: no se conocen en el área.

Ejemplares examinados: MÉXICO. Guerrero, municipio Acatepec, Tres Cruces, C. Flores 7302 (FCME). Municipio Atoyac de Álvarez, $3 \mathrm{~km}$ sobre la desviación Los Piloncillos, V. C. Aguilar 679 (FCME, MEXU); 4 km adelante de El Paraíso, rumbo a Atoyac, R. M. Fonseca 705 (ENCB, FCME, MEXU); 4 km adelante de El Paraíso, rumbo a Atoyac, por el camino a río Verde, $M$. Gual 705 (FCME). Municipio Ayutla de los Libres, $\mathrm{Cu}-$ pinola, V. C. Aguilar 1579 (FCME, MEXU); La Concordia, camino hacia Las Mesas, G. Campos 2043 (ENCB, FCME, IEB, MEXU); poblado de Ayutla de los Libres, $V$. M. Cruz 5745 (FCME); $1 \mathrm{~km}$ de Coapinola por camino a La Concordia, J. L. Marín 43 (IEB); La Concordia, sobre el camino Ayutla de los Libres a Coapinola, F. Morales 27 (ENCB, FCME, IEB, MEXU), 28 (ENCB, FCME, IEB, MEXU), 33 (ENCB, FCME, IEB, MEXU). Municipio Chilpancingo de los Bravo, camino hacia cerro de la Vaca, C. Verduzco 211 (ENCB, FCME, IEB, MEXU). Municipio Coahuayutla de José María Izazaga, Potreritos, $2.74 \mathrm{~km}$ al NE, J. Calónico 20873 (FCME); Potreritos, $3.29 \mathrm{~km}$ al E, J. Calónico 20989 (FCME). Municipio Iliatenco, $2 \mathrm{~km}$ al NNE de San Isidro, G. Campos 1073 (ENCB, FCME, IEB, MEXU). Municipio Malinaltepec, Potrerillos del Rincón, camino San Luis Acatlán a Iliaten- 


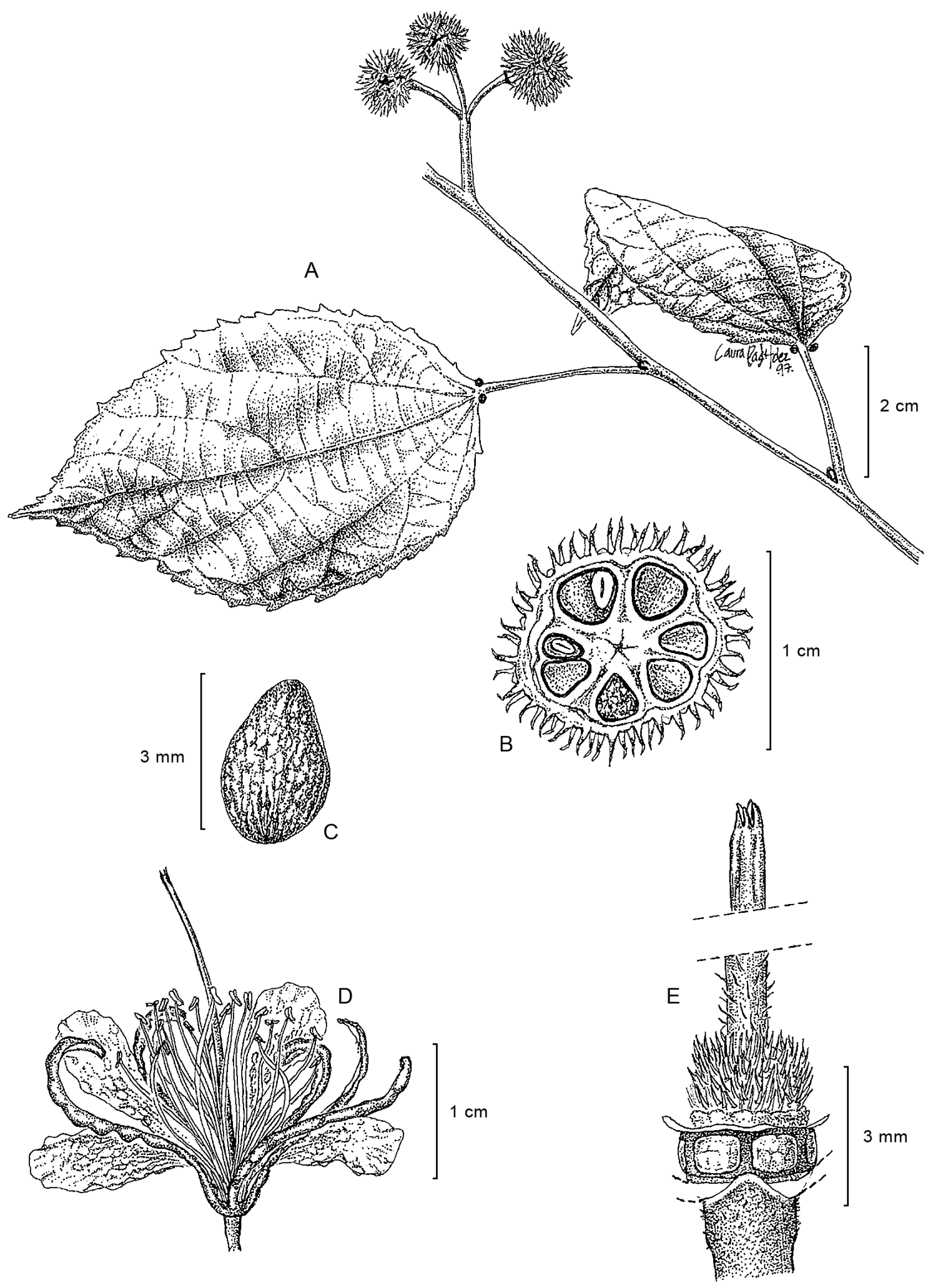

Figura 14: Triumfetta coriacea Hochr. A. rama con hojas y frutos; B. corte transversal de fruto mostrando espínulas falcadas; C. semilla; D. flor con sépalos, pétalos, estambres y estilo; E. gineceo desprovisto de cáliz y corola, mostrando el anillo, el ovario cubierto por espinas y el estigma 5-lobado. Basados en M. Gual 662 (FCME). 
co, V. C. Aguilar 1401 (ENCB, FCME, IEB, MEXU); loc. cit., T. Mozo 26 (ENCB, FCME, IEB, MEXU). Municipio Metlatónoc, $5.5 \mathrm{~km}$ al NE de San Pedro, G. Campos 1101 (ENCB, FCME, IEB, MEXU). Municipio Mochitlán, 2 $\mathrm{km}$ antes de San Roque, camino a Ximilcotitlán, $R$. Cruz 5943 (FCME); 4 km adelante de Acahuizotla, rumbo a San Roque, L. M. Godinez 239 (FCME); loc. cit., A. Peláez 239 (FCME). Municipio Petatlán, $12 \mathrm{~km}$ al NE de El Mameyal, V. C. Aguilar 1092 (ENCB, FCME, MEXU, IEB); $2 \mathrm{~km}$ al S de El Parotal, camino a Corrales, G. Campos 1556 (ENCB, FCME, IEB, MEXU). Municipio San Luis Acatlán, a $10 \mathrm{~km}$ al N de Horcasitas, camino a San Luis Acatlán - Horcasitas - El Potrerillo - El Rincón, E. Martínez y B. Morales 3460 (MEXU). Municipio Tecpan de Galeana, Bajitos de La Laguna, A. Almazán $453 C$ (FCME). Municipio Xochistlahuaca, $3 \mathrm{~km}$ al NE de Xochistlahuaca, M. Gual 662 (ENCB, FCME, IEB, MEXU).

Discusión: en cuanto a su categoría de conservación esta especie se le ubica como preocupación menor (LC), está ampliamente representada en el estado.

Triumfetta falcifera Rose, Contr. U.S. Natl. Herb. 12: 285. 1909. TIPO: MÉXICO. Guerrero, near Acapulco and vicinity, E. Palmer 266 (sintipo: NY-NY00415576!, isosintipos: USUS26634!, MICH-MICH1115338!). Fig. 15.

Arbustos, hermafroditas, $0.30-4 \mathrm{~m}$ de alto; tallos pardos, con abundantes lenticelas, estrellado-pubescentes, glabrescentes, sin corteza exfoliante; hojas con peciolos, 2.5-11.5 cm de largo, densamente estrellado-pubescentes, estípulas filiformes, $0.5 \mathrm{~cm}$ de largo, con tricomas simples y estrellados, láminas equiláteras, ovadas, $3-18 \mathrm{~cm}$ de largo, 2.5-8 cm de ancho, ápice largo acuminado, margen dentado mucronado, base cordada o semicordada, 5-nervadas, de textura aterciopelada, haz con tricomas simples y estrellados, envés densamente estrellado-tomentoso, color blanquecino; inflorescencias en cimas, terminales o axilares, 6-11 cm de largo, brácteas lanceoladas, 2.8-3 $\mathrm{cm}$ de largo, 0.8-1 cm de ancho, con características se- mejantes a las hojas; flores con sépalos linear-lanceolados, constreñidos en la parte media, $33 \mathrm{~mm}$ de largo, 29 $\mathrm{mm}$ de ancho, haz glabro, envés densamente estrelladopubescente, barbado, con apéndices simples o trífidos, 5 $\mathrm{mm}$ de largo; pétalos obovados, ápice redondeado, con 2 pequeños dientes, barbados en la base por ambas superficies, gonóforo $0.5 \mathrm{~mm}$ de largo, con glándulas elípticas, anillo $0.5 \mathrm{~mm}$ de alto, estambres 40 , filamentos $8-10 \mathrm{~mm}$ de largo; ovario $1 \mathrm{~mm}$ de largo, cubierto por numerosas espinas hialinas; estilo $1 \mathrm{~mm}$ de largo; estigma 2-denticulado; fruto globoso, 2 lóculos, cuerpo $4 \mathrm{~mm}$ de diámetro, pubescente, indehiscente, aproximadamente con 40 espinas rectas, $2 \mathrm{~mm}$ de largo, glabras, espínulas uncinadas; semillas pardo claras, piriformes, 2.5-3 mm de largo, 1.4$1.5 \mathrm{~mm}$ de ancho, 1 por lóculo.

Distribución: especie endémica de México (Guerrero, Oaxaca, Tabasco).

Tipo de vegetación y altitud: bosque de Quercus y tropical subcaducifolio; 350-2040 m s.n.m.

Fenología: florece en octubre y noviembre, y fructifica en noviembre y diciembre.

Usos: no se conocen en el área.

Ejemplares examinados: MÉXICO. Guerrero, municipio Acapulco de Juárez, El Veladero, N. Noriega 233 (FCME). Municipio Atlixtac, Zoyapexco, $0.16 \mathrm{~km}$ al NO, S. Saucedo 142 (FCME). Municipio Azoyú, ladera N en la base del cerro del Burro, a $1800 \mathrm{~m}$ al S de Jolotichán, C. Mayorga 9 (FCME). Municipio Chilpancingo de los Bravo, base of bluff of Chilpancingo, A. J. Sharp 441475 (MEXU). Municipio Tetipac, camino a Santiago Tetipac, J. Rojas et al. 2158 (FCME). Municipio Tixtla de Guerrero, La Estacada, I. Villalva 74 (FCME).

Discusión: por su escasa colecta, así como por el impacto en los bosques tropicales y templados en donde habita derivado, entre otras acciones, por el incremento 


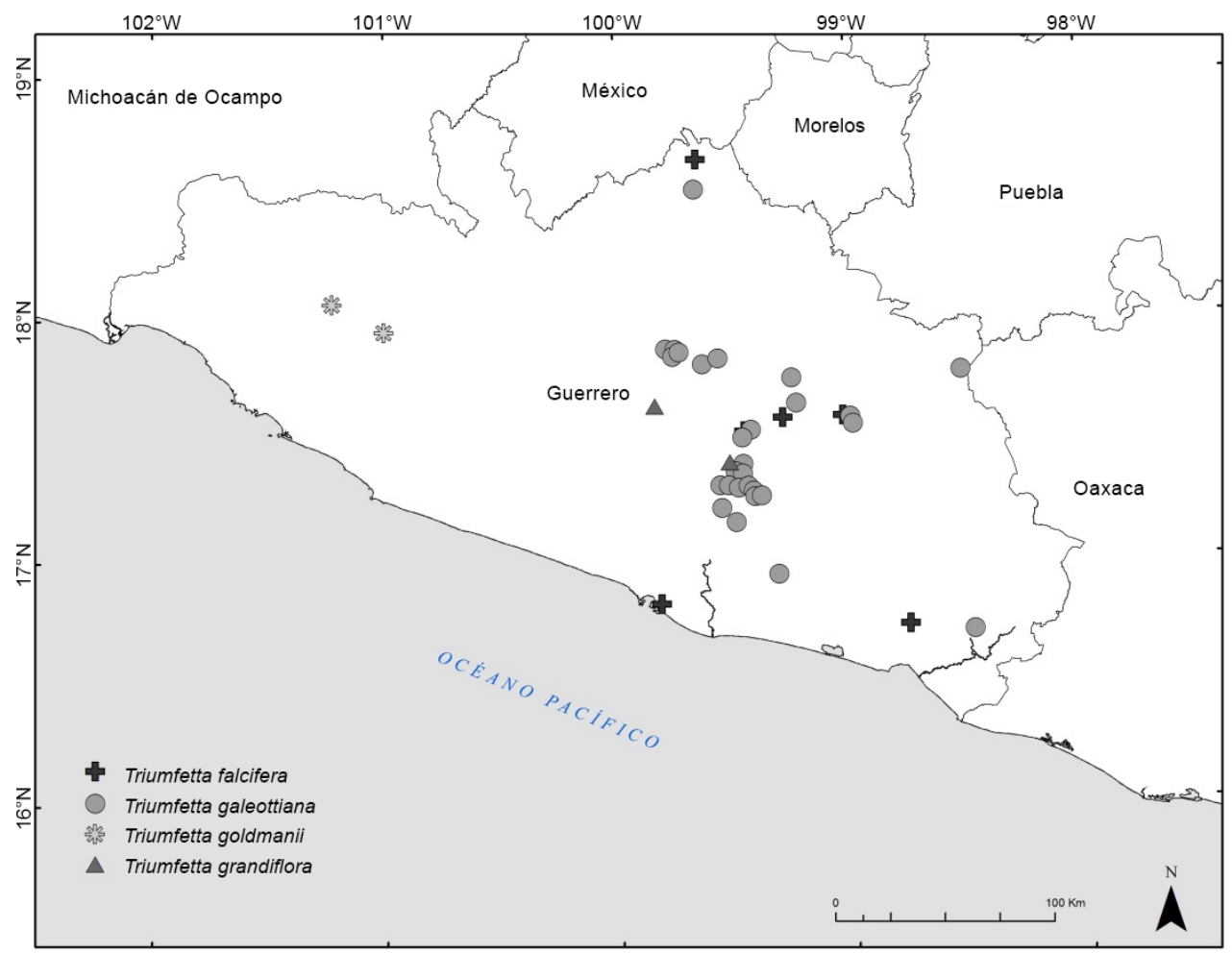

Figura 15: Distribución conocida de Triumfetta falcifera Rose (†), T. galeottiana Turcz. (○), T. goldmanii Rose (绿) y T. grandiflora Vahl (४).

de las áreas de cultivo o pastoreo, se le considera como vulnerable (VU).

Triumfetta galeottiana Turcz., Bull. Soc. Imp. Naturalistes Moscou 32: 260. 1859. TIPO: MÉXICO. Veracruz, Zacuapan cordillera, H. G. Galeotti 4153 (holotipo: KW-KW001000092!, isotipos: BR-BR0000005421657!, G-G00357186!， USUS00098444!). Fig. 15.

= Triumfetta apetala Hochr., Annuaire Conserv. Jard. Bot. Genève 18: 97. 1914. TIPO: MÉXICO. Oaxaca, $H$. G. Galeotti 4152 (holotipo: G-DEL foto, F23814, isotipo: BR-BR0000005421329!).

Hierbas o arbustos, ginodioicos o hermafroditas, 0.6-2 $\mathrm{m}$ de alto; tallos color pardo ferrugíneos, con abundantes lenticelas, densamente cubiertos por tricomas simples o estrellados, sin corteza exfoliante; hojas con peciolos, 11-12 cm de largo, densamente estrellado-pubescentes, estípulas triangulares o filiformes ca. $5 \mathrm{~mm}$ de largo, estrellado- pubescentes, láminas equiláteras, 3-lobadas, ovadas, $3.5-18 \mathrm{~cm}$ de largo, $2.5-11 \mathrm{~cm}$ de ancho, ápice acuminado o caudado, margen irregularmente serrado, base cordada o truncada, rara vez cuneada, membranáceas, 7-nervadas, haz y envés con tricomas estrellados; inflorescencias en cimas terminales, rara vez axilares, $11.5-20 \mathrm{~cm}$ de largo, pedúnculos $1.5-6 \mathrm{~cm}$ de largo, densamente estrellado-pubescentes, brácteas ovadas, $4-9.5 \mathrm{~cm}$ de largo, $2-5 \mathrm{~cm}$ de ancho, con características similares a las hojas; flores hermafroditas con sépalos $6 \mathrm{~mm}$ de largo; pétalos espatulados, 3-4 $\mathrm{mm}$ de largo, $2 \mathrm{~mm}$ de ancho, ápice redondeado o desigualmente lobado; gonóforo ca. $1.5 \mathrm{~mm}$ de largo, con glándulas oblongas, anillo $1 \mathrm{~mm}$ de alto; estambres 20-30, filamentos 1-2.5 mm de largo; ovario ca. $5 \mathrm{~mm}$ de diámetro; estilo 1-2 $\mathrm{mm}$ de largo; estigma 2-3-lobado; flores pistiladas con sépalos lanceolados o linear-lanceolados, no constreñidos en la parte media, 
3.5-5 mm de largo, 1.5-2 $\mathrm{mm}$ de ancho, ápice con pequeños apéndices en el envés, pétalos y estambres ausentes, gonóforo no visto; fruto globoso, 2 lóculos, cuerpo $5 \mathrm{~mm}$ de largo, 3-4 mm de diámetro, glabro, indehiscente, cubierto por 30-40 espinas rectas, 3-4 mm de largo, glabras, espínulas uncinadas; semillas color pardo oscuro, piriformes, $2.5 \mathrm{~mm}$ de largo, 2-2.2 $\mathrm{mm}$ de ancho, una por lóculo.

Distribución: especie endémica de México (Guerrero, Jalisco, México, Michoacán, Nayarit, Oaxaca, Sinaloa, Veracruz).

Tipo de vegetación y altitud: bosque de Quercus, Pinus, Pinus-Quercus y galería, así como en ecotonía con bosque tropical caducifolio, Quercus y vegetación secundaria; 470-1850 m s.n.m.

Fenología: florece y fructifica en agosto a noviembre.

Nombre común: tlacohuizapolli.

Usos: medicinal en trabajo de parto.

Ejemplares examinados: MÉXICO. Guerrero, municipio Atlixtac, Zoyapexco, $0.47 \mathrm{~km}$ al ENE, C. Granados 155 (FCME); Petatlán, $0.54 \mathrm{~km}$ al S, L. Mendizábal 146 (FCME); Zoyapexco, $0.47 \mathrm{~km}$ al ENE, L. Mendizábal 2003 (FCME). Municipio Chilpancingo de los Bravo, Palo Blanco, B. E. Carreto 738-A (FCME); Rancho Viejo, H. Flores 718 (FCME); loc. cit., R. M. Fonseca 1650 (ENCB, FCME, IEB, MEXU); $22 \mathrm{~km}$ al S de Chilpancingo, por la carretera a Acapulco, Loma Estrella, S. D. Koch y P. A. Fryxell 8267 (MEXU); Acahuizotla $337 \mathrm{~km}$ hacia Acahuizotla sobre camino a Acapulco, H. E. Moore 5275 (MEXU); Soyatepec a cerro de El Toro, L. C. Rodríguez 263 (FCME); km 18 carretera Ocotito - Zoyatepec, $R$. de Santiago y R. Fragoso 851 (FCME); camino al NE de La Presa, $1 \mathrm{~km}$ al $\mathrm{N}$ de Rincón de la Vía, C. Verduzco 348 (FCME). Municipio Eduardo Neri, Amatitlán, 2 km al NO, J. Calónico 1216 (FCME); Amatitlán, $3 \mathrm{~km}$ al SE camino a Carrizalillo, R. Cruz y M. E. García 108 (FCME); Puer- to de Los Tepetates, $3 \mathrm{~km}$ al N de Amatitlán, R. Cruz 317 (FCME); Cañada Carrizalillo, $1 \mathrm{~km}$ al SE de Amatitlán, $R$. Cruz 639 (FCME), 647 (FCME); Xochipala - Las Lagunitas, A. Gómez 1881 (FCME); Mezcala, $12.5 \mathrm{~km}$ al SO, M. A. Monroy 702 (FCME). Municipio Igualapa, $5 \mathrm{~km}$ despues de Igualapa, dirección Ometepec, G. Gaxiola 147 (FCME); $3 \mathrm{~km}$ de Quetzalapa, dirección a Acalmaní, $A$. Núñez 455 (FCME). Municipio Juan R. Escudero, El Zapote, L. Y. Astudillo 659 (FCME). Municipio Mártir de Cuilapan, La Esperanza, reserva campesina, N. Diego et al. 4514 (FCME), 7514 (FCME); loc. cit., E. Teyuco 60 (FCME). Municipio Mochitlán, camino al poblado El Guayabo, $H$. Flores 376 (FCME), 422 (FCME); camino de La Cumbre a El Guayabo, H. Flores 421 (FCME); camino al cerro de La Cueva del Agua, H. Flores 452 (FCME); camino al poblado Tepetxintla, H. Flores 582 (FCME); $3.37 \mathrm{~km}$ hacia Acahuizotla sobre camino a Acapulco, H. E. Moore 5275 (MEXU). Municipio Taxco de Alarcón, La Cascada, $10 \mathrm{~km}$ al SO de Taxco, por el camino a Ixcateopan, J. Calónico 3950 (FCME), 3950-b (FCME). Municipio Tecoanapa, 5 km de El Saucito, dirección Xalpatláhuac, A. Núñez 428 (FCME); Huamuchapa, V. M. Pano-Chino 671 (FCME). Municipio Tixtla de Guerrero, a $250 \mathrm{~m}$ de la cortina de la presa El Molino, E. Domínguez 255 (FCME); aproximadamente a $6 \mathrm{~km}$ al SE de Chilpancingo, ladera $\mathrm{S}$ del cerro Las Cruces, R. M. Fonseca 2395 (FCME). Municipio Zitlala, Topiltepec, reserva campesina, C. Illsley 121 (FCME).

Discusión: en cuanto a su categoría de conservación esta especie es considerada como preocupación menor (LC).

Triumfetta goldmanii Rose, Contr. U.S. Natl. Herb. 12: 285. 1909. TIPO: MÉXICO. Sinaloa, Sierra de Choix, $50 \mathrm{mi}$ NE of the town of Choix, E. A. Goldman 264 (holotipo: US-US00098445!, isotipos: F, K-K000381129!). Fig. 15.

= Triumfetta sanctae-luciae Sprague, Bull. Misc. Inform. Kew 1923 (3): 114. 1923. TIPO: MÉXICO. Sinaloa, $W$. Seemann 2147 (holotipo: K-K000381126!). 
$=$ Triumfetta quercetorum Bullock, Bull. Misc. Inform. Kew 5: 295-296. 1937. TIPO: MÉXICO. Temascaltepec, Pungarancho, G. B. Hinton 6746 (holotipo: MO-MO194203!, isotipos: K-K000381129!, MO, NYNY00415588!).

Árboles pequeños o arbustos, hermafroditas, 1-3.5 m de alto; tallos color pardo oscuro, con abundantes lenticelas, tricomas estrellados, a veces hirsutos, glabrescentes con la edad, corteza no exfoliante; hojas con peciolos, 2-4.5 cm de largo, estípulas deciduas, láminas elípticas o angostamente ovadas, 6-10 cm de largo, 3-4.5 $\mathrm{cm}$ de ancho, ápice acuminado, margen crenado serrado, base truncada, cuneada o subcordada, 5-7 nervadas, con pubescencia muy fina de tricomas estrellados en el haz, pilosa en la superficie de la venas principales y en la base del envés; inflorescencias en cimas o panículas, terminales o axilares, brácteas elípticas, $1.1-1.3 \mathrm{~cm}$ de largo, $0.9 \mathrm{~cm}$ de ancho, con características similares a las hojas; flores con sépalos estrechamente oblongos, 15-20 mm de largo, no constreñidos en la parte media, estrellado-pubescentes, con apéndices 0.5-2 $\mathrm{mm}$ de largo, pétalos color verde blanquecinos, elípticos a estrechamente obovados, 12-16 $\mathrm{mm}$ de largo, gonóforo ca. $2.5 \mathrm{~mm}$ de largo, con glándulas elípticas, anillo $0.3 \mathrm{~mm}$ de alto, estambres 20, filamentos $9 \mathrm{~mm}$ de largo, ovario $5 \mathrm{~mm}$ de diámetro, estilo 1-2 $\mathrm{mm}$ de largo; estigma 2-3 lobado; fruto globoso, 4-locular, cuerpo 4-5 $\mathrm{mm}$ de diámetro, pubescente, indehiscente, aproximadamente con 75 espinas falcadas, 2-3 $\mathrm{mm}$ de largo, ligeramente pubescentes, espínulas rectas; semillas no vistas (ni registradas en literatura).

Distribución: especie endémica de México (Chihuahua, Durango, Guerrero, Jalisco, México, Michoacán, Sinaloa, Sonora).

Tipo de vegetación y altitud: bosque de QuercusPinus; 1600-1640 m s.n.m.

Fenología: florece y fructifica de septiembre a octubre.
Usos: no se conocen en el área.

Ejemplares examinados: MÉXICO. Guerrero, municipio Coyuca de Catalán, Zihuaquio - Ojo de Agua, $G$. B. Hinton 9710 (MO); Chiriagua, G. B. Hinton y J. C. Hinton 10663 (MO).

Discusión: por su distribución reducida y escasa recolecta en el estado (dos efectuadas en 1937), así como por el impacto en los tipos de vegetación que actualmente ocupa (fragmentados y reducidos por la expansión urbana), se le considera como peligro crítico (CR).

Triumfetta grandiflora Vahl, Eclog. Amer. 2: 34. 1798. TIPO: MONTSERRAT. R. W. Ryan s.n. (holotipo: M-M0210265!). Fig. 15.

= Triumfetta longicuspis Turcz., Bull. Soc. Imp. Naturalistes Moscou 31: 229. 1858. TIPO: MÉXICO. Oaxaca, Sierra San Pedro Nolasco, Talea, C. Jurgensen 882 (holotipo: KW-KW001000089!, isotipo: G-G00357183!).

Arbustos, hermafroditas, 1-2 m de alto; tallos color pardo ferrugíneo, con abundantes lenticelas, tricomas simples, estrellados o glabrescentes, sin corteza exfoliante; hojas con peciolos, $1.5-4 \mathrm{~cm}$ de largo, con tricomas simples y estrellados, estípulas deciduas, láminas equiláteras, simples, ovadas, 3.5-13 cm de largo, 2-5 cm de ancho, ápice largo acuminado, margen serrado, base cuneada, semicoriáceas, 5-nervadas, con escasos tricomas simples y estrellados en haz y envés; inflorescencias en cimas, 3-4 flores, terminales o axilares, brácteas ovadas, $1.2-1.4 \mathrm{~cm}$ de largo, $0.8 \mathrm{~cm}$ de ancho, con características semejantes a las hojas; flores con sépalos linear-ovados, 15-25 mm de largo, $3 \mathrm{~mm}$ de ancho, haz glabro, no constreñidos en la parte media, envés con escasos tricomas simples y estrellados, apéndices 1-1.5 mm de largo; pétalos espatulados o lanceolados, 25-30 mm de largo, ápice agudo, barbados en la base de ambas superficies; gonóforo $1.5 \mathrm{~mm}$ de largo, con glándulas esféricas, anillo $0.2 \mathrm{~mm}$ de alto; ovario globoso, $1.5 \mathrm{~mm}$ de largo; estilo $1.5 \mathrm{~mm}$ de largo; estigma 
3-lobado; fruto globoso, 3 locular, cuerpo 5-6 mm de diámetro, pubescente, dehisente, espinas numerosas más de 200, rectas, 4-5 mm de largo, pubescentes o ligeramente plumosas en la base, espínulas uncinadas; semillas color pardo oscuro, piriformes, $2.5-3 \mathrm{~mm}$ de largo, $1.5-2.5 \mathrm{~mm}$ de ancho, 2 por lóculo.

Distribución: México (Guerrero, Oaxaca, Veracruz), Centroamérica, Antillas y Sudamérica.

Tipo de vegetación y altitud: bosque de PinusQuercus; ca. 2100 m s.n.m.

Fenología: florece y fructifica en noviembre.

Usos: no se conocen en el área.

Ejemplares examinados: MÉXICO. Guerrero, municipio Chilpancingo de los Bravo; El Alquitrán, primera antena, L. Lozada 1654 (FCME). Municipio Leonardo Bravo, La Pastora, Laboratorio de Biogeografia 246 (FCME).

Discusión: esta especie se cita por primera vez para Guerrero; es una planta escasa en el estado (dos municipios). Por su distribución reducida, así como por el impacto en el bosque templado en donde habita, derivado entre otras acciones, del incremento de las áreas de cultivo o pastoreo, se le considera como vulnerable (VU).

Triumfetta guerrerensis Gual, S. Peralta \& Diego, Acta Bot. Mex. 56: 13-18. 2001. TIPO: MÉXICO. Guerrero, municipio José Azueta, desviación a El Calabazalito, a $3.5 \mathrm{~km}$ del entronque con la carretera a Ciudad Altamirano, Costa Grande, M. Gual et al. 825 (holotipo: MEXU-MEXU01240495!, isotipos: FCME!, IEB!, MEXU!, paratipo: MEXU-MEXU00067498!).

Fig. 16.

Arbustos o pequeños árboles, hermafroditas, 0.4-4 $\mathrm{m}$ de alto; tallos jóvenes color blanquecino con abundan- tes lenticelas, tallos maduros color rojizo, corta y densamente estrellado-pubescentes o glabrescentes, ocasionalmente con corteza exfoliante; hojas con peciolos, 1.2-8 $\mathrm{cm}$ de largo, densamente estrellado-pubescentes, estípulas filiformes, $1 \mathrm{~mm}$ de largo, con tricomas simples o estrellados, deciduas, láminas demediadas, ovadas o 3-lobadas, inequiláteras, 4-17.5 cm de largo, 2-14.5 cm de ancho, ápice largamente acuminado, margen dentado mucronado, los 2-4 dientes basales de cada lado con glándulas, frecuentemente color rojo, base cuneada u obtusa, suave o ligeramente escabrosa, 5-nervadas, haz con tricomas simples y estrellados, concentrándose en las venas, envés densamente estrellado-pubescente; inflorescencias en dicasios compuestos, axilares, 2-3 en cada axila, pedicelos 5-6 $\mathrm{mm}$ de largo en flor, con tricomas estrellados; flores con sépalos obovados, 5-9 $\mathrm{mm}$ de largo, acuminados, envés densamente estrellado-pubescente, con apéndices, $2 \mathrm{~mm}$ de largo, pétalos color blanco o amarillo-claro, espatulados, 3.5-6 $\mathrm{mm}$ de largo, $2 \mathrm{~mm}$ de ancho, ápice redondeado o agudo, gonóforo $0.7-1 \mathrm{~mm}$ de largo, con glándulas oblongas, anillo $0.4 \mathrm{~mm}$ de alto, ciliado; estambres 50-70, filamentos 3-4 mm de largo; ovario 0.5-1 $\mathrm{mm}$ de largo; estilo 2.5-7 mm de largo; estigma 5-lobado; fruto globoso, 5-locular, cuerpo 7.5-8.5 mm de diámetro, glabro, indehiscente, aproximadamente con 280 espinas, rectas, 3.5-4.5 $\mathrm{mm}$ de largo, con escasa pubescencia simple, espínulas uncinadas; semillas color blanquecino, piriformes, ca. 2.7 mm de largo, ca. $2.3 \mathrm{~mm}$ de ancho, 1-2 por lóculo.

Distribución: especie endémica de México (Guerrero, Oaxaca).

Tipo de vegetación y altitud: bosque de galería; 40350 m s.n.m.

Fenología: florece y fructifica de octubre a enero.

Usos: no se conocen en el área.

Ejemplares examinados: MÉXICO. Guerrero, municipio Acapulco de Juárez, hacia la parte alta, carretera 


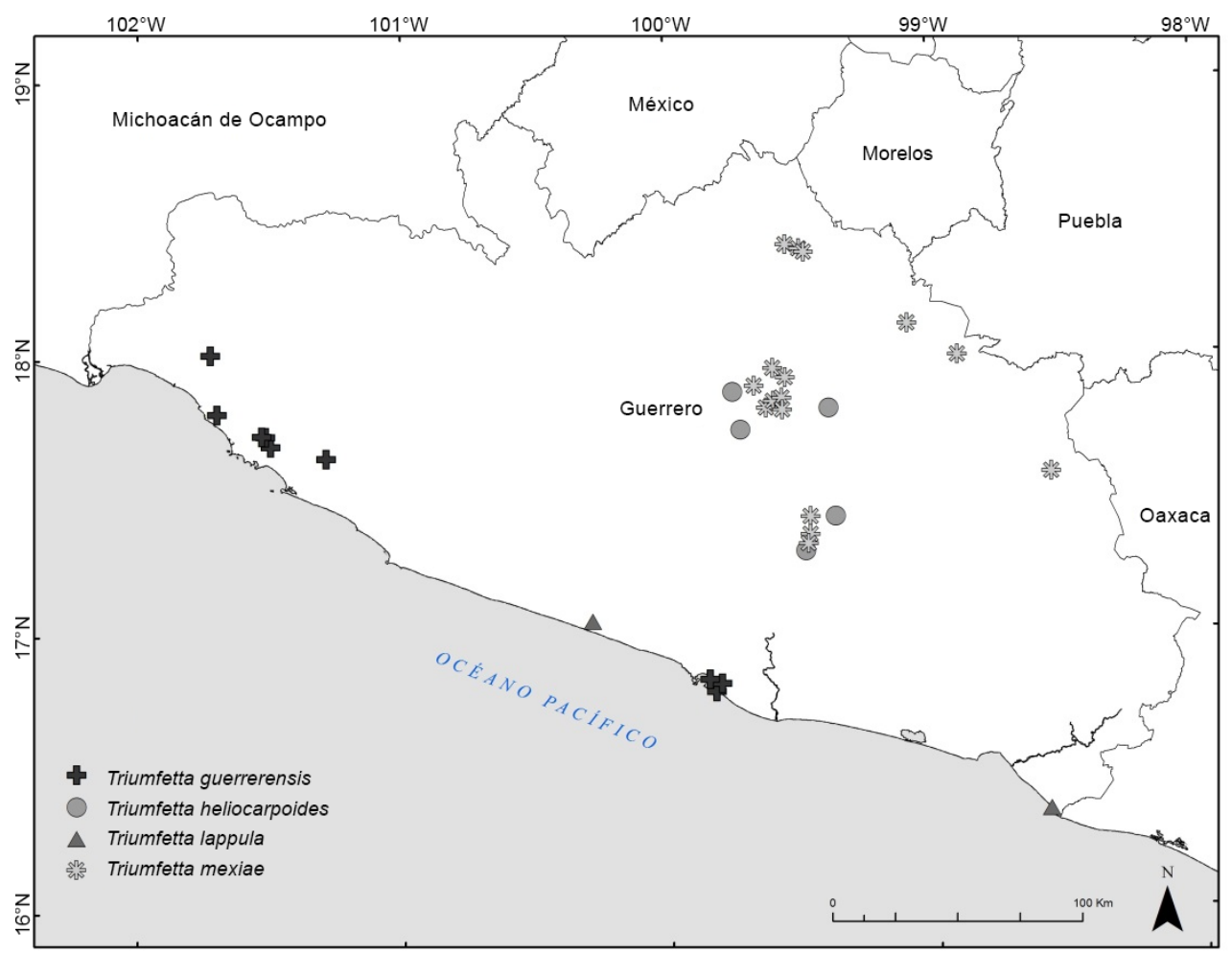

Figura 16: Distribución conocida de Triumfetta guerrerensis Gual, S. Peralta \& Diego (\$), T. heliocarpoides Bullock (O), T. lappula L. (ム) y T. mexiae C.V. Morton (急).

Puerto Marqués a Acapulco, F. Miranda 8412 (MEXU); Parque Nacional El Veladero, N. Noriega 268 (FCME); Acapulco, L. Paray 2318 (MEXU). Municipio Petatlán, Llanos de la Puerta, G. Campos 1486 (FCME). Municipio La Unión de Isidoro Montes de Oca, $11.5 \mathrm{~km}$ al $\mathrm{N}$ de La Unión camino a Coahuayutla, M. Gual 646 (FCME), 648 (FCME); a $2 \mathrm{~km}$ al NO de Troncones, A. Hanan 135 (FCME). Municipio Zihuatanejo de Azueta, $1.8 \mathrm{~km}$ al SO del caserío La Vainilla, C. Gallardo et al. 179 (FCME); carretera a Ciudad Altamirano, desviación a La Vainilla, Costa Grande, M. Gual 464 (FCME); por la desviación a El Calabazalito a $3.5 \mathrm{~km}$ del entronque con la carretera a Ciudad Altamirano, Costa Grande, M. Gual et al. 825 (FCME, IEB, MEXU), 826 (FCME, IEB, MEXU), 827 (FCME, IEB, MEXU).

Discusión: por su distribución reducida (cuatro municipios), así como por el impacto en los bosques de galería en donde habita, derivado entre otras acciones, del incremento de las áreas de cultivo o pastoreo, se le considera como vulnerable (VU).

Triumfetta heliocarpoides Bullock, Bull. Misc. Inform. Kew 293. 1937. TIPO: MÉXICO. México, Temascaltepec, Ixtapan, G. B. Hinton 5159 (holotipo: K-K000381781!, isotipos: A-A00052592!, G-G00357182!, LL-LL00371840!). Fig. 16.

Arbustos, ginodioicos o hermafroditas, $1-1.5 \mathrm{~m}$ de alto; tallos color pardo, con abundantes lenticelas, finamente estrellado-pubescentes, sin corteza exfoliante; hojas con peciolos 5-10 cm de largo, estrellado-pubescentes, láminas equiláteras, ovadas, 3-lobadas, $10-15 \mathrm{~cm}$ de largo, 7-9 cm de ancho, ápice acuminado, margen biserrado, base subcordada o redondeada, membranáceas, 7-nervadas, haz escabroso o ligeramente pubescente con tricomas 
estrellados, envés con tricomas estrellados; inflorescencias en cimas, 4-6 címulas, pedúnculos $0.3-0.4 \mathrm{~cm}$ de largo, brácteas ovadas, $1.1-1.3 \mathrm{~cm}$ de largo, $0.9 \mathrm{~cm}$ de ancho, con característias semejantes a las hojas; flores hermafroditas no vistas (ni registrado en literatura), flores pistiladas con pedicelos, $2 \mathrm{~mm}$ de largo, sépalos oblongos, no constreñidos en la parte media, 3-4 mm de largo, tomentosos externamente, pétalos obovados, $1 \mathrm{~mm}$ de largo, uña plumosa; gonóforo $0.5-7.5 \mathrm{~mm}$ de largo, con glándulas oblongas, anillo ciliado, $0.3 \mathrm{~mm}$ de alto, estaminodios 10, 1-2 mm de largo, ovario globoso, 3 lóculos, globoso, $5 \mathrm{~mm}$ de diámetro, estilo $1.5 \mathrm{~mm}$ de largo, estigma 2-lobado; fruto globoso, 3 lóculos, cuerpo $2 \mathrm{~mm}$ de diámetro, glabro, indehiscente, cubierto por 20-25 espinas rectas, 3-4 mm de largo, glabras, espínulas uncinadas; semillas pardo oscuro, piriformes, 1.8-2 $\mathrm{mm}$ de largo, 0.8-1.2 mm de ancho, 1-2 por lóculo.

Distribución: especie endémica de México (Guerrero, México, Oaxaca).

Tipo de vegetación y altitud: bosque de Quercus y Pinus; 540-1200 m s.n.m.

Fenología: florece y fructifica de septiembre a noviembre.

Nombre común: abrojo.

Usos: no se conocen en el área.

Ejemplares examinados: MÉXICO. Guerrero, municipio Chilpancingo de los Bravo, carretera antigua a Rincón Viejo, H. Kruse 520 (FCME), 836 (FCME); Palo Blanco, km 298 carretera México - Acapulco, H. Kruse 2036 (FCME). Municipio Eduardo Neri, Cañada Carrizalillo, $0.5 \mathrm{~km}$ al ESE de Amatitlán, R. Cruz y M. E. García 371 (FCME); La Laguna, J. Maldonado 618 (FCME). Municipio Mochitlán, Cajeles, falda $\mathrm{O}$ de cerro El Fresno, H. Kruse 1960 (MEXU). Municipio Tepecoacuilco de Trujano, $16 \mathrm{~km}$ al S de San Miguel, $7 \mathrm{~km}$ al SE de auto- pista y $1.5 \mathrm{~km}$ al SE de Milpas, J. Amith y G. Hall 940 (FCME).

Discusión: por su distribución reducida (cuatro municipios), así como por el impacto en los bosques templados en donde habita, derivado entre otras acciones, del incremento de las áreas de cultivo o pastoreo, se le considera como vulnerable (VU).

Triumfetta lappula L., Sp. P1. ed. 1. 444. 1753. TIPO: no designado. Fig. 16.

Hierbas sufruticosas o pequeños arbustos, hermafroditas, 0.3-0.5 m de alto; tallos color pardo oscuro, con abundantes lenticelas, escasamente estrelladopubescentes, sin corteza exfoliante; hojas con peciolos, 1-2.5 cm de largo, estrellado-pubescentes, estípulas triangulares, $0.4 \mathrm{~mm}$ de largo, láminas equiláteras, ovadas u ovado-elípticas, enteras o 3-lobadas, $1.8-8 \mathrm{~cm}$ de largo, 1.5-5.6 cm de ancho, ápice largo acuminado, margen dentado, base cuneada, con 4 pares de dientes basales glandulares, textura suave, 3-5 nervadas, haz con escasa pubescencia de tricomas simples y estrellados, envés estrellado-pubescente; inflorescencias en cimas, terminales o axilares, $6-16 \mathrm{~cm}$ de largo, pedúnculos 1-3 $\mathrm{cm}$ de largo, brácteas ovadas, $1.2-1.4 \mathrm{~cm}$ de largo, $1 \mathrm{~cm}$ de ancho, con características semejantes a las de las hojas; flores con sépalos linear-lanceolados, no constreñidos en la parte media, $5 \mathrm{~mm}$ de largo, con apéndices 1 $\mathrm{mm}$ de largo; corola ausente; gonóforo ausente, anillo inconspícuo; estambres 15, filamentos $3 \mathrm{~mm}$ de largo; ovario $1 \mathrm{~mm}$ de largo; estilo $2 \mathrm{~mm}$ de largo; estigma denticulado; fruto ovoide o elipsoidal, 2 lóculos, cuerpo $3 \mathrm{~mm}$ de diámetro, estrellado-pubescente, indehiscente, aproximadamente con 50 espinas rectas, 2-3 mm de largo, retrorso-pilosas, espínulas uncinadas; semillas color pardo oscuro, piriformes, 2.3-2.5 mm de largo, 1.5-1.6 mm de ancho, 1-2 por lóculo.

Distribución: México (Campeche, Chiapas, Guerrero, Yucatán), Antillas y Sudamérica. 
Tipo de vegetación y altitud: bosque tropical caducifolio y vegetación secundaria (cultivos de coco); ca. 50 m s.n.m.

Fenología: florece y fructifica en febrero.

Usos: no se conocen en el área.

Ejemplares examinados: MÉXICO. Guerrero, municipio Atoyac de Álvarez, El Porvenir, laguna de Mitla, L. Lozada 359 (FCME). Municipio Cuajinicuilapa, $5 \mathrm{~km}$ de Punta Maldonado a Montesillo, M. T. Mozo 17 (FCME).

Discusión: por su distribución reducida (dos municipios), así como por el impacto en los bosques templados en donde habita, derivado entre otras acciones, del incremento de las áreas de cultivo o pastoreo, se le considera como vulnerable (VU).

Triumfetta mexiae C.V. Morton \& Lay, Ann. Missouri Bot. Gard. 37(3): 348. 1950. TIPO: MÉXICO. Guerrero, barranca below ore mill, Y. Mexiae 8834 (holotipo: US-US00098449!, isotipos: CAS-CAS0004906!, F-F0074015F!, MO-MO356239!, UC-UC645158!). Fig. 16.

Árboles o arbustos, ginomonoicos, 0.5-7 m de alto; tallos con corteza exfoliante color rojizo, ramas jóvenes con abundantes lenticelas, estrellado-ferrugíneas, glabrescentes; hojas con peciolos, 1.5-5.5 cm de largo, estípulas color verde, $4-5 \mathrm{~mm}$ de largo, láminas elípticas u ovadas, 5-15 cm de ancho, 3.5-12.5 $\mathrm{cm}$ de ancho, ápice largo-acuminado, margen finamente serrado, base semicordada, cuneada, algunas veces atenuada, 5 nervadas, haz estrellado-pubescente, envés densamente estrellado-pubescente; inflorescencias en cimas terminales, 4-13 cm de largo, pedúnculos $1-3.5 \mathrm{~cm}$ de largo, brácteas elípticas, $1.4-1.5 \mathrm{~cm}$ de largo, $1-1.2 \mathrm{~cm}$ de ancho, con características semejantes a las hojas; flores hermafroditas con sépalos angostamente obovados, 5-8 $\mathrm{mm}$ de largo, $3 \mathrm{~mm}$ de ancho, ápice con apéndices cortos, haz glabro, envés esparcidamente estrellado-pubescentes, pétalos elípticos a angostamente obovados, 4-6 $\mathrm{mm}$ de largo, estambres 40, filamentos 3-4 mm de largo, gonóforo ca. $0.7 \mathrm{~mm}$ de largo, con glándulas elípticas, anillo ca. $0.3 \mathrm{~mm}$ de largo; ovario ovoide, ca. $1.5 \mathrm{~mm}$ de largo, estilo $0.6 \mathrm{~mm}$ de largo, estigma bilobulado; flores pistiladas con sépalos lineares o angostamente ovados, 3-6 mm de largo, $2 \mathrm{~mm}$ de ancho, ápice con apéndices, 1 $\mathrm{mm}$ de largo, corola ausente, gonóforo inconspicuo, con glándulas elípticas, anillo incospicuo, estigma bilobado; fruto globoso, 2 lóculos, cuerpo 6-7 $\mathrm{mm}$ de diámetro, glabro, indehiscente, cubierto por 75-100 espinas falcadas, color pardo oscuro, 3-4 mm de largo, glabras, espínulas rectas; semillas color pardo oscuro, piriformes, 1-1.5 mm de largo, 0.5-0.8 mm de ancho, muricadas, 1-2 por lóculo.

Distribución: especie endémica de México (Guerrero, Michoacán).

Ejemplares examinados: MÉXICO. Guerrero, municipio Apaxtla de Castrejón, $2250 \mathrm{~m}$ al SO de Tlatzala, E. Chávez 99 (FCME). Municipio Atenango del Río, $5 \mathrm{~km}$ al $\mathrm{N}$ de Atenango del Río, camino a Comalá, J. L. Contreras 2431 (FCME). Municipio Chilpancingo de los Bravo, $0.5 \mathrm{~km}$ al SO de la desviación a Mazatlán, carretera México a Acapulco, L. Lozada 1319 (FCME); Acahuizotla, A. Reyna 140 (FCME); 25 miles south of Chilpancingo, C. M. Rowell y F. A. Barkley 17810 (MEXU). Municipio Copalillo, barranca Tecomá, 0.5 $\mathrm{km}$ al E de Papalutla, J. Calónico 344 (FCME). Municipio Eduardo Neri, $3 \mathrm{~km}$ al SE de Mezcala, abanico pluvial, G. Campos 10 (FCME); $3 \mathrm{~km}$ al NE de Mezcala, abanico pluvial, G. Campos 10-a (FCME); $4 \mathrm{~km}$ al $\mathrm{S}$ de Mezcala, cañada húmeda, J. L. Contreras 589 (FCME); $6.5 \mathrm{~km}$ al S de Mexcala por la carretera Iguala a Chilpancingo, J. L. Contreras 641 (FCME). $2.5 \mathrm{~km}$ al $\mathrm{N}$ de Xochipala, M. Gual y C. Villegas 240 (FCME); $10 \mathrm{~km}$ al O de Mezcala, M. Gual 450 (FCME); $3 \mathrm{~km}$ al $\mathrm{N}$ de Casas Verdes, carretera México a Acapulco, $F$. 
Lorea 1121 (FCME); barranca El Salado, Xochipala, $S$. Peralta y C. Villegas 305 (FCME). Municipio Iguala de la Independencia, $5 \mathrm{~km}$ al $\mathrm{N}$ del poblado, ladera $\mathrm{O}$ del cerro El Jumil, F. Terán y S. Vázquez 189 (FCME); 4 km al $\mathrm{N}$ de Tuxpan, ladera $\mathrm{O}$ del cerro El Jumil, F. Terán y S. Vázquez 198 (FCME). Municipio Taxco de Alarcón, Mexcaltepec, F. Terán y P. Lara 547 (FCME).

Tipo de vegetación y altitud: bosque tropical caducifolio y subcaducifolio, y vegetación secundaria; 6901230 m s.n.m.

Fenología: florece y fructifica de agosto a diciembre y raramente en marzo.

Usos: no se conocen en el área.

Discusión: por su distribución restingida a dos estados, así como por el impacto en los bosques tropicales en donde habita, derivado entre otras acciones, del incremento de las áreas de cultivo o pastoreo, se le considera como vulnerable (VU).

Triumfetta paniculata Hook. \& Arn., Bot. Beechey Voy. 279. 1838. TIPO: MÉXICO. Nayarit, Beechey s.n. (lectotipo: K-K000381784!). Fig. 17.

= Heliocarpus tigrinus Hochr., Annuaire Conserv. Jar. Bot. Genevé 18: 123. 1914 = Triumfetta tigrina (Hochr.) Standl., Contr. U.S. Natl. Herb. 23: 1674. 1926. TIPO: MÉXICO. Michoacán, La Morena, E. Langlassé 708 (holotipo: G-G00357177!, isotipos: K, MPU-MPU017149!, US-US00098483!).

= Triumfetta leiocarpa Standl., Publ. Field Mus. Nat. Hist., Bot. Ser. 11: 167. 1936. TIPO: MÉXICO. Colima, Coahuayana, G. M. Emrick 130 (holotipo: F-F0074013F!, isotipo: G-G00357175!).

= Triumfetta matudae Lundell, Contr. Univ. Michigan Herb. 7: 27. 1942. TIPO: MÉXICO. Chiapas, Escuintla, E. Matuda 2148 (holotipo: MICH, isotipos: F-F0074014F!, LL-LL00371842!).
Arbustos o pequeños árboles, andromonoicos, 1-4 $\mathrm{m}$ de alto; tallos jóvenes, color pardo, con abundantes lenticelas, cortamente estrellado-pubescentes, glabrescentes, de tonalidades oscuras, sin corteza exfoliante; hojas con peciolos, 1.8-12.5 cm de largo, escasamente estrelladopubescentes o glabrescentes; estípulas no vistas, láminas equiláteras, 3-lobadas, aproximadamente cuadradas, 6.5$24 \mathrm{~cm}$ de largo y ancho, ápice acuminado, margen serrado, base cordada, ásperas, 7 nervadas, haz con tricomas simples y estrellados, envés con el mismo indumento, pero los tricomas más largos y densos; inflorescencias en cimas, terminales o axilares, $6-25 \mathrm{~cm}$ de largo, brácteas ovadas, $1.3-1.5 \mathrm{~cm}$ de largo, $1 \mathrm{~cm}$ de ancho; flores hermafroditas con sépalos lanceolados, 2.5-9 mm de largo, no constreñidos en la parte media, con apéndice vestigial ocasionalmente ausente, haz glabro, envés con tricomas simples y estrellados; pétalos obovados o espatulados, 2.5-5.5 mm de largo, estambres 40-60, filamentos 5.5-7 $\mathrm{mm}$ de largo, gonóforo $0.5 \mathrm{~mm}$ de largo, con glándulas esféricas a elípticas, anillo $0.2 \mathrm{~mm}$ de largo, ovario ca. 5 $\mathrm{mm}$ de largo; estilo $0.5 \mathrm{~mm}$ de largo, estigma bilobado; flores estaminadas con sépalos, 1.5-2 $\mathrm{mm}$ de largo, con apéndice vestigial, pétalos $1.5 \mathrm{~mm}$ de largo, ápice redondeado a dentado, base barbada, estambres 40-60, filamentos $1 \mathrm{~mm}$ de largo; fruto globoso, 2 lóculos, cuerpo $6 \mathrm{~mm}$ de diámetro, glabro, indehiscente, aproximadamente con 75 espinas rectas, 3-5 mm de largo, glabras, espínulas uncinadas; semillas color pardo oscuro, piriformes, 2.3-2.5 $\mathrm{mm}$ de largo, 1.8-2 $\mathrm{mm}$ de ancho, 2 por lóculo.

Distribución: especie endémica de México (Chiapas, Colima, Guerrero, Jalisco, Michoacán, Nayarit, Oaxaca, Sinaloa).

Tipo de vegetación y altitud: bosque de galería, tropical subcaducifolio y tropical caducifolio con elementos de mesófilo de montaña; 750-1300 m s.n.m.

Fenología: florece y fructifica de noviembre a enero.

Usos: no se conocen en el área. 


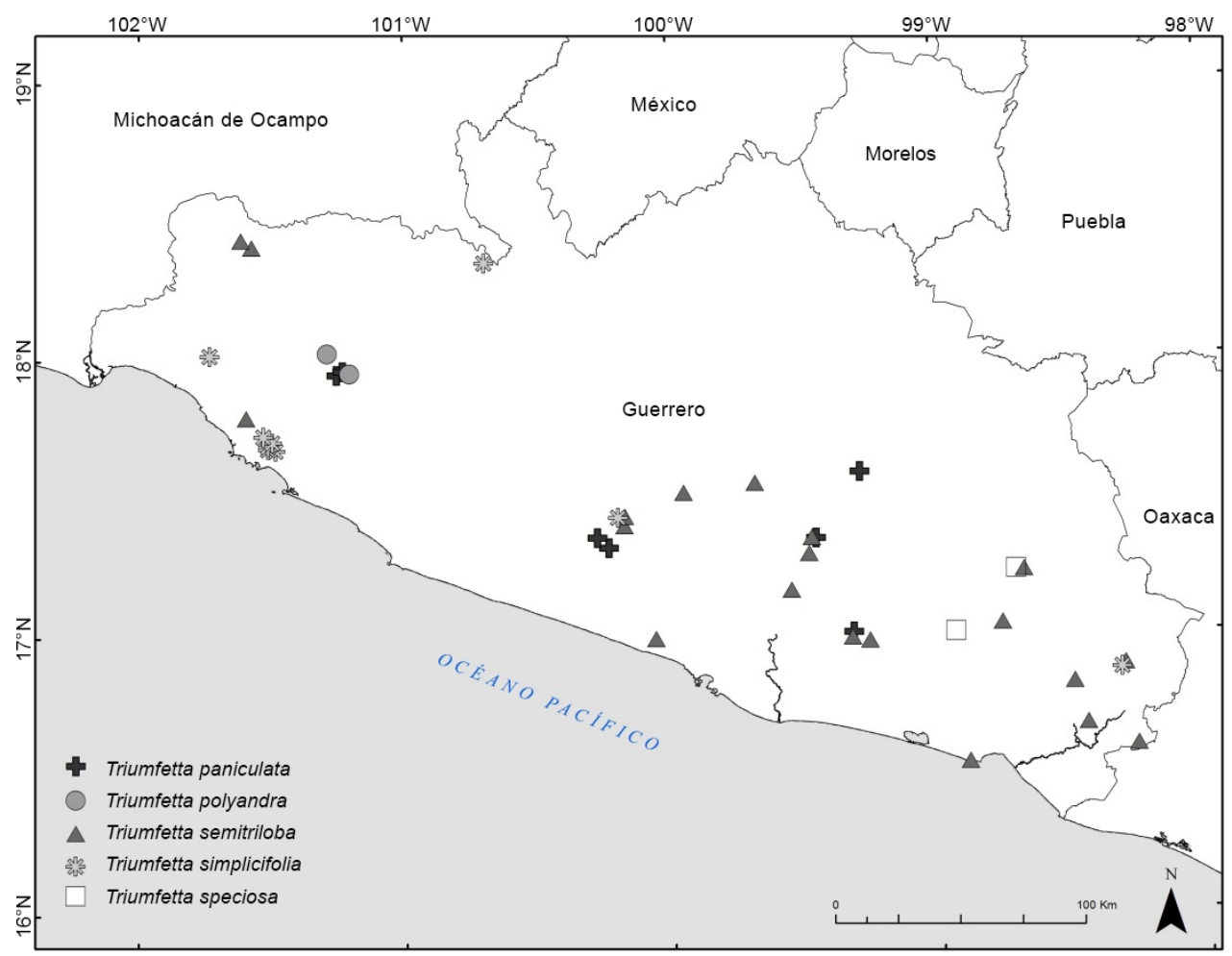

Figura 17: Distribución conocida de Triumfetta paniculata Hook. \& Arn. (\$), T. polyandra Sessé \& Moc. ex DC. (О), T. semitriloba Jacq. (४), T. simplicifolia (Sessé \& Moc.) Fryxell (触) y T. speciosa Seem. ( $\square$ ).

Ejemplares examinados: MÉXICO. Guerrero, municipio Atoyac de Álvarez, $3.5 \mathrm{~km}$ al N de El Cacao, camino hacia El Fortín, G. Campos y V. Valverde 1753 (FCME, MEXU); desviación a Puente del Rey, V. Valverde 157 (ENCB, FCME, MEXU). Municipio Chilpancingo de los Bravo; Acahuizotla, A. Ojendiz y R. Rodríguez 303 (FCME). Municipio Tixtla de Guerrero, La Estacada, El Sotolo, M. Candela 135 (FCME). Municipio Zihuatanejo de Azueta, San Antonio, carretera 134, N. Diego 5584 (FCME); 7 $\mathrm{km}$ al NE de Vallecitos de Zaragoza, L. Lozada 1588 (FCME, MEXU).

Discusión: por su distribución reducida en el estado (cuatro municipios), así como por el impacto en los bosques tropicales en donde habita, derivado entre otras acciones, del incremento de las áreas de cultivo o pastoreo, se le considera como vulnerable (VU).
Triumfetta polyandra Sessé \& Moc. ex DC., In: DC. Prodr. 1: 508. 1824. TIPO: MÉXICO. Icones Florae Mexicanae 347, de Sessé \& Mociño, representado por De Candolle lámina 117 (lectotipo: G-DC), designado por McVaugh, 2000. Fig. 17.

= Triumfetta obovata Schltdl. \& Cham., Linnaea 5: 228. 1830. TIPO: MÉXICO. Veracruz, hacienda de La Laguna C. F. W. Schiede y F. Deppe 460? (holotipo: HALHAL0107646!).

$=$ Triumfetta insignis S. Watson, Proc. Amer. Acad. Arts 22: 400. 1887. TIPO: MÉXICO. Jalisco, río Blanco, $E$. Palmer 152 (holotipo: GH, isotipos: GH-GH00052594!, NDG-NDG30790!, US-US00098447!).

Arbustos, hermafroditas, 0.1-0.8 m de alto; tallos color pardo, con abundantes lenticelas, densamente estrellado-pubescentes, sin corteza exfoliante; hojas con peciolos, 
0.3-0.5 cm de largo, densamente estrellado-pubescentes, con tricomas largos y cortos, estípulas filiformes, 1.3-2.3 $\mathrm{cm}$ de largo, persistentes, láminas equiláteras, simples, obovadas a elípticas, 9-12.5 cm de largo, 4.5-8.5 cm de ancho, ápice agudo, margen irregularmente serrado, base cuneada o cordada, 3-5 nervadas, haz densamente pubescente con tricomas simples y estrellados, envés densamente estrellado-pubescente, haz de consistencia áspera o escabrosa, envés suave; inflorescencias en cimas, terminales o axilares, $7-15 \mathrm{~cm}$ de largo, brácteas elípticas, $1.5-1.7 \mathrm{~cm}$ de largo, $1.3 \mathrm{~cm}$ de ancho, con características semejantes a las hojas; flores con sépalos lanceolados, constreñidos en la parte media, 25-35 $\mathrm{mm}$ de largo, con apéndices, $2 \mathrm{~mm}$ de largo, pétalos espatulados, $30 \mathrm{~mm}$ de largo, ápice redondeado, ocasionalmente 2-denticulados, barbados en la base de ambas superficies, gonóforo 1.5-2 $\mathrm{mm}$ de largo, con glándulas oblongas, anillo $1 \mathrm{~mm}$ de alto, estambres 50-60, filamentos $2.6 \mathrm{~mm}$ de largo; ovario $3 \mathrm{~mm}$ de largo, estilo $3 \mathrm{~mm}$ de largo, estigma bilobado; fruto globoso, 4 lóculos, cuerpo 6-10 mm de diámetro, dehiscente, espinas falcadas, probablemente más de 200, 6-10 mm de largo, plumosas, espínula recta; semillas color pardo oscuro, ovoides, 2.7-3 $\mathrm{mm}$ de largo, 1.8-2 $\mathrm{mm}$ de ancho, 2 por lóculo.

Distribución: especie endémica de México (Chiapas, Guerrero, Jalisco, México, Michoacán, Nayarit, Veracruz).

Tipo de vegetación y altitud: bosque de Quercus y Pinus; 950-1200 m s.n.m.

Fenología: florece y fructifica en noviembre.

Usos: no se conocen en el área.

Ejemplares examinados: MÉXICO. Guerrero, municipio Zihuatanejo de Azueta; $19 \mathrm{~km}$ al NE de Vallecitos de Zaragoza, carretera Zihuatanejo a Ciudad Altamirano, G. Campos 1321 (FCME); El Limoncito, 3 a $4 \mathrm{~km}$ al N del Real de Guadalupe, F. González-Medrano et al. 6563 (MEXU).
Discusión: el material de C.F.W. Schiede y F. Deppe 460 con denotación -?-, en el ejemplar tipo no es claro si corresponde a ese número de colecta o al 489 (mismos colectores). Por su distribución reducida y escasa recolecta en el estado (sólo dos colectas, un municipio), así como por el impacto en los tipos de vegetación que actualmente ocupa (fragmentados y reducidos por la expansión urbana), se le considera como peligro crítico (CR).

Triumfetta semitriloba Jacq., Enum. Syst. P1. 22. 1760. TIPO: WEST INDIES. In Caribaearum fruticetis, $N$. Jacquin s.n., representado por De Candolle lámina 119 (lectotipo: G-DC), designado por McVaugh, 2000. Fig. 17.

Hierbas sufruticosas o arbustos, hermafroditas, 0.5-2 $\mathrm{m}$ de alto; tallos color guinda o rojizo, con abundantes lenticelas, aracnoide-tomentosos, sin corteza exfoliante; hojas con peciolos color guinda, $0.4-3 \mathrm{~cm}$ de largo, láminas equiláteras, ampliamente ovadas, algunas veces lanceoladas o 3-lobadas, 2-7 cm de largo, 0.7-5.5 cm de ancho, ápice acuminado, margen irregularmente serrado, base cuneada o redondeada, suave o aterciopelada, 3-5 nervadas, haz escasamente pubescente con tricomas simples y estrellados, envés densamente estrellado-pubescente, no coriáceas; inflorescencias en cimas, axilares o terminales, $5-12 \mathrm{~cm}$ de largo, brácteas lanceoladas $\mathrm{u}$ ovadas, $2.5-3 \mathrm{~cm}$ de largo, 1-1.5 cm de ancho, con características semejantes a las hojas; flores con sépalos linearlanceolados, constreñidos en la parte media, 6-10 mm de largo, haz glabro, envés estrellado-pubescente, apéndices 0.5-1 mm de largo; pétalos espatulados a elípticos, 6-10 $\mathrm{mm}$ de largo, ápice desigualmente dentado, barbados en la base de ambas superficies; gonóforo $0.5 \mathrm{~mm}$ de largo, con glándulas oblongas, anillo ca. $1 \mathrm{~mm}$ de alto, ciliado; estambres 20, filamentos 3.5-7 mm de largo; ovario 1-2 mm de largo; estilo 2.5-7 mm de largo, estigma 3-lobado; fruto subgloboso, 3 lóculos, cuerpo 4-5 mm de diámetro, estrellado-pubescente, indehiscente, aproximadamente con 50-75 espinas rectas, 2-3 $\mathrm{mm}$ de largo, hialinas, retrorso-pilosas, espínula uncinada; semillas color pardo 
oscuro, piriformes, 2.8-3 $\mathrm{mm}$ de largo, 1.5-2 $\mathrm{mm}$ de ancho, 2 por lóculo.

Distribución: México (Campeche, Chihuahua, Chiapas, Guerrero, Hidalgo, Jalisco, Michoacán, Morelos, Nayarit, Puebla, San Luis Potosí, Sinaloa, Sonora, Tamaulipas, Veracruz, Yucatán), Centroamérica, Antillas y Sudamérica.

Tipo de vegetación y altitud: bosque de Quercus, Pinus, Pinus-Quercus, mesófilo de montaña, así como vegetación secundaria y dunas costeras; 0-1900 m s.n.m.

Fenología: florece y fructifica de noviembre a mayo.

Usos: son variados los usos medicinales que se mencionan para esta planta, destaca como antidiarreico (Nayarit), aunque también se indica para aliviar otros malestares digestivos como bilis, disentería, dolor de estómago, lombrices y tapazón. Asimismo, se refiere útil en casos de cálculos, "resfrío de los ojos" y para realizar lavados vaginales, labor de parto, paludismo y calentura (BDMTM, 2009).

Ejemplares examinados: MÉXICO. Guerrero, municipio Atoyac de Álvarez, $1 \mathrm{~km}$ adelante de Nueva Delhi, carretera Atoyac a Puerto Gallo, R. M. Fonseca 481 (FCME); Nueva Delhi, km 70 Atoyac a Xochipala, Laboratorio de Biogeografía 715 (FCME). Municipio Chilpancingo de los Bravo, $3 \mathrm{~km}$ antes de Agua de Obispo, E. Lazos 32 (FCME); cañada de La Vainilla, 2 km al NO de Rincón de la Vía, C. Verduzco 90 (FCME); Omiltemi, barranca El Retaje, P. Zamora 3468 (FCME). Municipio Coahuayutla de José María Izazaga, El Pantano, J. Calónico 19046 (FCME); El Maguey, J. Calónico 19184 (FCME). Municipio Copala, colonia Juan N. Álvarez, aproximadamente $2 \mathrm{~km}$ al $\mathrm{SE}$, sobre la costa, $R$. Gutiérrez 8 (FCME). Municipio Coyuca de Benítez, Las Ceibas Cuatas, A. Aquino 116 (FCME); Las Lajas, C. Verduzco 494 (FCME). Municipio Cuajinicuilapa, camino a
Huajintepec a $49 \mathrm{~km}$ de la desviación de Cuajinicuilapa, G. Gaxiola 193 (FCME). Municipio General Heliodoro Castillo, cerca de la Hierba Santa, $42 \mathrm{~km}$ al SO de Filo de Caballo, E. Martínez y G. Silva 5798 (MEXU). Municipio Igualapa, río Quetzalapa, $2 \mathrm{~km}$ al SE de San José, G. Campos 1903 (FCME); 6 km de Igualapa, dirección Ometepec, A. Núñez 471 (FCME). Municipio Juan R. Escudero, along highway 95, between kilometer markers Tierra Colorada, J. D. Santos 12383 (FCME). Municipio Malinaltepec, Tilapa, A. Galeana 1081 (FCME); Malinaltepec, I. Wagenbreth 800 (MEXU). Municipio Tecoanapa, Tecoanapa, R. Díaz 11383 (FCME). Municipio Tlacoachistlahuaca, $33 \mathrm{~km}$ al $\mathrm{N}$ de Ometepec, camino de Tlacoachistlahuaca a San Isidro, E. Martínez y F. Barrie 5772 (MEXU). Municipio Xalpatláhuac, $5 \mathrm{~km}$ de Los Saucitos, dirección Xalpatláhuac, A. Núñez 439 (FCME). Municipio Zihuatanejo de Azueta, $0.5 \mathrm{~km}$ al E de El Sandial, A. Díaz et al. 312 (FCME).

Discusión: en cuanto a su categoría de conservación se le considera como preocupación menor (LC), está regularmente representada en Guerrero, pero abunda en otros estados del país.

Triumfetta simplicifolia (Sessé \& Moc.) Fryxell, Diversity \& Taxonomy Trop. Fl. Pl. 187. 1998 = Connarus simplicifolius Sessé \& Moc., Pl. Nov. Hisp. 1: 106. 1889. TIPO: MÉXICO. Guerrero, Chilapa, M. Sessé y M. Mociño 3309 (lectotipo: MA-MA602523!), designado por Fryxell, 1998. Fig. 17.

= Triumfetta hintonii Sprague, Bull. Misc. Inform. Kew 1937: 294. 1937. TIPO: MÉXICO. México, Temascaltepec, cumbre de Tejupilco, G. B. Hinton 7018 (holotipo: K, isotipos: F-F0074010F!, G-G00357180!, K, LL-LL00371841!, MEXU-MEXU00019674!, MOMO-194205!, NY-NY00415579!, US-US00098446!).

Arbustos, hermafroditas, $0.70-2.50 \mathrm{~m}$ de alto; tallos color pardo, con abundantes lenticelas, con tricomas simples y estrellados, hirsuto-pilosos, sin corteza 
exfoliante; hojas con peciolos, 1-6 cm de largo, densamente hirsuto-pilosos, estípulas triangulares, densamente hirsuto-pilosas, láminas equiláteras, ovadas, elípticas en ramas terminales, 3-12 cm de largo, $1.6-6 \mathrm{~cm}$ de ancho, ápice acuminado, margen dentado, base truncada o semicordada, 3-5 nervadas, haz con pubescencia escasa de tricomas bifurcados y estrellados, envés estrelladopubescente; inflorescencias en cimas, axilares, ca. $2 \mathrm{~cm}$ de largo, brácteas ovadas, 1.2-1.4 $\mathrm{cm}$ de largo, $1 \mathrm{~cm}$ de ancho, con características semejantes de las hojas; flores con sépalos elípticos, 10-12 mm de largo, $1 \mathrm{~cm}$ de ancho, no constreñidos en la parte media, con apéndices, $1 \mathrm{~mm}$ de largo; pétalos espatulados, 6-7 mm de largo, ápice redondeado; gonóforo $0.5 \mathrm{~mm}$ de largo, con glándulas esféricas, anillo $0.5 \mathrm{~mm}$ de alto, estambres $15-20$, filamentos $7 \mathrm{~mm}$ de largo, ovario $0.5 \mathrm{~mm}$ de largo; fruto elipsoide, 2 lóculos, cuerpo 3-3.5 mm de diámetro, glabro, indehiscente, aproximadamente con 25 espinas rectas, 1-2 mm de largo, glabras, espínulas rectas; semillas no observadas (ni registradas en literatura).

Distribución: especie endémica de México (Guerrero, Jalisco, México, Michoacán).

Ejemplares examinados: MÉXICO. Guerrero, municipio Atoyac de Álvarez, Nueva Delhi km 70 Atoyac a Xochipala, Laboratorio de Biogeografia 693 (FCME). Municipio Pungarabato, poblado Ciudad Altamirano, $N$. Diego et al. 5607 (FCME). Municipio Tlacoachistlahuaca, $7 \mathrm{~km}$ de Las Minas a Tierra Blanca, N. Diego 2342 (FCME). Municipio La Unión de Isidoro Montes de Oca, $9 \mathrm{~km}$ al N de La Unión, J. C. Soto et al. 6000 (MEXU, FCME). Municipio Zihuatanejo de Azueta, Cerro Bolonche, situado al E del mirador del Parque Ecológico La Vainilla, C. Gallardo et al. 206 (FCME, MEXU); 250 $\mathrm{m}$ al NO del caserío La Vainilla, C. Gallardo et al. 347 (FCME); $1.5 \mathrm{~km}$ al $\mathrm{S}$ del caserío La Vainilla, por la cañada, C. Gallardo et al. 673 (FCME); 4 km de Zihuatanejo, camino a La Vainilla, Costa Grande, M. Gual 435 (FCME); carretera Ciudad Altamirano desviación a La Vainilla, Costa Grande, M. Gual 458 (FCME).
Tipo de vegetación y altitud: bosque tropical subcaducifolio y caducifolio, de galería, mesófilo de montaña, y vegetación secundaria; 70-1400 m s.n.m.

Fenología: florece y fructifica en los meses de octubre a febrero.

Usos: no se conocen en el área.

Discusión: por su distribución reducida (cinco municipios), así como por el impacto en los bosques tropicales en donde habita, derivado entre otras acciones, del incremento de las áreas de cultivo o pastoreo, se le considera como vulnerable (VU).

Triumfetta speciosa Seem., Bot. Voy. Herald, 86. 1853. TIPO: PANAMÁ. Volcano of Chiriquí, near the Hacienda de Boquete, B. C. Seeman 1240 (holotipo: K-K000381758!, isotipo: BR-BR0000005421831!).

Fig. 17.

$=$ Triumfetta macrocalyx Turcz., Bull. Soc. Imp. Naturalistes Moscou 31(1): 230. 1858. TIPO: MÉXICO. Veracruz, Mirador, s.f., J. J. Linden 25 (holotipo: G-G00357276!, isotipo: BR-BR0000005421831!).

= Triumfetta micropetala Hochr., Annuaire Conserv. Jard. Bot. Genève 18: 98. 1914. TIPO: MÉXICO. Veracruz, Mirador, s.f., J .J. Linden 25 (holotipo: G-G00357276!, isotipo: BR-BR0000005421831!).

Árboles o arbustos, hermafroditas, 4-6 m de alto; tallos color pardo oscuro, con abundantes lenticelas, estrellado-ferrugíneos o glabrescentes, sin corteza exfoliante; hojas con peciolos, 0.5-7 cm de largo, estrellado-ferrugíneos, estípulas 1.8-2 mm de largo, con tricomas simples, no persistentes, láminas equiláteras, 3-lobadas, transversalmente oblongas o ampliamente ovadas, $3.5-15.5 \mathrm{~cm}$ de largo, 2.5-12.5 cm de ancho, ápice central largo acuminado, los laterales corto acuminados, margen biserrado, base cordada, semicordada, ocasionalmente obtusa, aterciopelada, 5-7 nervadas, haz con escasos tricomas estre- 
llados, envés con tricomas estrellados de brazos largos y blanquecinos; inflorescencias en cimas terminales, 6.5-14 $\mathrm{cm}$ de largo, brácteas elípticas a lanceoladas, $3-5 \mathrm{~cm}$ de largo, con características semejantes a las hojas, aproximadamente los últimos 8 pares de dientes basales glandulares; flores con sépalos lanceolados o linear-lanceolados, 25-30 mm de largo, no constreñidos en la parte media, haz con tricomas simples, envés estrellado-pubescente, apéndices 1.9-2 mm de largo, pétalos estrechamente elípticos u oblícuos, 4.8-5 mm de largo, ápice asimétrico, densamente barbado en la base de ambas superficies, gonóforo $1 \mathrm{~mm}$ de largo, con glándulas esféricas, anillo $1 \mathrm{~mm}$ de alto, ciliado; estambres 18-20, filamentos $30 \mathrm{~mm}$ de largo, ovario $1 \mathrm{~mm}$ de largo, estilo $2.5 \mathrm{~cm}$ de largo, estigma 5-lobado; fruto color pardo oscuro, globoso, 4 lóculos, cuerpo 6-8 $\mathrm{mm}$ de diámetro, densamente pubescente, indehiscente, aproximadamente 100 espinas, falcadas, 3-4 $\mathrm{mm}$ de largo, plumosas, hialinas, espínulas rectas; semillas no vistas (ni registradas en literatura).

Distribución: México (Chiapas, Guerrero, Jalisco, Veracruz) y Centroamérica.

Tipo de vegetación y altitud: bosque de Quercus; 1500-1800 m s.n.m.

Fenología: florece y fructifica en los meses de enero y junio.

Usos: no se conocen en el área.

Ejemplares examinados: MÉXICO. Guerrero, municipio Acatepec, Tres Cruces, $20 \mathrm{~km}$ al E de Ayutla de 10 s Libres, C. Gallardo 15 (FCME). Municipio Malinaltepec, Malinaltepec, I. Wagenbreth 805 (MEXU).

Discusión: esta especie se cita por primera vez para Guerrero; es una planta escasa en el estado (solo registrada en dos municipios); en cuanto a su categoría de conservación se le ubica como peligro crítico (CR). El tipo de vegetación que actualmente ocupa está siendo fragmenta- do y reducido, entre otras acciones, por la expansión urbana y el incremento de las áreas de cultivo o pastoreo; desafortunadamente, no se cuenta con información que permita evaluar el grado de impacto en las poblaciones de esta especie y sobre otras con las que comparte el hábitat.

\section{Subfamilia Tilioideae Arn., Botany 100. 1832. (como Tilieae).}

Árboles, hermafroditas, con pubescencia de tricomas simples, o estrellados; hojas alternas, simples, pecioladas, estípulas deciduas, láminas frecuentemente enteras, ápice acuminado o agudo, margen serrado o dentado, base cordada, obtusa, ocasionalmente oblicua, suaves a papiraceas, palmatinervadas, con tricomas simples y estrellados; inflorescencias en cimas, algunas veces en dicasios raramente reducidas a flores solitarias, axilares, terminales u opuestas a las hojas (axilares), brácteas adnadas o no al pedúnculo; flores actinomorfas, hermafroditas, pediceladas, cáliz con 5 sépalos, con tricomas estrellados; corola con 5 pétalos, usualmente color amarillo, blanco o verdoso, libres, generalmente glabros; estambres numerosos, presencia de estaminodios petaloides, libres, anteras dorsifijas, dehiscencia longitudinal; gineceo sincárpico, 5-carpelar, ovario súpero, a veces globoso o lobulado, 5-locular, con tricomas simples y estrellados, placentacion axial, óvulos 2-locular, estilo simple, estigma 5-lobado; frutos indehiscentes tipo nuez, densamente pubescente; semillas 1 o 2 por lóculo, obovoides, ovoides, o piriformes, sin cilios.

Tilia L., Sp. Pl. 1: 514. 1753.

\section{TIPO: Tilia europaea L.}

Árboles; tallos con tricomas simples y estrellados, glabrescentes; hojas con láminas ovadas, oblongolanceoladas o elípticas, ápice acuminado, 5-nervadas, papiráceas; inflorescencias en cimas, terminales o axilares, bráctea foliácea adnada al pedúnculo, oblonga, membranácea; flores; cáliz con sépalos, ovados, ligeramente cuculados en botón, acuminados, corola con pétalos, co- 
lor blanco o amarillo, glabros; estaminodios 5; frutos con pedicelos estrellado-pubescentes; semillas color negro o pardo oscuro.

Único género de la familia que presenta distribución en zonas templadas de América y Europa, aunque también se le ha citado en zonas subtropicales de Asia, presenta de 40 a 70 especies (Brizicky, 1965; Cronquist, 1981; Mabberley, 1987). En México se han reportado dos especies, una introducida de Europa; en Guerrero se registra la nativa. El origen del nombre genérico Tilia proviene del griego ptilon=ala, haciendo referencia a la bráctea foliácea que acompaña a la inflorescencia (Brizicky, 1965).

Género de importancia económica, fuera de México se emplea como ornamental; su madera se utiliza en la construcción, elaboración de muebles y para la elaboración de pulpa para papel, además, las fibras de la corteza se usan en la manufactura de cordones; la corteza, hojas y flores son de uso medicinal, como calmantes y para combatir el reumatismo (Standley, 1923; Brizicky, 1965; Rendle, 1971; Mabberley, 1987). En México, las hojas y flores se utilizan para aliviar los cólicos menstruales y como tranquilizante de alteraciones nerviosas (Aguilar et al., 1994), como cicatrizante, digestivo, para la cura del reumatismo y de la tos (USDA, 2017).

Tilia americana var. mexicana (Schltdl.) Hardin, Syst. Bot. 15(1): 45. 1990 三 Tilia mexicana Schltdl., Linnaea 11: 377. 1837. TIPO: MÉXICO. Veracruz, Cuesta Grande de Chiconquiaco, C. J. W. Schiede s.n. (sintipo: HAL-HAL0042250!; isosintipos: BMBM000795128!, GOET-GOET011226!). Figs. 18, 19.

$=$ Tilia houghii Rose, Contr. U.S. Natl. Herb. 8: 318. 1905. TIPO: MÉXICO. Morelos, above Cuernavaca, J. N. Rose y W. Hought 4398 (holotipo: US-US00098387!).

= Tilia mexicana var. occidentalis V. Engl., Monogr. Gatt. Tilia 125. 1909.

= Tilia nelsoni Bush, Amer. Midl. Naturalist 11: 553. 1929. TIPO: MÉXICO. Guerrero, Canon at Omiltemi, E. Nelson 7044 (isotipo: GH-GH00052519!).

= Tilia occidentalis Rose, Contr. U.S. Natl. Herb. 8:
317. 1905. TIPO: MÉXICO. Michoacán, Pátzcuaro, $C$. G. Pringle 4126 (holotipo: US-US00098390!, isotipos: A-A00052520!, GH-GH00052521!, UC-UC18666!).

Árboles, 5-22 m de alto; tallos estrellado-pubescentes, glabrescentes; hojas con peciolos, 2-5 cm de largo, densamente estrellado-pubescentes, láminas demediadas, 6-25 cm de largo, 3.5-15 cm de ancho, haz glabro o esparcidamente estrellado-pubescente, envés densamente estrellado-pubescente; inflorescencia, 8-17 cm de largo, pedúnculos 4-8.5 cm de largo, pedúnculo y bráctea densamente estrellado-pubescentes; flores $6.5-18 \mathrm{~mm}$ de diámetro, pedicelos 5-12 $\mathrm{mm}$ de largo, densamente estrellado-pubescentes, sépalos 4-18 $\mathrm{mm}$ de largo, 3-5 $\mathrm{mm}$ de ancho, margen entero, haz con tricomas simples y estrellados, envés cortamente estrellado-pubescente; pétalos espatulados, obovados u ovados, 4-9 mm de largo, 2-4 $\mathrm{mm}$ de ancho, ápice redondeado, margen entero; estambres connados formando 10-15 falanges, filamentos filiformes, 2.5-5 mm de largo, bifurcados en el ápice, cada bifurcación portando 1 teca, estaminodios espatulados, 3-6 mm de largo, 1.5-2.5 mm de ancho, ápice redondeado, intercalados entre 2-3 fascículos; ovario 1.5-2 mm de largo y ancho, lobulado, estilo rollizo, 1.5-7 mm de largo; frutos 5-10 mm de largo y ancho, semillas color pardo oscuro, 5-8 $\mathrm{mm}$ de largo, 3-4 $\mathrm{mm}$ de ancho.

Distribución: variedad endémica de México (Chihuahua, Coahuila, Durango, Guerrero, Hidalgo, Jalisco, México, Michoacán, Morelos, Nuevo León, Oaxaca, Querétaro, Puebla, San Luis Potosí, Sinaloa, Tamaulipas, Veracruz).

Tipo de vegetación y altitud: bosque de Abies, Quercus, Pinus-Quercus y mesófilo de montaña; 20002500 m s.n.m.

Fenología: florece y fructifica de marzo a mayo y en julio.

Nombres comunes: simano, sirimo, tilo. 


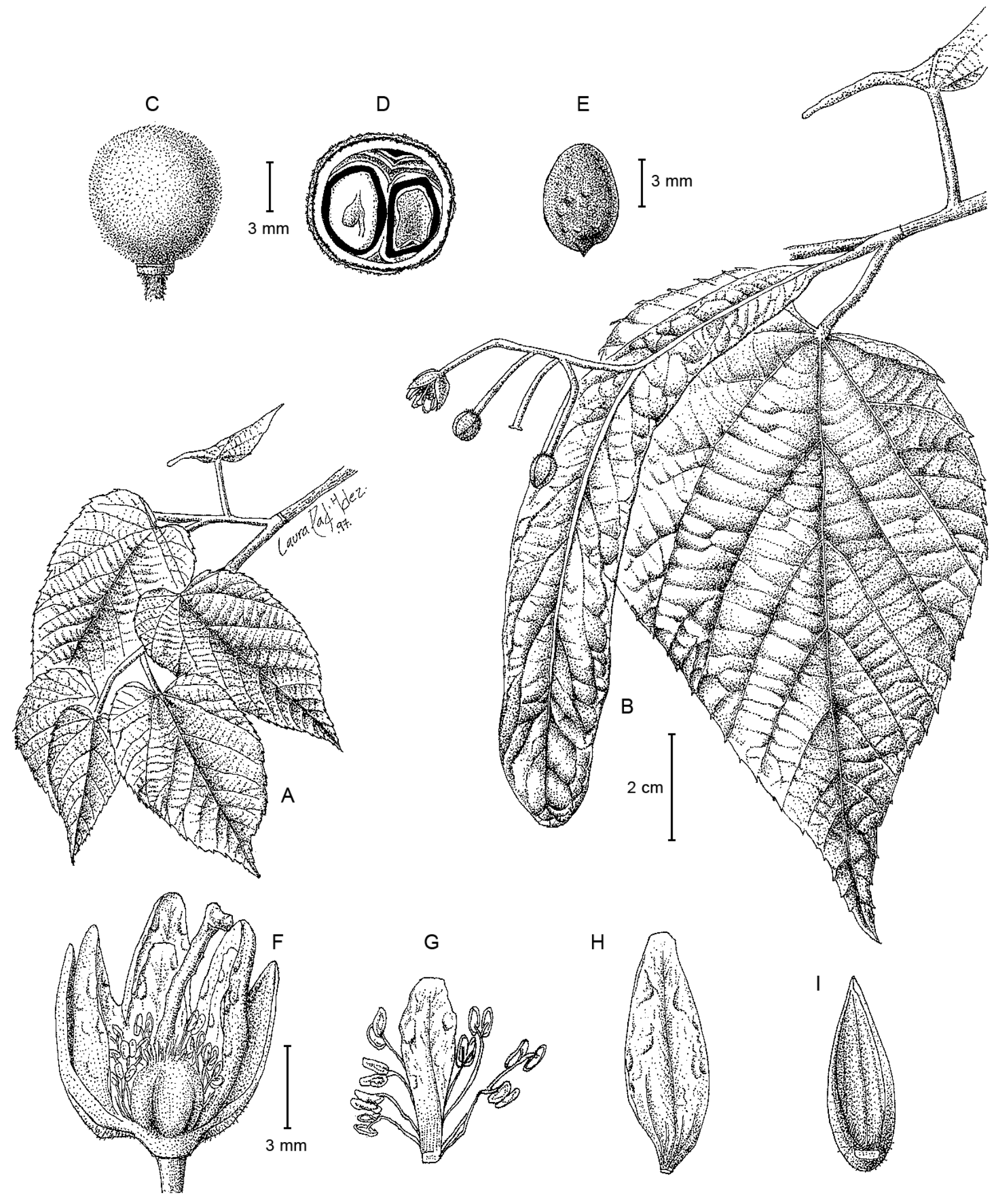

Figura 18: Tilia americana var. mexicana (Schltdl.) Hardin A. rama; B. rama con hojas, inflorescencia y bráctea foliácea adnada al pedúnculo; C. fruto; D. corte transversal de fruto; E. semilla; F. detalle de la flor mostrando los estambres y el gineceo; G. estambres y estaminodios petaloides; H. pétalo; I. sépalo. Basados A y B en M. Gual 660 (FCME); C, D, E, F, G, H e I en F. Lorea 2018 (FCME). 


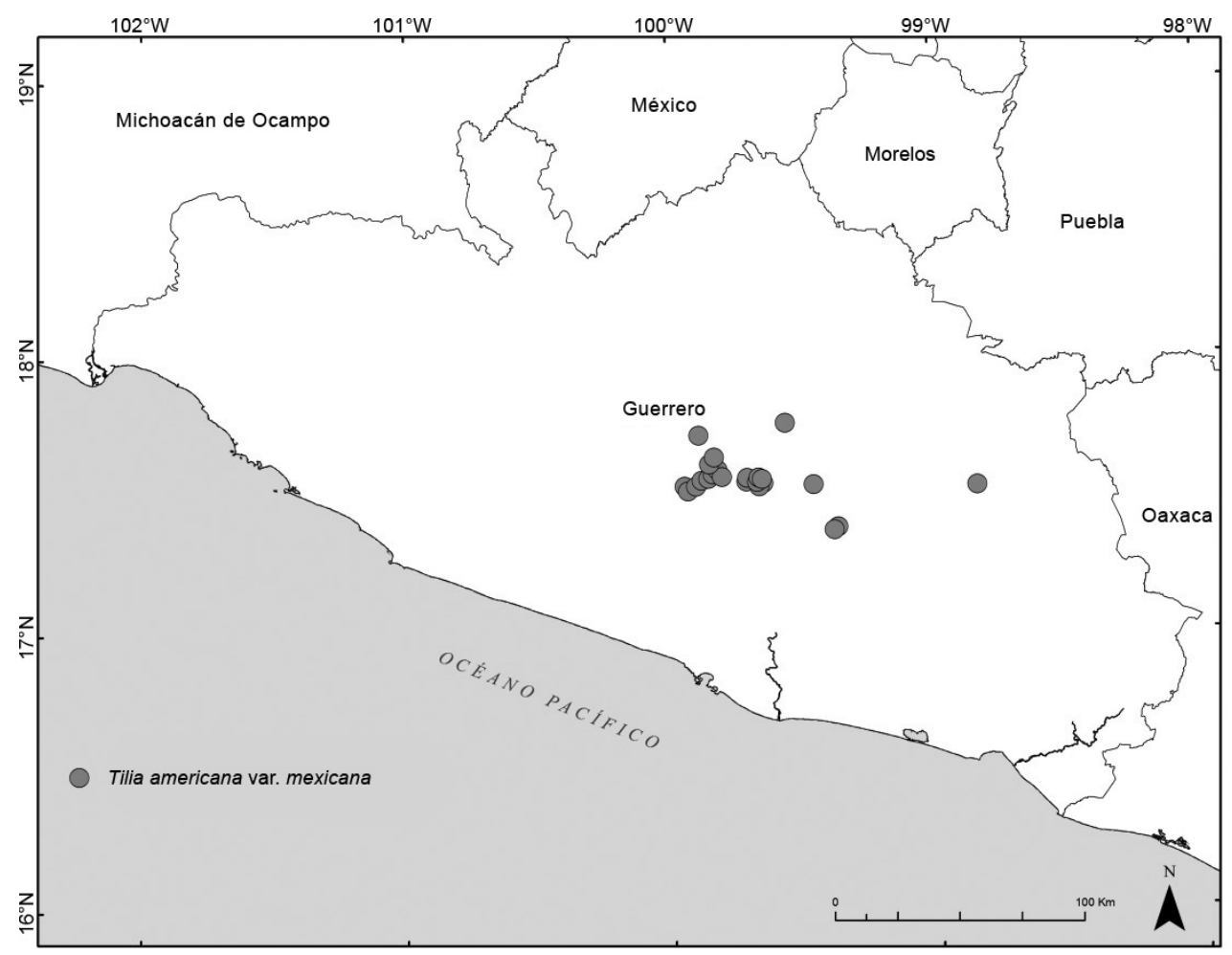

Figura 19: Distribución conocida de Tilia americana var. mexicana (Schltdl.) Hardin (O).

Usos: en Guerrero la infusión de la corteza se utiliza para los riñones. En Michoacán, este árbol es muy apreciado por su madera suave, por lo que se utiliza para la realización de artesanías como bateas, guitarras, máscaras y utensilios de cocina; también se usa como planta curativa por sus propiedades tranquilizantes, para aliviar la tos por sus propiedades antiespasmódicas, y para el tratamiento de la enterocolitis, gastroenteritis, hemorroides, cólicos hepáticos y nefríticos, dolores de la vejiga inflamada y el corazón.

Ejemplares examinados: MÉXICO. Guerrero, municipio Atlixtac, $2.5 \mathrm{~km}$ al SO de Tlatlauquitepec, $F$. Lorea 2018 (FCME, IEB). Municipio Chilpancingo de los Bravo, along road from Chilpancingo west toward Omiltemi, through limestone mountains 14 miles west of Chilpancingo, W. R. Anderson y C. Anderson 4943 (ENCB); al SE de Omiltemi, camino a El Cedral, $R$. Antonio 250 (FCME); $2 \mathrm{~km}$ al E de Omiltemi, cañada de
Potrerillos sobre el río que viene de Agua Fría, $R$. Antonio 305 (FCME); Omiltemi, barranca Potrerillos, $C$. González 383 (FCME); cañada La Perra, Omiltemi, $M$. Gual 660 (ENCB, FCME, IEB, MEXU); $3 \mathrm{~km}$ al E de Omiltemi, E. Martínez y O. Téllez 511 (ENCB, FCME, IEB, MEXU); Omiltemi, A. May-Nah 759 (ENCB); Omiltemi, barranca Agua Fría, A. Méndez 412 (FCME); $2 \mathrm{~km}$ al E de Omiltemi, sobre camino a Chilpancingo, J. Rzedowski 16054 (ENCB); near Olmitemi, S. Sharp 44153 (MEXU); Omiltemi, M. A. Soto-Arenas 1259 (FCME); Omiltemi, barranca Agua Fría, S. Valencia 412 (FCME). Municipio Eduardo Neri, carretera Milpillas a Chilpancingo, 3 a $4 \mathrm{~km}$ adelante de Milpillas, $\mathrm{A}$. Carrillo 117 (FCME, IEB). Municipio General Heliodoro Castillo, Verde Rico, $2.3 \mathrm{~km}$ al N camino a La Ciénega, R. Cruz 3071 (FCME), 3950 (FCME). Municipio Leonardo Bravo, $21 \mathrm{~km}$ después de Carrizal de Bravo sobre la carretera Filo de Caballo a Atoyac, J. L. Contreras y L. Lorenzo 1111 (FCME); Filo de Caballo, $3 \mathrm{~km}$ al SO, $B$. 
González 1843 (FCME); Carrizal de Bravo, $3 \mathrm{~km}$ al SE de Puerto Pichones, M. Gual 660 (FCME); La Pastora, km 181 de Atoyac a Xochipala, Laboratorio de Biogeografia 319 (FCME); Puerto Pichones, aproximadamente $3 \mathrm{~km}$ de El Carrizal de Bravos, carretera Filo de Caballo a Chilpancingo, A. R. López-Ferrari 73 (FCME); Puerto Pichones, 4.VI.1980, F. Lorea et al. s.n. (FCME); aproximadamente a $3 \mathrm{~km}$ al NE de Cruz de Ocote, $F$. Lorea 3488 (FCME); $3.5 \mathrm{~km}$ al SO de Filo de Caballo, E. Martínez et al. 3907 (ENCB, MEXU); $15 \mathrm{~km}$ al SO de Carrizalillo, camino a Puerto de El Gallo, E. Martínez et al. 3935 (ENCB); Carrizal de Bravo, $1.5 \mathrm{~km}$ al S, $T$. Reyes et al. 72 (FCME); $5 \mathrm{~km}$ al O de Camotla, J. Rzedowski 16414 (ENCB, MEXU); Puerto Chico, $10 \mathrm{~km}$ al O de Camotla, J. Rzedowski 18514 (ENCB, MEXU); 6 $\mathrm{km}$ al NE de Cruz de Ocote, E. Velázquez 222 (ENCB, FCME). Municipio Mochitlán, cerro Tepila, $5 \mathrm{~km}$ al $\mathrm{O}$ de Coaxtlahuacán, A. Núñez 859 (FCME); Coaxtlahuacán, dirección a El Salado, por camino de herradura, $A$. Núñez 1130 (FCME).

Discusión: en cuanto a su categoría de conservación esta especie esta catalogada por la NOM-ECOL-059-2001 y la NOM-059-SEMARNAT-2010 como peligro de extinción. En el estado está ampliamente representada, siendo un elemento típico del bosque mesófilo de montaña, aunque se le ha reportado también en otros bosques templados de México. Los tipos de vegetación que actualmente ocupa están siendo fragmentados y reducidos entre otras acciones, por la expansión urbana y el incremento de las áreas de cultivo o pastoreo. Desafortunadamente, no se cuenta con información que permita evaluar el grado de impacto en las poblaciones de esta especie y sobre otras con las que comparte el hábitat.

\section{CONTRIBUCIONES DE AUTORES}

MGD y NDP concibieron y desarrollaron el trabajo. MGD realizó la diagnósis, el análisis y la adquisición de los ejemplares de herbario. Ambas escribieron el manuscrito y contribuyeron a la discusión, revisión y aprobación del manuscrito final.

\section{FINANCIAMIENTO}

La Facultad de Ciencias (UNAM) financió el inicio del proyecto.

\section{AgRADECIMIENTOS}

Por las recomendaciones y sugerencias de dos revisores reconocidos a nivel nacional e internacional que mejoraron el manuscrito en gran medida; así mismo se agradece a Edgar Saavedra Cárdenas por la elaboración y digitalización de los mapas, a Fernanda D. Dorantes Hernández, Lorena Noemí Alamilla Fonseca y Sebastián Mejía Valencia por el refuerzo en diversos aspectos de la versión final de este trabajo; de igual manera a Laura Padilla por la elaboración profesional de las ilustraciones que acompañan al manuscrito. Con admiración y respeto para todos los pueblos del estado de Guerrero.

\section{LITERATURA CITADA}

Aguilar,A., J.R.Camacho, S.Chino, P. Jácquezy M.E.López. 1994. Heliocarpus. Herbario Medicinal del Instituto Mexicano del Seguro Social. Información Etnobotánica. Instituto Mexicano del Seguro Social. México, D.F., México. 218 pp. Alverson, W. S., B. A. Whitlock, R. Nyffeler, C. Bayer y D. A. Baum. 1999. Phylogeny of the core Malvales: evidence from NDHF sequence data. American Journal of Botany 86(10): 1474-1486.

APG II. 2003. An update of the Angiosperm Phylogeny Group classification for the orders and families of flowering plants: APG II. Botanical Journal of the Linnean Society 141(4): 399-436. DOI: http://dx.doi. org/10.1046/j.1095-8339.2003.t01-1-00158.x

APG IV. 2016. An update of the Angiosperm Phylogeny Group classification for the orders and families of flowering plants: APG IV. Botanical Journal of the Linnean Society 181(1): 1-20. DOI: https://doi.org/10.1111/boj.12385

BDMTM. 2009. Atlas de las plantas de la medicina tradicional mexicana. Biblioteca Digital de la Medicina Tradicional Mexicana. Universidad Nacional Autónoma de México. México, D.F., México. http://www. medicinatradicionalmexicana.unam.mx/index.php (consultado diciembre de 2009). 
Bhandari, M. M. 1978. Flora of the Indian Desert. Editorial Pawan Kumar Sharma. Udaipur, India. 471 pp.

Bornstein, A. J. 1989. Tiliaceae. In: Howard, R. A. (ed.). Flora of the Lesser Antilles, Dicotyledoneae 5(2): 191.

Brizicky, G. K. 1965. The genera of Tiliaceae and Elaeocarpaceae in the southeastern United States. Journal of the Arnold Arboretum 46(3): 286-307.

CITES. 2013. Convención sobre el Comercio Internacional de Especies Amenazadas de Fauna y Flora Silvestres. Suiza. http://www.cites.org (consultado mayo de 2013).

Cheek, M. R. 2007. Malvaceae. In: Heywood, V. H., R. K. Brummitt, A. Culham y O. Seberg (eds.). Flowering Plant Families of the World. Royal Botanic Gardens Kew. Kew, UK. Pp. 201-202.

Colmenero, R. A., M. Gual-Díaz y R. Fernández-Nava. 2010. El género Corchorus (Tiliaceae) en México. Polibotánica 29: 29-65.

Cronquist, A. 1981. Tiliaceae. In: Cronquist, A. (ed.). An integrated system of classification of flowering plants. Columbia University Press. New York, USA. Pp. 350352.

Diego, P, N., G. S. Peralta y B. Ludlow-Wiechers. 2001. El Jilguero: bosque mesófilo de montaña. In: Diego-Pérez, N. y R. M. Fonseca (eds.). Estudios Florísticos en Guerrero, No. 11. Las Prensas de Ciencias. Facultad de Ciencias, Universidad Nacional Autónoma de México. México, D.F., México. 42 pp.

Dorr, L. J. 1992. The identity of Riddelia Raf. and remarks on Corchorus L. (Tiliaceae). Taxon 41(1): 80-83. DOI: http://dx.doi.org/10.2307/1222494

Dorr, L. J. 2011. Trichospermum lessertianum comb. n., the correct name for the Cuban species of Trichospermum (Malvaceae, Grewioideae) also found in Mexico and Central America. PhytoKeys 2: 17-22. DOI: http://dx.doi. org/10.3897/phytokeys.2.731

Fawcett, W. y A. B. Rendle (eds.). 1926. Flora of Jamaica: Dicotyledons Vol. 5. British Museum. London, UK. p. 88.

Fonseca, R. M., M. E. Velázquez y E. Domínguez. 2001. Carrizal de Bravos: bosque mesófilo de montaña. In: Diego-Pérez, N. y R. M. Fonseca (eds.). Estudios Florísticos en Guerrero, No. 12. Las Prensas de Ciencias.
Facultad de Ciencias, Universidad Nacional Autónoma de México. México, D.F., México. 41 pp.

Fryxell, P. A. 1998. A synopsis of the neotropical species of Triumfetta (Tiliaceae). In: Mathew, P. y M. Sivadasan (eds.). Diversity and taxonomy of tropical flowering plants. Mentor Books. Calicut, India. Pp. 167-192.

Fryxell, P. A. 2001. Tiliaceae. Flora Novo-Galiciana 3: 68-109. García, E. 1988. Modificaciones al sistema de clasificación climática de Köppen. Serie libros No. 6. Instituto de Geografía, Universidad Nacional Autónoma de México. México, D.F., México. 90 pp.

González, C. V. 1989. Malaspina en Acapulco. Turner Libros, S.A. Madrid, España. 217 pp.

González-Espinosa, M., J. A. Meave, F. G. Lorea-Hernández, G. Ibarra-Manríquez y A. C. Newton. 2011. The Red List Of Mexican Cloud Forest Trees. Fauna and Flora Internacional (FFI). Cambridge, UK. 150 pp.

Good, R. 1974. The geography of the flowering plants. 4th ed. Longmans. London, UK. 574 pp.

Gual-Díaz, M. 1998. La familia Tiliaceae Juss., en el estado de Guerrero, México. Tesis de maestría (Biología Vegetal). Facultad de Ciencias, Universidad Nacional Autónoma de México. México, D.F., México. 170 pp.

Gual-Díaz, M. 2011. Tiliaceae Juss. In: García-Mendoza, A. y J. A. Meave (eds.). Diversidad florística de Oaxaca: de musgos a angiospermas. Instituto de Biología, Universidad Nacional Autónoma de México-Comisión Nacional para el Conocimiento y Uso de la Biodiversidad. México, D.F., México. Pp. 297-298.

Gual-Díaz, M. y G. E. Moreno. 2009. Especie nueva de Heliocarpus (Tiliaceae), de la depresión del Balsas, Guerrero, México. Revista Mexicana de Biodiversidad 80(2): 283-286.

Gual-Díaz, M., G. S. Peralta y P. N. Diego. 2001. Una especie nueva de Triumfetta (Tiliaceae) del estado de Guerrero, México. Acta Botanica Mexicana 56: 13-18. DOI: http:// dx.doi.org/10.2189/abm56.2001.878

Gual-Díaz, M., N. Diego P. y O. Téllez V. 2008. Nuevo registro de Corchorus capsularis (Tiliaceae) para la flora de México. Boletín de la Sociedad Botánica de México 83: 89-91. 
Hardin, J. W. 1990. Variation patterns and recognition of varieties of Tilia americana s.1. Systematic Botany 15(1): 33-48. DOI: http://dx.doi.org/10.2307/2419014

Heywood, V. H. 1993. Tiliaceae. In: Heywood, V. H. Flowering plants of the world. Oxford University Press. New York, USA. Pp. 90-91.

Hochreutiner, B. P. G. 1914. Notes sur les Tiliacées, avec descriptions de'espéces, de sections et de sous-familles nouvelles ou peu connues. Annuaire du Conservatoire et du Jardin Botanique de Genève 18: 68-128.

INEGI. 2016. Anuario estadístico y geográfico de Guerrero 2016. Instituto Nacional de Estadística y Geografía. Aguascalientes, México. http:/www.datatur.sectur. gob.mx/ITxEF_Docs/GRO_ANUARIO_PDF16.pdf (consultado enero de 2017).

IUCN. 2010. The IUCN Red List Threatened Species, version 2015.4. The International Union for Conservation of Nature. Red List Unit. Cambridge, UK. http://www. iucnredlist.org/ (consultado junio de 2010).

Jansen-Jacobs, M. J. y W. Meijer. 1995. Tiliaceae. Flora of the Guianas, Series A: Phanerogams 17: 5-49.

JSTOR. 2017. JSTOR. Global Plants. http://plants.jstor.org/ (consultado mayo de 2017).

Kostermans, A. J. G. H. 1962. The genera Belotia Rich. and Trichospermum B1. (Tiliaceae). Reinwardtia 6(3): 277279.

Lay, K. K. 1949. A revision of the genus Heliocarpus L. Annals of the Missouri Botanical Garden 36(2): 507-541. DOI: http://dx.doi.org/10.2307/2394471

Lay, K. K. 1950. The American species of Triumfetta L. Annals of the Missouri Botanical Garden 37(3): 315-395. DOI: http://dx.doi.org/10.2307/2394513

Mabberley, D. J. 1987. The plant-book. A portable dictionary of the higher plants. Cambridge University Press. Cambridge, UK. 706 pp.

McVaugh, R. 2000. Botanical Results of the Sessé \& Mociño expedition (1787-1803), VII, A guide to relevant scientific name of plants. Hunt Institute for Botanical Documentation. Pittsburg, USA. Pp. 526-528.

Meijer, W. 2001. Tiliaceae. In: Stevens, D. W., C. Ulloa Ulloa, A. Pool y O. M. Montiel (eds.). Flora de Nicaragua III.
Monographs in Systematic Botany from the Missouri Botanical Garden 85(3): 2452-2468.

Meza, L. y J. López. 1997. Vegetación y mesoclima de Guerrero. In: Diego, N. y R. M. Fonseca (eds.). Estudios florísticos en Guerrero. Facultad de Ciencias, Universidad Nacional Autónoma de México. México D.F., México. 54 pp.

Pennington, T. D. y J. Sarukhán. 1968. Tiliaceae. In: Pennington, T. D. y J. Sarukhán (eds.) Árboles tropicales de México. Manual para la identificación de campo de los diferentes árboles tropicales de México. Organización de las Naciones Unidas para la Agricultura y la Alimentación. México, D.F., México. Pp. 346-363.

Pennington, T. D. y J. Sarukhán. 2012. Tiliaceae. In: Pennington, T. D. y J. Sarukhán (eds.) Árboles tropicales de México. Manual para la identificación de campo de los diferentes árboles tropicales de México. Universidad Nacional Autónoma de México; Fondo de Cultura Económica. México, D.F., México. 346 pp.

Peralta, G. S., N. Diego y M. Gual-Díaz. 2000. La Costa Grande de Guerrero. Listados florísticos de México No. XIX. Instituto de Biología, Universidad Nacional Autónoma de México. México, D.F., México. 44 pp.

Pérez-Calix, E. 2009. Tiliaceae. Flora del Bajío y de regiones adyacentes 160: 1-38.

Peters, C. H., J. Rosenthal y T. Urbina. 1987. Otomi bark paper in Mexico: Commercialization of a prehispanic technology. Economic Botany 41(3): 423-432.

Ramos, C. H. 2015. Tiliaceae Juss. Flora del Valle de TehuacánCuicatlán 127: 1-19.

Rendle, A. B. 1971. The classification of flowering plants. Vol. II. Dicotyledons. Cambridge University Press. New York, USA. 429 pp.

Robyns, A. 1964. Tiliaceae. Flora of Panama, part VI, family 114. Annals of the Missouri Botanical Garden 51(1-4): 1-35. DOI: http://dx.doi.org/10.2307/2394900

Rose, J. N. 1897. A synopsis of the species of Heliocarpus. Contributions from the United States National Herbarium 5(3): 125-129.

Rose, J. N. 1905. Notes in Heliocarpus with new species. Contributions from the United States National Herbarium 8(4): 315-317. 
Rzedowski, J. 1978. Vegetación de México. Editorial Limusa. México, D.F., México. 432 pp.

SEMARNAT. 2001. Norma Oficial Mexicana NOM-059SEMARNAT-2001, Protección ambiental-Especies nativas de México de flora y fauna silvestres-Categorías de riesgo y especificaciones para su inclusión, exclusión o cambio-Lista de especies en riesgo. Secretaría del Medio Ambiente y Recursos Naturales. Diario Oficial de la Federación. Cd. Mx., México. 85 pp.

SEMARNAT. 2010. Norma Oficial Mexicana NOM-059SEMARNAT-2010, Protección ambiental-Especies nativas de México de flora y fauna silvestres-Categorías de riesgo y especificaciones para su inclusión, exclusión o cambio-Lista de especies en riesgo. Secretaría del Medio Ambiente y Recursos Naturales. Diario Oficial de la Federación. Cd. Mx., México. 78 pp.

Sessé, M. y J. M. Mociño. 1893. Plantae Novae Hispaniaea. Edition Secunda. Oficina Tipográfica de la Secretaría de Fomento. México. Home Page, http://www. biodiversitylibrary.org/item/120055\#page/1/mode/1up (consultado junio de 2017).

SPP. 1981. Carta Edafológica 1: 1,000,000. Hojas México y Guadalajara. Secretaría de Programación y Presupuesto. México.

Standley, P. C. 1923. Tiliaceae. Trees and shrubs of Mexico. Contributions from the United States National Herbarium 23(3): 734-746.
Standley, P. C. y J. A. Steyermark. 1946. Tiliaceae. Flora of Guatemala. Fieldiana Botany 24(6): 302-324.

TROPICOS. 2017. Tropicos.org. Missouri Botanical Garden. http://www.tropicos.org (consultado junio de 2017).

USDA. 2017. U.S. Department of Agriculture (USDA), Agricultural Research Service. 1992-2016. Dr. Duke's Phytochemical and Ethnobotanical Databases. http:// phytochem.nal.usda.gov/ (consultado junio de 2017).

Villaseñor, J. L. 2004. Los géneros de plantas vasculares de la flora de México. Boletín de la Sociedad Botánica de México 75: 105-135.

Villaseñor, J. L. 2016. Checklist of the native vascular plants of Mexico. Revista Mexicana de Biodiversidad 87(3): 559902. DOI: http://dx.doi.org/10.1016/j.rmb.2016.06.017

Watson, E. E. 1923. The genus Heliocarpus. Bulletin of the Torrey Botanical Club 50(3): 109-128. DOI: http://dx.doi. org/10.2307/2480125

Watson, S. 1887. Lists of plants collected by Dr. Edward Palmer in the state of Jalisco, Mexico in 1886. Proceeding of the American Academy of Arts and Sciences 22: 396-481.

White, J. J., R. McVaugh y R. W. Kiger. 1998. The Torner Collection of Sessé \& Mociño Biological Illustrations. Digital reproduction by Frank A. Reynolds. Hunt Institute for Botanical Documentations and The Universal Library. http://www.huntbotanical.org/art/show.php?10= 